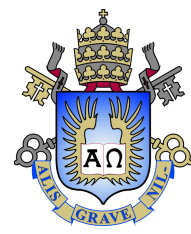

Felipe Leite Coelho da Silva

\title{
Extensão Estocástica Bayesiana da Abordagem Bottom-up Determinística para a Previsão de Longo Prazo do Consumo de Energia
}

Tese de Doutorado

Tese apresentada como requisito parcial para obtenção do grau de Doutor pelo Programa de Pós-graduação em Engenharia Elétrica da PUC-Rio.

Orientador : Prof. Reinaldo Castro Souza

Co-orientador: Prof. Fernando Luiz Cyrino Oliveira 


\section{Pontifícia Universidade Católica \\ DO RIO DE JANEIRO}

\section{Felipe Leite Coelho da Silva}

\section{Extensão Estocástica Bayesiana da Abordagem Bottom-up Determinística para a Previsão de Longo Prazo do Consumo de \\ Energia \\ Tese apresentada como requisito parcial para obtenção do grau de Doutor pelo Programa de Pós-Graduação em Engenharia Elétrica da PUC-Rio. Aprovada pela Comissão Examinadora abaixo assinada.}

Prof. Reinaldo Castro Souza

Orientador

Departamento de Engenharia Elétrica - PUC-Rio

Prof. Fernando Luiz Cyrino Oliveira

Co-orientador

Departamento de Engenharia Industrial - PUC-Rio

Prof. Rodrigo Flora Calili

Programa de Pós-graduação em Metrologia - PUC-Rio

Prof. Eugenio Kahn Epprecht Departamento de Engenharia Industrial - PUC-Rio

Prof. Adiel Teixeira de Almeida Filho

UFPE

Prof. Carlos Antonio Abanto-Valle UFRJ

Prof. José Francisco Moreira Pessanha CEPEL

Prof. Márcio da Silveira Carvalho

Coordenador Setorial do Centro

Técnico Científico - PUC-Rio

Rio de Janeiro, 15 de dezembro de 2017 
Todos os direitos reservados. É proibida a reprodução total ou parcial do trabalho sem autorização da universidade, do autor e do orientador.

Felipe Leite Coelho da Silva

Bacharel em Matemática pela Universidade Federal Rural do Rio de Janeiro; Mestre em Engenharia Oceânica (Enfâse em Engenharia Costeira) pela COPPE-UFRJ.

Ficha Catalográfica

Leite Coelho da Silva, Felipe

Extensão Estocástica Bayesiana da Abordagem Bottom-up Determinística para a Previsão de Longo Prazo do Consumo de Energia / Felipe Leite Coelho da Silva; orientador: Reinaldo Castro Souza; co-orientador: Fernando Luiz Cyrino Oliveira. - Rio de janeiro: PUC-Rio, Departamento de Engenharia Elétrica, 2017.

v., 96 f: il. color. ; $30 \mathrm{~cm}$

Tese (doutorado) - Pontifícia Universidade Católica do Rio de Janeiro, Departamento de Engenharia Elétrica.

Inclui bibliografia

1. Engenharia Elétrica - Teses. 2. Séries Temporais Hierárquicas;. 3. Abordagem bottom-up;. 4. Abordagem top-down;. 5. Modelo Linear Hierárquico;. 6. Método de Monte Carlo via Cadeias de Markov;. 7. Inferência Bayesiana.. I. Castro Souza, Reinaldo. II. Cyrino Oliveira, Fernando Luiz. III. Pontifícia Universidade Católica do Rio de Janeiro. Departamento de Engenharia Elétrica. IV. Título. 


\section{Agradecimentos}

Agradeço a Deus pela direção nos caminhos da minha vida.

Aos meus orientadores, professores Reinaldo e Fernando, pela confiança, clareza e pelo conhecimento compartilhado.

Aos professores do Departamento de Engenharia Elétrica, área de Métodos de Apoio à Decisão, da PUC-Rio pelo conhecimento aqui adquirido. $\mathrm{E}$ aos funcionários deste departamento pela eficiência e respeito.

Aos meus professores e amigos do DEMAT/UFRRJ por todo incentivo.

Aos meus queridos amigos que conviveram comigo neste período, que inicialmente comecei listando mas voltei atrás porque achei injusto não escrever o nome de todos.

Aos professores membros da banca, por aceitarem o convite e pelas contribuições que melhoraram o trabalho.

À minha esposa Josi pelo amor, compreensão e apoio em todos os momentos. Ao meu filho Davi que trouxe muito amor e que, mesmo sem entender o que o pai estava fazendo naquelas horas de revisão de tese e artigos, teve influência na conclusão deste trabalho.

À minha família, aos meus pais Luis Paulo e Fátima, irmãos Fábio e Fabiana, cunhada Rany, avós Paulo Coelho (in memorian), Mara, Geraldo Leite e Maria Neusa, tios(as) (alguns in memorian) e primos(as) por acreditarem sempre em mim. Ao meu sobrinho Théo que estará chegando em breve. E, à família da Josi, em especial aos pais Josias e Maria, e aos irmãos Welington e Welton, por todo seu carinho comigo nesta caminhada.

Ao meu amigo Plutarcho, pelas conversas e parceria durante este trabalho.

Aos meus amigos que fiz na PUC-Rio, em especial aos amigos da equipe do Projeto ENEVA. 


\section{Resumo}

Leite Coelho da Silva, Felipe; Castro Souza, Reinaldo; Cyrino Oliveira, Fernando Luiz. Extensão Estocástica Bayesiana da Abordagem Bottom-up Determinística para a Previsão de Longo Prazo do Consumo de Energia. Rio de Janeiro, 2017. 96p. Tese de Doutorado - Departamento de Engenharia Elétrica, Pontifícia Universidade Católica do Rio de Janeiro.

O comportamento do consumo de energia elétrica do setor industrial tem sido amplamente investigado ao longo dos últimos anos, devido a sua importância econômica, social e ambiental. Mais especificamente, o consumo de eletricidade dos subsetores da indústria brasileira exerce grande importância para o sistema energético brasileiro. Neste contexto, as projeções de longo prazo do seu consumo de energia elétrica para um país ou uma região são informações de grande relevância na tomada de decisão de órgãos e entidades que atuam no setor energético. A abordagem bottom-up determinística tem sido utilizada para obter a previsão de longo prazo em diversas áreas de pesquisa. Neste trabalho, propõe-se uma metodologia que combina a abordagem bottom-up com os modelos lineares hierárquicos para a previsão de longo prazo considerando os cenários de eficiência energética. Além disso, foi utilizada a inferência bayesiana para a estimação dos parâmetros do modelo, permitindo a incorporação de incerteza nessas previsões. Os resultados utilizando os dados de consumo de eletricidade de subsetores da indústria brasileira mostraram que a metodologia proposta consegue capturar a tajetória do consumo de eletricidade, em particular, dos subsetores de papel e celulose, e de metais não-ferrosos e outros de metalurgia. Por exemplo, os intervalos de credibilidade de $95 \%$ construídos a partir do modelo estocástico contemplam os valores reais observados nos anos de 2015 e 2016.

\section{Palavras-chave}

Séries Temporais Hierárquicas; Abordagem bottom-up; Abordagem top-down; Modelo Linear Hierárquico; Método de Monte Carlo via Cadeias de Markov; Inferência Bayesiana. 


\section{Abstract}

Leite Coelho da Silva, Felipe; Castro Souza, Reinaldo (Advisor); Cyrino Oliveira, Fernando Luiz (Co-Advisor). Bayesian Stochastic Extension of Deterministic Bottom-up Approach for the Long Term Forecasting of Energy Consumption. Rio de Janeiro, 2017. 96p. Tese de doutorado - Departamento de Engenharia Elétrica, Pontifícia Universidade Católica do Rio de Janeiro.

The electricity consumption behaviour in the Brazilian industry has been extensively investigated over the past years due to its economic, social and environmental importance. Specifically, the electricity consumption of the subsectors of Brazilian industry have great importance for the Brazilian energy system. In this context, the long-term projections of energy consumption of a country or region are highly relevant information to decision-making of organs and entities operating in the energy sector. The deterministic bottom-up approach has been used for the long-term forecast in several areas of research. In this paper, we propose a methodology that combines the bottom-up approach with hierarchical linear models for long-term forecasting considering energy efficiency scenarios. In addition, Bayesian inference was used to estimate the parameters of the model, allowing the uncertainty incorporation in these forecasts. The results using the electricity consumption data from subsectors of the Brazilian industry showed that the proposed methodology is able to capture the trajectory of their electricity consumption, in particular of the pulp and paper, and of non-ferrous metals and other metallurgical subsectors. For example, the 95 $\%$ credibility intervals constructed from the stochastic model contemplate the actual values observed in the years 2015 and 2016 .

\section{Keywords}

Hierarchical Time Series; Bottom-up Approach; Top-down Approach; Hierarchical Linear Model; Markov Chain Monte Carlo; Bayesian Inference. 


\section{Sumário}

1 Introdução 14

1.1 Motivação da tese $\quad 15$

$\begin{array}{lll}1.2 & \text { Objetivo } & 15\end{array}$

$\begin{array}{lll}1.3 & \text { Organização da tese } & 16\end{array}$

2 Revisão Bibliográfica $\quad 17$

3 Modelagem Proposta $\quad 24$

3.1 Modelo Geral 24

$\begin{array}{ll}3.2 & \text { Estimação dos parâmetros }\end{array}$

4 Aplicação do Modelo Proposto $\quad 29$

4.1 Mapeamento da indústria brasileira 29

4.2 Medidas de Eficiência Energética (MEEs) 32

4.2.1 MEEs para o subsetor de papel e celulose 33

4.2.2 MEEs para o subsetor de metais não ferrosos e outros de metalurgia 35

4.3 Definição dos cenários de difusão tecnológica 36

4.4 Modelo para o setor industrial 38

4.4.1 Consumo específico de eletricidade 39

4.4.2 Estimação dos parâmetros do modelo proposto para o setor industrial 40

4.5 Modelo proposto para o setor industrial com as medidas de eficiência energética 43

4.6 Cálculo do percentual de consumo de eletricidade por tecnologia transversal $\quad 45$

4.7 Previsão da produção e do valor adicionado da indústria brasileira 46

5 Resultados e Discussão $\quad 49$

5.1 Subsetor de papel e celulose 49

5.2 Subsetor de metais não-ferrosos e outros de metalurgia 59

6 Conclusão $\quad 68$

$\begin{array}{ll}6.1 \text { Trabalhos futuros } & 70\end{array}$

A Conceitos de Estatística Bayesiana e o Método de Simulação de Monte Carlo via Cadeias de Markov (MCMC) $\quad 72$

$\begin{array}{lll}\text { A.1 Teorema de Bayes } & 72\end{array}$

$\begin{array}{lll}\text { A.2 Distribuição a Priori } & 72\end{array}$

A.3 Método de Monte Carlo via Cadeias de Markov (MCMC) 74

$\begin{array}{lll}\text { A.3.1 Algoritmo de Metropolis-Hastings } & 75\end{array}$

$\begin{array}{lll}\text { A.3.2 Amostrador de Gibbs } & 77\end{array}$

$\begin{array}{lll}\text { B Fonte dos dados } & 78\end{array}$

$\begin{array}{ll}\text { C Conceitos sobre as MEEs } & \mathbf{8 0}\end{array}$ 
D Percentual de consumo de eletricidade para as tecnologias transversais

82

$\begin{array}{lll}\text { E } & \text { Resumo dos valores calculados de difusão tecnológica } & 83\end{array}$

$\begin{array}{lll}\text { F } & \text { Estudo simulado } & 86\end{array}$ 


\section{Lista de figuras}

Figura 3.1 Estrutura hierárquica com dois níveis.

Figura 4.1 Consumo de eletricidade dos subsetores da indústria brasileira.

Figura 4.2 Consumo de eletricidade (TWh) dos processos da indústria brasileira em 2012 (Tabela B.2).

Figura 4.3 Estrutura hierárquica do setor industrial com algumas medidas de eficiência energética de um subsetor.

Figura 4.4 Ilustração das curvas de difusão tecnológica, onde Auto representa a curva de difusão autonôma, Max é curva de difusão Máxima, e Cost é a curva de difusão cost-effective.

Figura 4.5 Estrutura hierárquica do consumo de eletricidade dos subsetores da indústria brasileira.

Figura 4.6 A estrutura hierárquica com as medidas de eficiência energética.

Figura 5.1 Cadeia do consumo de eletricidade de cada processo do subsetor de papel e celulose para o ano de 2015 e 2016, em que a linha vermelha é a média da cadeia.

Figura 5.2 Histograma do consumo de eletricidade de cada processo do subsetor de papel e celulose para o ano de 2015 e 2016, em que a linha tracejada em azul é a média a posteriori e a linha tracejada em vermelho é o intervalo de credibilidade de $95 \%$.

Figura 5.3 Resumo a posteriori da distribuição preditiva do consumo de eletricidade de longo prazo do subsetor de papel e celulose com as medidas de eficiência congeladas, isto é, um cenário frozen.

Figura 5.4 Consumos de eletricidade gerados pelos modelos proposto e o FORECAST para o subsetor de papel e celulose.

Figura 5.5 Histogramas do consumo de eletricidade do subsetor de papel e celulose para os anos de 2015 e 2016. A linha cheia verde representa o valor real obtido pela EPE, a linha tracejada azul representa a média e as linhas tracejadas em vermelho representam o intervalo de credibilidade de $95 \%$ do consumo de eletricidade.

Figura 5.6 Consumo de eletricidade de longo prazo do subsetor de papel e celulose considerando os cenários de difusão autônoma e cost-effective.

Figura 5.7 Consumo de eletricidade de longo prazo do subsetor de papel e celulose comparando os cenários de difusão frozen, autônoma, cost-effective e máxima.

Figura 5.8 Evolução do consumo de eletricidade e o intervalo de credibilidade de $95 \%$ por tecnologia transversal do subsetor de papel e celulose no Brasil. 
Figura 5.9 Cadeia do consumo de eletricidade de cada processo do subsetor de metais não-ferrosos e outros de metalurgia para o ano de 2015, em que a linha vermelha é a média da cadeia.

Figura 5.10 Cadeia do consumo de eletricidade de cada processo do subsetor de metais não-ferrosos e outros de metalurgia para o ano de 2016, em que a linha vermelha é a média da cadeia.

Figura 5.11 Histograma do consumo de eletricidade de cada processo do subsetor de metais não-ferrosos e outros de metalurgia para o ano de 2015, em que a linha tracejada em azul é a média a posteriori e a linha tracejada em vermelho é o intervalo de credibilidade de $95 \%$.

Figura 5.12 Histograma do consumo de eletricidade de cada processo do subsetor de metais não-ferrosos e outros de metalurgia para o ano de 2016, em que a linha tracejada em azul é a média a posteriori e a linha tracejada em vermelho é o intervalo de credibilidade de $95 \%$.

Figura 5.13 Resumo a posteriori da distribuição preditiva do consumo de eletricidade de longo prazo do subsetor de metais não-ferrosos e outros de metalurgia com as medidas de eficiência congeladas, isto é, um cenário frozen.

Figura 5.14 Consumos de eletricidade gerados pelos modelos proposto e o FORECAST para o subsetor de metais não-ferrosos e outros de metalurgia.

Figura 5.15 Histogramas do consumo de eletricidade do subsetor de metais não-ferrosos e outros de metalurgia para os anos de 2015 e 2016. A linha cheia verde representa o valor real obtido pela EPE, a linha tracejada azul representa a média e as linhas tracejadas em vermelho representam o intervalo de credibilidade de $95 \%$ do consumo de eletricidade.

Figura 5.16 Consumo de eletricidade de longo prazo do subsetor de metais não-ferrosos e outros de metalurgia considerando os cenários de difusão autônoma e cost-effective.

Figura 5.17 Consumo de eletricidade de longo prazo do subsetor de metais não-ferrosos e outros de metalurgia comparando os cenários de difusão frozen, autônoma e cost-effective.

Figura 5.18 Evolução do consumo de eletricidade com o intervalo de credibilidade de $95 \%$ por tecnologia transversal do subsetor de metais não-ferrosos e outros de metalurgia no Brasil.

5.18(a)Cenário frozen.

5.18(b)Cenário Cost-effective.

Figura A.1 Distribuição Normal com média 0 e variância baixa (linha cheia preta) e distribuição Normal com média 0 e variância suficientemente grande (linha cheia vermelha).

Figura F.1 Dados artificiais gerado pelo modelo proposto. 
Figura F.2 Estudo simulado: Histogramas das distribuições a posteriori dos parâmetros do modelo para o processo simulado com os valores verdadeiros dos parâmetros (linha vertical vermelha) e o intervalo de credibilidade de $95 \%$ (linha tracejada vermelha).

Figura F.3 Estudo simulado: Histogramas das distribuições a posteriori das variâncias do modelo com os valores verdadeiros dos parâmetros (linha vertical vermelha) e o intervalo de credibilidade de $95 \%$ (linha tracejada vermelha). 


\section{Lista de tabelas}

Tabela 4.1 Subsetores e processos da indústria brasileira

Tabela 4.2 Resumo das medidas de eficiência energética aplicadas aos processos da indústria de papel e celulose.

Tabela 4.3 Resumo das medidas de eficiência energética aplicadas às tecnologias transversais da indústria de papel e celulose.

Tabela 4.4 Resumo das medidas de eficiência energética aplicadas aos processos da indústria de metais não-ferrosos e outros de metalurgia.

Tabela 4.5 Produção anual (em milhões de toneladas) por processo e o valor adicionado anual (em milhões de Reais) do subsetor de papel e celulose no Brasil.

Tabela 4.6 Produção anual (em $10^{5}$ toneladas) por processo e o valor adicionado anual (em milhões de Reais) do subsetor de metais não-ferrosos e outros de metalurgia no Brasil.

Tabela 5.1 Evolução do consumo de eletricidade, com o intervalo de credibilidade de $95 \%$, para o subsetor de papel e celulose. E, a redução percentual (\%) do consumo de eletricidade, a partir da utilização de medidas de eficiência energética, em comparação com o cenário frozen para os anos de 2015, 2016, 2020, 2030, 2040 e 2050.

Tabela 5.2 Taxa de crescimento médio, com o intervalo de credibilidade de $95 \%$, do consumo total de eletricidade no subsetor de papel e celulose da indústria brasileira (\%).

Tabela 5.3 Evolução do consumo de eletricidade, com o intervalo de credibilidade de $95 \%$, e o percentual de redução do consumo, quando comparado ao cenário frozen, por tecnologia transversal utilizada no subsetor de papel e celulose.

Tabela 5.4 Evolução do consumo de eletricidade, com o intervalo de credibilidade de $95 \%$, para o subsetor de metais não-ferrosos e outros de metalurgia. E, a redução percentual (\%) do consumo de eletricidade, a partir da utilização de medidas de eficiência energética, em comparação com o cenário frozen para os anos de 2015, 2016, 2020, 2030, 2040 e 2050.

Tabela 5.5 Taxa de crescimento médio, com o intervalo de credibilidade de $95 \%$, para o consumo total de eletricidade no subsetor de metais não-ferrosos e outros de metalurgia da indústria brasileira (\%).

Tabela 5.6 Evolução do consumo de eletricidade, com o intervalo de credibilidade de $95 \%$, e o percentual de redução do consumo, quando comparado ao cenário frozen, por tecnologia transversal utilizada no subsetor de metais não-ferrosos e outros de metalurgia. 
Tabela B.1 Fonte dos dados de produção dos processos e do valor adicionado por subsetor da indústria brasileira.

Tabela B.2 Classificação dos processos pelo consumo de eletricidade em 2012.

Tabela D.1 Percentual de consumo de eletricidade por tecnologia transversal do subsetor de papel e celulose.

Tabela D.2 Percentual de consumo de eletricidade por tecnologia transversal do subsetor de metais não-ferrosos e outros de metalurgia.

Tabela E.1 Resumo dos valores calculados de difusão aplicados nos processos do subsetor de papel e celulose: taxa de difusão por medida de eficiência energética para diferentes cenários.

Tabela E.2 Resumo dos valores calculados de difusão para cada MEE aplicado as tecnologias transversais: taxa de difusão por medida de eficiência energética em diferentes cenários.

Tabela E.3 Resumo dos valores calculados de difusão aplicados aos processos do subsetor de metais não-ferrosos: taxa de difusão por medida de eficiência energética para diferentes cenários.

Tabela E.4 Evolução do consumo médio de eletricidade e o percentual de redução do consumo, quando comparado ao cenário frozen, por processo definido no subsetor de papel e celulose.

Tabela E.5 Evolução do consumo médio de eletricidade e o percentual de redução do consumo, quando comparado ao cenário frozen, por processo definido no subsetor de metais não-ferrosos e outros de metalurgia. 


\section{Introdução}

A previsão de cenários futuros é importante para a tomada de decisão em diversas áreas, como no controle de processos industriais, na gestão de operações de produção, no planejamento econômico, no gerenciamento ambiental, no planejamento do setor energético etc. Este interesse, em geral, é devido ao grande impacto financeiro e social que pode surgir no futuro.

Os cenários futuros podem ser de curto, médio e longo prazo. Para as previsões de curto e médio prazo existem diversos modelos e métodos estabelecidos na literatura (ARDAKANI; ARDEHALI, 2014). Por outro lado, existe uma limitação de técnicas para obter a previsão de longo prazo (ARDAKANI; ARDEHALI, 2014), a qual é uma informação de grande relevância na tomada de decisão de órgãos e entidades que atuam no planejamento de uma empresa ou um país (HAHN et al., 2009; ARDAKANI; ARDEHALI, 2014; CABRAL et al., 2017).

Neste trabalho, desenvolve-se uma metodologia para obter a previsão de longo prazo para o consumo de eletricidade dos subsetores da indústria brasileira. Os dados do consumo de eletricidade são anuais e estão organizados em uma estrutura hierárquica, isto é, as séries temporais do consumo de eletricidade são hierárquicas. Essa estrutura hierárquica é caracterizada pelo agrupamento de séries temporais de níveis mais baixos para formar séries em outro nível da hierarquia. Atualmente, as abordagens bottom-up e top-down têm sido utilizadas para a previsão de séries temporais hierárquicas (ZELLNER; TOBIAS, 2000; ATHANASOPOULOS et al., 2009; HYNDMAN et al., 2011).

$\mathrm{Na}$ abordagem bottom-up, primeiramente são geradas as previsões independentes para cada série no nível mais baixo da hierarquia e, em seguida, elas são agregadas para produzir a previsão dos níveis superiores da hierarquia. Essa abordagem requer um detalhamento muito grande nos níveis da hierarquia, mas é uma condição para que poucas informações sejam perdidas devido à agregação.

Por outro lado, a abordagem top-down gera as previsões da série completamente agregada e, em algumas situações, desagrega tais previsões para os níveis exigidos, baseada em proporções históricas. Essas proporções 
utilizadas para a desagregação da série agregada não podem mudar ao longo do tempo. Desta forma, as proporções históricas tendem a produzir previsões menos precisas em níveis mais baixos da hierarquia do que a abordagem bottom-up.

Recentemente, a abordagem bottom-up, composta por modelos determinísticos, tem sido empregada para obter a previsão de longo prazo considerando os cenários de eficiência energética (FLEITER et al., 2012; HUANG et al., 2016). Os modelos determinísticos são construídos por um conjunto de equações matemáticas conhecidas, e com algumas condições iniciais estabelecidas, e é possível obter sua solução em um dado momento. Esses modelos são utilizados em diversas áreas de pesquisas científicas, tais como biologia, química, física e engenharia.

No contexto de modelos estocásticos, os modelos lineares hierárquicos podem ser utilizados na modelagem de dados que seguem uma estrutura hierárquica. Esses modelos permitem que cada nível da hierarquia seja agregado separadamente e que, em seguida, sejam reunidos em um único modelo. Os modelos também concedem a incorporação de efeitos aleatórios associados a cada nível da hierarquia.

Combinar os modelos lineares hierárquicos com abordagem bottom-up para obter a previsão de longo prazo pode ser uma estratégia para inserir a incerteza na previsão de dados que possuem uma estrutura hierárquica. Portanto, essa metodologia pode contribuir com informações que permitem a tomada de decisões em bases mais sólidas.

\section{1 \\ Motivação da tese}

As projeções de longo prazo do consumo de energia elétrica de um país ou uma região são informações de grande relevância na tomada de decisão de órgãos e entidades que atuam no setor energético. O planejamento adequado de um sistema de transmissão e produção de eletricidade exige a disponibilidade de projeções de demanda de médio e longo prazo do consumo de eletricidade.

Neste contexto, o comportamento do consumo de energia elétrica do setor industrial tem sido amplamente investigado ao longo dos últimos anos, devido a sua grande participação no total de eletricidade consumida. Por exemplo, esse setor foi responsável em 2016 pelo consumo de 37,6\% de energia elétrica no Brasil (EPE, 2017). 


\section{Objetivo}

O objetivo deste trabalho é obter a previsão de longo prazo para séries temporais hierárquicas. Para isso, foi proposta uma metodologia que permite incorporar a incerteza em previsões de longo prazo desenvolvidas por uma abordagem bottom-up. Em particular, essa metodologia será utilizada para prever o consumo de eletricidade de longo prazo de subsetores da indústria brasileira. Neste estudo, deseja-se, também, verificar os efeitos de medidas de eficiência energética sobre essas previsões.

Desta forma, este trabalho consiste em uma extensão dos trabalhos de Farla et al. (1997), Fleiter et al. (2012) e Huang et al. (2016), que adotaram uma abordagem bottom-up determinística para estudar o comportamento das medidas de eficiência energética de oito países da Organização de Cooperação e Desenvolvimento Econômico (OECD), e para obter a previsão de longo prazo do consumo de eletricidade considerando os cenários de eficiência energética na Alemanha e Taiwan, respectivamente.

\section{3}

\section{Organização da tese}

No Capítulo 2, são apresentadas várias referências bibliográficas relacionadas ao trabalho. Neste capítulo, foi realizada uma revisão de literatura sobre as abordagens utilizadas para a previsão de longo prazo de séries temporais hierárquicas. No Capítulo 3 é apresentado o modelo geral proposto que combina a previsão bottom-up com os modelos lineares hierárquicos. O Capítulo 4 apresenta o mapeamento da indústria brasileira, a descrição das medidas de eficiência energética e a especificação do modelo proposto para o consumo de eletricidade de cada subsetor do setor industrial. No Capítulo 5, são apresentados os resultados da aplicação do modelo proposto. E, finalmente, no Capítulo 6 são apresentadas as conclusões deste trabalho, e apontando os possíveis trabalhos futuros. 


\section{2}

\section{Revisão Bibliográfica}

Neste Capítulo, será apresentada uma revisão sobre vários trabalhos envolvendo as abordagens bottom-up e top-down utilizadas para obter previsões de longo prazo. Em particular para a abordagem bottom-up serão apresentados os efeitos das medidas de eficiência energética.

Segundo Zellner e Tobias (2000), Athanasopoulos et al. (2009), Hyndman et al. (2011), Fleiter et al. (2012), Herbst et al. (2012) e Huang et al. (2016), as abordagens bottom-up e top-down são utilizadas quando uma variável é organizada seguindo uma estrutura hierárquica. A abordagem top-down trata as variáveis de interesse como um todo, fornecendo resultados diretos para essas variáveis. Na abordagem bottom-up, as variáveis de interesse são separadas em componentes, para as quais é aplicado um tratamento, e os resultados gerados pelas componentes são agrupadas para compor as variáveis de interesse.

Ao comparar esses dois tipos de abordagens, observa-se que a abordagem top-down utiliza uma quantidade menor de dados para alcançar os resultados. No entanto, a interpretação da influência de alguns agentes externos em tais resultados é menos explícita. Já a abordagem bottom-up permite uma melhor interpretação da influência de fatores externos nos resultados às custas de uma quantidade maior de dados. Portanto, a quantidade de informações necessárias para uma previsão hierárquica usando abordagem bottom-up aumenta o nível de detalhamento da estrutura hierárquica e, consequentemente, aumenta o grau de complexidade da modelagem (FLIEDNER, 2001; FLEITER et al., 2012; HERBST et al., 2012; HUANG et al., 2016).

Athanasopoulos et al. (2009), Hyndman et al. (2011), Hyndman et al. (2014) e Hyndman et al. (2016) apresentaram uma revisão sobre as abordagens bottom-up, top-down e uma combinação entre as duas abordagens para produzir previsões de curto prazo de séries temporais hierárquicas.

Os trabalhos de Kinney (1971), Collins (1976), Dunn et al. (1976), Zellner e Tobias (2000), e Dangerfield e Morris (1992) mostraram que a previsão desenvolvida pela abordagem bottom-up é mais precisa do que a conseguida com a abordagem top-down devido principalmente ao detalhamento da estrutura dos dados. Fliedner (2001) apresentou um detalhamento sobre as informações necessárias para uma previsão hierárquica. Esse detalhamento 
busca melhorar o desempenho da previsão de séries temporais hierárquicas.

A abordagem bottom-up é utilizada na análise de sistemas de energia desde 1980 (CHATEAU; LAPILLONNE, 1978; CHATEAU; LAPILLONNE, 1981; GEROSKI, 2000). Herbst et al. (2012) apresentaram uma descrição dos modelos de energia bottom-up e top-down utilizados para avaliar a demanda e o abastecimento de energia futura. Destacaram que a principal característica de um modelo bottom-up é o seu grau relativamente elevado de detalhamento tecnológico dos dados em comparação com os modelos energéticos top-down. Os autores apontaram que recentemente a abordagem híbrida desses modelos tem sido utilizada para o planejamento do sistema energético.

Jacobsen (1998) modelou o consumo de eletricidade de longo prazo do setor residencial na Dinamarca usando um modelo que integra as abordagens bottom-up e top-down. Este estudo mostrou que a integração de abordagens bottom-up e de top-down depende do tipo de modelos que serão integrados. Koopmans e Veld (2001) apresentaram um estudo do consumo de energia na Holanda usando as abordagens bottom-up, top-down e uma combinação entre as duas abordagens. Swan e Ugursal (2009) apresentaram uma revisão de várias técnicas de modelagem utilizadas para obter o consumo de energia do setor residencial. Eles ressaltaram que os modelos bottom-up são mais apropriados para incorporar novas tecnologias.

Hourcade et al. (2006) definiram três categorias de modelos híbridos, sendo os modelos bottom-up com feedbacks macroeconômicos, os modelos bottom-up com parâmetros macroeconômicos para a escolha das tecnologias e os modelos top-down com explicação tecnológica. Segundo Jochem et al. (2007), o modelo desenvolvido no projeto ADAM (Adaptation and Mitigation Strategies) combina um modelo macroeconômico com um conjunto de modelos bottom-up. Esse modelo foi utilizado para projetar a demanda e oferta de energia até 2050 de 29 países europeus.

Georgiou (2016) apresentou um modelo determinístico de programação linear inteira mista bottom-up para o planejamento de energia a longo prazo na Grécia. Yi et al. (2016) modelaram o planejamento de rede elétrica inter-regional até 2030 na China usando abordagem bottom-up. Lee e Huh (2017) usaram o modelo bottom-up para previsão de longo prazo do fornecimento de energia nova e renovável na Coréia do Sul. Berntsen e Trutnevyte (2017) apresentaram um modelo de energia bottom-up denominado de Modelo de Geração Alternativas (MGA) para analisar os cenários suiços de suprimento de eletricidade de longo prazo. MGA é uma técnica que pode gerar diferentes cenários de energia (BRILL et al., 1982; DECAROLIS, 2011; DECAROLIS et al., 2016; TRUTNEVYTE, 2013; TRUTNEVYTE, 2016). 
Outros estudos recentes sobre a previsão de consumo de eletricidade de longo prazo que foram desenvolvidos usando diferentes metodologias podem ser vistos em Perwez et al. (2015), Thangavelu et al. (2015), Koltsaklis et al. (2015), Hussain et al. (2016), Hong e Fan (2016), Wierzbowski et al. (2016), Kaboli et al. (2016), Kaboli et al. (2017) e He et al. (2017).

No contexto de eficiência energética, Beer et al. (1997) destacaram que, a partir da crise do petróleo na década de setenta, os potenciais de melhoria da eficiência energética no curto e médio prazo têm sido extensivamente estudados. Eles apresentaram um método para identificar e caracterizar as tecnologias que podem melhorar a eficiência energética de longo prazo para indústria de papel e celulose com base nos países da OECD. Worrell e Price (2001) apresentaram um estudo sobre a existência de potenciais para melhoria da eficiência energética na indústria. Tanaka (2011) apresentou uma revisão sobre as medidas de eficiência energética aplicadas na indústria, abrangendo cerca de 570 medidas, implementadas pelos governos dos países da IEA, China, Índia, México, Rússia e África do Sul.

Worrell et al. (2003) propõem uma metodologia para avaliar os benefícios de produtividade dos investimentos em eficiência energética e incorporá-los em avaliações de potencial de economia de energia em toda a indústria. Esta abordagem começa com a documentação dos benefícios adicionais associados a uma tecnologia energeticamente eficiente e observando todos os pressupostos necessários para quantificar esse benefício em termos de custo, se possível. Abdelaziz et al. (2011) mostraram uma revisão da literatura sobre economia de energia industrial por meio de gerenciamento, tecnologias e políticas. Foram compiladas as últimas literaturas em termos de tese (MSc e PhD), artigos de revistas, atas de conferências, materiais web, relatórios, livros, manuais sobre gestão de energia industrial, políticas e estratégias de poupança de energia. A economia de energia através da gestão, incluindo a auditoria energética, programas de formação e gestão doméstica, ao lado de algumas práticas de gestão de energia no mundo, foi revista. Os períodos de retorno para diferentes medidas de eficiência foram identificados e considerados economicamente viáveis na maioria dos casos.

Os trabahos de Neelis et al. (2007), Saygin et al. (2011a), Saygin et al. (2011b), Xu et al. (2014) e Flues et al. (2015) usaram a abordagem bottom-up para estimar os potenciais de economia de energia de vários setores da indústria e em diferentes países do mundo. Estes estudos não investigaram o potencial de poupança de energia a longo prazo.

Saidur (2010) apresentou uma revisão da literatura sobre análise do consumo de energia de motores elétricos utilizados no setor industrial. Esse 
artigo apresenta um estudo detalhado sobre os motores procurando explorar as perdas, a eficiência e estratégias de economia de energia. Nesta revisão, foram discutidas as ferramentas computacionais que podem ser usadas para analisar a energia elétrica utilizada pelos motores elétricos. Foram mostrados os parâmetros de custo para realizar a análise econômica. Além disso, foram identificados períodos de retorno para diferentes estratégias de economia de energia.

Mathews e Baroni (2013) apresentaram uma estudo sobre a aceitação de uma nova tecnologia como um processo de substituição industrial que ocorre ao longo do tempo. Para avaliar a penetração de uma nova tecnologia na indústria foi utilizada uma curva logística (ou curva de difusão em forma de S). A curva de difusão resultante é simplesmente um resumo do efeito de uma série de políticas, e de interações sociais e econômicas. Todos eles exercem seus efeitos de várias maneiras, resultando no final em uma taxa acelerada ou desacelerada de economia de energia.

Cagno et al. (2013) propõem uma taxonomia como um instrumento útil tanto para as empresas como para orgãos governamentais, a fim de identificar fatos críticos para melhorar a eficiência energética do setor industrial. Essa taxonomia mostra as barreiras existentes na indústria para a adoção de novas tecnologias eficientes em termos de energia. O estudo apresenta o efeito das barreiras nos processos de tomada de decisão.

Giraldo e Hyman (1995), Giraldo e Hyman (1996) mostraram um detalhamento dos modelos de energia de uso final aplicado à indústria de papel e celulose dos Estados Unidos da América (EUA). Farla et al. (1997) apresentaram um método para comparar o desenvolvimento da eficiência energética na indústria de transformação. O método baseia-se na utilização de dados de produção física como uma medida do crescimento da atividade para a indústria de transformação. A metodologia foi aplicada à indústria de papel e celulose de oito países da Organização de Cooperação e Desenvolvimento Econômico (OECD). Com esta metodologia é possível acompanhar a evolução da eficiência energética, separadamente, para o consumo de combustível e eletricidade.

Kramer et al. (2009a) apresentaram um estudo sobre as medidas de eficiência energética que podem ser aplicadas na indústria de papel e celulose em todo o mundo. Esse trabalho mostra as tendências, estrutura e características de consumo de energia da indústria de papel e celulose dos EUA, juntamente com descrições das principais tecnologias de processo utilizadas na indústria.

Oda et al. (2007) avaliaram os potenciais de redução das emissões de 
gás carbônico e o custo mínimo das opções tecnológicas no setor siderúrgico por regiões do mundo (EUA, Canadá, Austrália, China, Índia, Brazil etc) até 2030. Nesse estudo foram adotados as abordagens bottom-up e top-down. Szabó et al. (2009) modelaram o consumo de eletricidade e a emissão gás carbônico da indústria mundial de papel e celulose até 2030. Essa modelagem foi realizada utilizando a abordagem bottom-up que incorporou detalhadamente várias tecnologias da indústria mundial de 47 regiões. Karali et al. (2014) estudaram os impactos da redução de emissões de $\mathrm{CO}_{2}$ a longo prazo no setor siderúrgico dos EUA usando uma abordagem bottom-up. Calili et al. (2014) estimaram a emissão de $\mathrm{CO}_{2}$ no Brasil durante o período de 2012 a 2016. Esses estudos também mostraram que as economias de energia podem ser traduzidas em redução de $\mathrm{CO}_{2}$. Dai et al. (2016) apresentaram uma metodologia para a previsão bottom-up e top-down do consumo e emissão $\mathrm{CO}_{2}$ na China. $\mathrm{O}$ principal objetivo deste estudo foi identificar a diferença existente entre as abordagens empregadas que são frequentemente utilizadas como ferramentas para explorar cenários de longo prazo do consumo de energia e as emissões de $\mathrm{CO}_{2}$. Kuramochi et al. (2017) apresentaram um estudo sobre as emissões de gases de efeito estufa até 2030 no Japão usando a abordagem bottom-up. Esse estudo mostrou que o Japão pode aumentar sua redução de emissões.

Fleiter et al. (2012) adotaram uma abordagem bottom-up para avaliar o consumo de energia de longo prazo do subsetor de papel e celulose na Alemanha. Essa modelagem mostrou resultados satisfatórios na utilização de medidas de eficiência energética. Esse estudo, também, mostrou que as economias de energia podem reduzir a emissão de $\mathrm{CO}_{2}$. Jakob et al. (2013) também usaram uma abordagem bottom-up e avaliaram os efeitos positivos da aplicação de medidas de eficiência na redução do consumo de energia no setor industrial europeu.

Silva et al. (2015) modelaram o consumo de eletricidade de longo prazo do subsetor de papel e celulose da indústria brasileira utilizando um modelo bottom-up. Os resultados mostraram que o consumo de eletricidade pode ser reduzido após a penetração das medidas de eficiência energética. Essas medidas de eficiência podem ser aplicadas nos processos e nas tecnologias transversais deste subsetor.

Brunke e Blesl (2014) utilizaram um modelo bottom-up para investigar o consumo de energia até 2035 da indústria de cimento alemã. O estudo projeta uma redução de $25 \%$ no consumo de eletricidade desta indústria até 2050 através de medidas de eficiência energética. Huang et al. (2016) adotaram uma abordagem bottom-up para avaliar o consumo de energia de longo prazo da indústria de cimento em Taiwan. Os resultados dessa modelagem mostraram 
o efeito de redução no consumo de energia através da utilização de medidas de eficiência energética.

Puksec et al. (2013) usaram um modelo bottom-up para prever o consumo de energia de longo prazo até 2050 para o setor de transporte da Croácia. O modelo incorporou a estrutura detalhada do setor de transporte croata, incluindo o transporte rodoviário, ferroviário, aéreo, público e os meios de transporte que utilizam água. Na Tailândia, Limanond et al. (2011) desenvolveram um modelo de regressão log-linear e redes neurais para projetar o consumo de longo prazo (20 anos) de energia do setor de transporte. Um modelo bottom-up foi utilizado para obter o consumo de energia do setor residencial na Argélia até 2040 (GHEDAMSIA et al., 2016). Esse estudo destacou a falta de informação sobre as medidas de eficiência energética adotadas e o histórico dos dados de consumo de energia disponíveis no país. A partir da decomposição da taxa de crescimento simples (PIB) e do valor adicionado bruto, Pérez-García e Moral-Carcedo (2016) desenvolveram um modelo para projetar o consumo de eletricidade da Espanha até 2030.

Bobmann e Staffell (2015) mostraram a evolução das curvas de carga até 2050 na Alemanha e Grã-Bretanha. Os valores da demanda de energia utilizados na evolução das curvas de carga foram projetados pelo programa FORECAST ${ }^{1}$. O FORECAST é uma plataforma determinística de previsão de longo prazo para a demanda de energia. Essa plataforma de previsão segue uma estrutura de um modelo hierárquico, isto é, uma abordagem bottom-up. Ele foi desenvolvido pelo instituto Fraunhofer, situado na Alemanha. Os trabalhos de Fleiter et al. (2012), Huang et al. (2016) e Jakob et al. (2013) utilizaram o FORECAST para a previsão de longo prazo da demanda de energia na Alemanha, Taiwan e Europa, respectivamente.

De acordo com a Empresa de Pesquisa Energética (EPE) (EPE, 2016b), as previsões de demanda de eletricidade de longo e médio prazo no Brasil são realizadas utilizando as abordagens do tipo bottom-up e top-down, que agregam e desagregam previsões dos níveis hierárquicos, respectivamente. Mas, esse trabalho não mostra o nível de detalhamento da estrutura hierárquica utilizada. Pao e Tsai (2011) mostraram a importância de modelar e prever o consumo de energia no Brasil. Eles adotaram uma abordagem top-down para prever o consumo de energia para o período de 2008 até 2013. Tolmasquim (2005) e EPE (2005) apresentaram o histórico do planejamento energético no Brasil.

No contexto de modelos estocásticos, os modelos lineares hierárquicos foram apresentados por Bryk e Raudenbush (1992), e posteriormente por

\footnotetext{
${ }^{1}$ http://www.forecast-model.eu/forecast-en/index.php
} 
Goldstein (1995). Mas de acordo com Lindley e Smith (1972) e Smith (1973), esses modelos surgiram no desenvolvimento de métodos de estimação bayesiana para os modelos lineares.

Lindley e Smith (1972) apontaram que a melhor estratégia para especificar uma distribuição a priori para descrever uma situação experimental é definir as distribuições a priori para os níveis inferiores da hierarquia.

Goldstein (1995) mostrou que o tratamento bayesiano pode ser utilizado na estimação de parâmetros dos modelos lineares hierárquicos, através dos métodos de Monte Carlo via Cadeias de Markov (MCMC).

Segundo Uusitalo et al. (2015), a incerteza nos resultados dos modelos determinísticos deve ser estimada quando são utilizados para tomada de decisão. O’Hagan (2012) concluiu que a incerteza presente nos modelos determinísticos é como uma distribuição de probabilidade para uma quantidade desconhecida.

Este capítulo apresentou uma visão geral de diferentes trabalhos usando as abordagens bottom-up e top-down na previsão de longo prazo do consumo de energia. Nesta revisão, observou-se que a abordagem top-down utiliza uma menor quantidade de dados para alcançar os resultados. Entretanto, a interpretação da influência de alguns fatores externos nos resultados é menos explícita. Por outro lado, a abordagem bottom-up permite uma melhor interpretação da influência de tais fatores nos resultados à custa de uma quantidade maior de dados. Além disso, algumas informações exigidas pela abordagem bottom-up podem ser difíceis de obter em alguns países, o que impõe o desenvolvimento de procedimentos específicos para obtê-los e aplicar a metodologia. No Brasil, por exemplo, o consumo específico de energia de alguns processos é uma informação que não está disponível em fontes oficiais, requerendo um procedimento para o seu cálculo.

Neste estudo será apresentada uma estrutura de modelagem utilizando uma combinação de um modelo estocástico com a abordagem bottom-up que não foi mostrada em nenhum trabalho pesquisado. Embora a abordagem bottom-up seja intensiva em dados, exigindo uma grande quantidade de dados com boa qualidade o que aumenta a sua complexidade, ela foi escolhida porque permite uma melhor interpretação da influência de alguns fatores nos resultados. 


\section{Modelagem Proposta}

Neste capítulo, será apresentada uma modelagem para séries temporais organizadas em uma estrutura hierárquica com dois níveis. Inicialmente, é descrito um modelo determinístico e, em seguida, é discutida a inserção de incerteza neste modelo, além do procedimento de inferência utilizado.

\section{1}

\section{Modelo Geral}

Neste trabalho, propõe-se modelar séries temporais que possuem uma estrutura hierárquica.

Considere $y_{i, 1}, y_{i, 2}, \cdots, y_{i, T}$ uma série temporal hierárquica para cada $i$, sendo $i=1,2, \cdots, N$. Desta forma, $y_{i, t}$ representa uma observação no tempo $t$ da $i$-ésima série temporal, para $i=1,2, \cdots, N$, e corresponde ao nível mais alto da hierarquia. Seguindo a estrutura hierárquica apresentada na Figura 3.1, cada $y_{i, t}$ é decomposta em $n_{i}$ séries desagregadas $x_{i, j, t}$ mais a componente $R_{i, t}$. Assim, definem-se os dois níveis de hierarquia do modelo. Além disso, cada série $x_{i, j, t}$, para $i=1,2, \cdots, N, j=1,2, \cdots, n_{i}$, e $t=1,2, \cdots, T$, é função de uma quantidade conhecida $z_{i, j, t}$.

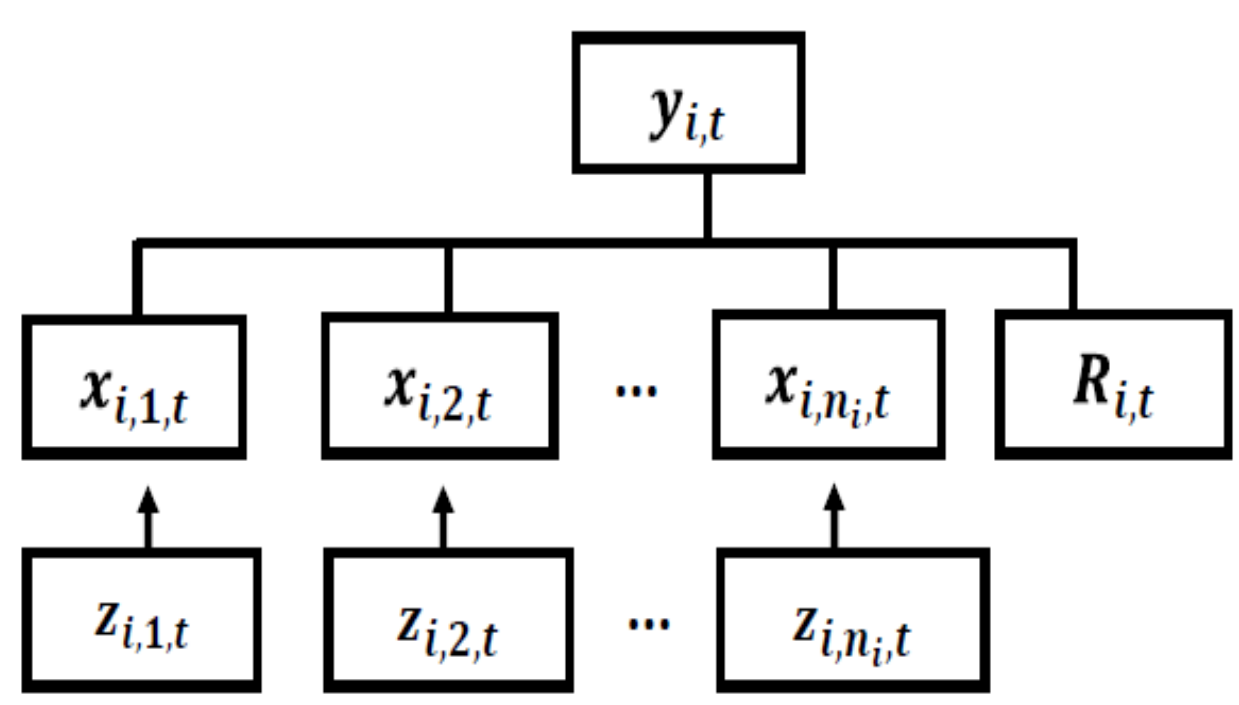

Figura 3.1: Estrutura hierárquica com dois níveis. 
O modelo determinístico definido para cada série temporal hierárquica é dado por

$$
\begin{aligned}
y_{i, t} & =\sum_{j=1}^{n_{i}} x_{i, j, t}+R_{i, t}, \\
x_{i, j, t} & =g\left(z_{i, j, t}\right)
\end{aligned}
$$

para $j=1,2, \cdots, n_{i}, t=1, \cdots, T, i=1,2, \cdots, N, R_{i, t}$ é uma componente que não foi identificada a priori no nível inferior da hierarquia, isto é, ela está no modelo para capturar estruturas latentes que possam estar presentes mesmo depois de considerarmos $\sum_{j=1}^{n_{i}} x_{i, j, t}$. A variável $z_{i, j, t}$ é uma componente conhecida e $g\left(z_{i, j, t}\right)$ é uma função conveniente para a modelagem. A componente $R_{i, t}$ pode ser calculada por

$$
R_{i, t}=y_{i, t}-\sum_{j=1}^{n_{i}} x_{i, j, t} .
$$

$\mathrm{Na}$ abordagem bottom-up, primeiramente são geradas as previsões das séries temporais no nível inferior da hierarquia e, em seguida, essas são agregadas para gerar as previsões do nível superior da hierarquia. Portanto, a previsão para as séries temporais hierárquicas $y_{i, 1}, y_{i, 2}, \cdots, y_{i, T}$, para $i=$ $1,2, \cdots, N$, no horizonte de previsão $h$, representada por $\hat{y}_{i, T}(h)$, pode ser gerada pelo modelo abaixo,

$$
\begin{aligned}
\hat{y}_{i, T}(h) & =\sum_{j=1}^{n_{i}} \hat{x}_{i, j, T}(h)+\hat{R}_{i, T}(h), \\
\hat{x}_{i, j, T}(h) & =g\left(\hat{z}_{i, j, T}(h)\right),
\end{aligned}
$$

em que $\hat{x}_{i, j, T}(h), \hat{R}_{i, T}(h)$ e $\hat{z}_{i, j, T}(h)$ representam as componentes $x_{i, j, t}, R_{i, t}$ e $z_{i, j, t}$ estimadas, respectivamente. Supõe-se que os valores das componentes $z_{i, j, t}$ e $R_{i, t}$ sejam conhecidas para $t=1, \cdots, T$. Para o horizonte de previsão, os valores de $\hat{z}_{i, j, T}(h)$ e $\hat{R}_{i, T}(h)$ serão gerados exogenamente e inseridos no modelo. A previsão dessas séries temporais pode ser obtida por qualquer método estatisticamente conveniente, isto é, uma metodologia de previsão que seja adequada para os dados e para a proposta do trabalho.

As estruturas hierárquicas modeladas por Bryk e Raudenbush (2002), Athanasopoulos et al. (2009), Hyndman et al. (2011), Hyndman et al. (2016) não apresentam nenhuma componente desconhecida no nível inferior da hierarquia, isto é, a estrutura hierárquica é completamente conhecida $\left(R_{i t}=0\right)$.

De acordo com Lindley e Smith (1972), e Bryk e Raudenbush (2002) dados organizados em uma estrutura hieráquica podem ser modelados pelos modelos lineares hierárquicos. Neste contexto, a estrutura hierárquica dos 
dados, apresentada na Figura 3.1, permite definir um modelo linear hierárquico para cada série temporal hierárquica, que é dado por

$$
\begin{aligned}
y_{i, t} & =\sum_{j=1}^{n_{i}} x_{i, j, t}+R_{i, t}+\epsilon_{i, t}, & \epsilon_{i, t} & \sim N\left(0, \sigma_{y_{i}}^{2}\right), \\
x_{i, j, t} & =g\left(z_{i, j, t}\right)+\delta_{i, j, t}, & \delta_{i, j, t} & \sim N\left(0, \sigma_{x_{i}}^{2}\right),
\end{aligned}
$$

para $t=1,2, \cdots, T, i=1,2, \cdots, N, j=1,2, \cdots, n_{i}, \epsilon_{i, t}$ segue uma distribuição normal com média zero e variância $\sigma_{y_{i}}^{2}$, e $\delta_{i, j, t}$ segue uma distribuição normal com média zero e variância $\sigma_{x_{i}}^{2}$. Além disso, é assumido que os erros $\epsilon_{i, t}$ e $\delta_{i, j, t}$ são internamente e mutuamente independentes. Portanto, o modelo (3-4) é uma versão estocástica do modelo determinístico (3-1). Na próxima Seção, será descrito o procedimento de inferência adotado.

\section{2}

\section{Estimação dos parâmetros}

Os parâmetros do modelo linear hierárquico serão estimados usando o enfoque bayesiano (Apêndice A) porque permite medir a incerteza dos parâmetros de interesse. Desta forma, será utilizado o método de Monte Carlo via Cadeias de Markov (MCMC) (METROPOLIS et al., 1953; HASTINGS, 1970; ROBERT; CASELLA, 2004; GAMERMAN; LOPES, 2006; MIGON et al., 2015), com ênfase no amostrador de Gibbs (GEMAN; GEMAN, 1984; GELFAND; SMITH, 1990), para estimar os parâmetros $x_{i, j, t}$, para $j=$ $1,2, \cdots, n_{i}, i=1,2, \cdots, N, t=1, \cdots, T, \sigma_{y_{i}}^{2}$ e $\sigma_{x_{i}}^{2}$.

$\mathrm{Na}$ abordagem bayesiana, tem-se que obter primeiramente a distribuição a posteriori para fazer inferência sobre os parâmetros do modelo. Suponha para cada $i$, o conjunto de parâmetros desconhecidos do modelo $\Theta=$ $\left(\sigma_{y_{i}}^{2}, \sigma_{x_{i}}^{2}, \mathbf{x}_{i, 1}, \cdots, \mathbf{x}_{i, T}\right)$, em que $\mathbf{x}_{i, t}=\left(x_{i, 1, t}, \cdots, x_{i, n_{i}, t}\right), \forall i, t$, com função de verossimilhança $p\left(\mathbf{y}_{\mathbf{i}} \mid \Theta\right)$, tal que $\mathbf{y}_{\mathbf{i}}=\left(y_{i, 1}, \cdots, y_{i, T}\right)$. Seja $p(\Theta)$ a distribuição a priori assumida para $\Theta$, o intuito é obter a distribuição a posteriori $p\left(\Theta \mid \mathbf{y}_{\mathbf{i}}\right)$, que é dada por

$$
\begin{aligned}
p\left(\Theta \mid \mathbf{y}_{\mathbf{i}}\right) & \propto p\left(\mathbf{y}_{\mathbf{i}} \mid \sigma_{y_{i}}^{2}, \sigma_{x_{i}}^{2}, \mathbf{x}_{i, 1}, \cdots, \mathbf{x}_{i, T}\right) p\left(\sigma_{y_{i}}^{2}, \sigma_{x_{i}}^{2}, \mathbf{x}_{i, 1}, \cdots, \mathbf{x}_{i, T}\right) \\
& \propto p\left(\mathbf{y}_{\mathbf{i}} \mid \sigma_{y_{i}}^{2}, \sigma_{x_{i}}^{2}, \mathbf{x}_{i, 1}, \cdots, \mathbf{x}_{i, T}\right) p\left(\mathbf{x}_{i, 1}, \cdots, \mathbf{x}_{i, T} \mid \sigma_{x_{i}}^{2}\right) p\left(\sigma_{y_{i}}^{2}, \sigma_{x_{i}}^{2}\right) \\
& \propto p\left(\mathbf{y}_{\mathbf{i}} \mid \sigma_{y_{i}}^{2}, \mathbf{x}_{i, 1}, \cdots, \mathbf{x}_{i, T}\right) p\left(\mathbf{x}_{i, 1}, \cdots, \mathbf{x}_{i, T} \mid \sigma_{x_{i}}^{2}\right) p\left(\sigma_{x_{i}}^{2}\right) p\left(\sigma_{y_{i}}^{2}\right)
\end{aligned}
$$

assumindo-se independência a priori. Lindley e Smith (1972) apontaram que a melhor estratégia para especificar uma distribuição a priori que descreve uma situação experimental é definir as distribuições a priori para os níveis inferiores 
da hierarquia.

Neste caso, para os parâmetros de variância $\sigma_{y_{i}}^{2}$ e $\sigma_{x_{i}}^{2}$ é usual atribuir-se distribuições a priori Inversa Gama ( $I G)$, devido à conjugação (GAMERMAN; LOPES, 2006), independentes e pouco informativas. Para uma explicação mais detalhada sobre as prioris pouco informativas, consultar Box e Tiao (1973), Berger (1985), e Bernardo e Smith (1994). Assim, foram adotadas as distribuições a priori independentes $\sigma_{y_{i}}^{2} \sim I G\left(\alpha_{1}, \beta_{1}\right)$, com $\alpha_{1}$ e $\beta_{1}$ conhecidos, e para $\sigma_{x_{i}}^{2} \sim I G\left(\alpha_{2}, \beta_{2}\right)$, com $\alpha_{2}$ e $\beta_{2}$ conhecidos.

Assim, o modelo completo é apresentado abaixo:

$$
\begin{aligned}
\left(y_{i, t} \mid \sigma_{y_{i}}^{2}, \mathbf{x}_{i, t}\right) & \sim N\left(\sum_{j=1}^{n_{i}} x_{i, j, t}+R_{i, t}, \sigma_{y_{i}}^{2}\right) \\
\left(x_{i, j, t} \mid \sigma_{x_{i}}^{2}, z_{i, j, t}\right) & \sim N\left(g\left(z_{i, j, t}\right), \sigma_{x_{i}}^{2}\right) \\
\sigma_{y_{i}}^{2} & \sim I G\left(\alpha_{1}, \beta_{1}\right) \\
\sigma_{x_{i}}^{2} & \sim I G\left(\alpha_{2}, \beta_{2}\right)
\end{aligned}
$$

para $i=1,2, \cdots, N$ e $t=1, \cdots, T$, em que $\alpha_{1}, \beta_{1}, \alpha_{2}$ e $\beta_{2}$ representam os hiperparâmetros considerados como conhecidos a priori.

Portanto, a distribuição a posteriori do vetor paramétrico $\Theta$ é dada por

$$
\begin{array}{r}
p\left(\Theta \mid \mathbf{y}_{\mathbf{i}}\right) \propto\left(2 \pi \sigma_{y_{i}}^{2}\right)^{-T / 2} \exp \left\{-\frac{1}{2 \sigma_{y_{i}}^{2}} \sum_{t=1}^{T}\left(y_{i, t}^{*}-\sum_{j=1}^{n_{i}} x_{i, j, t}\right)^{2}\right\} \\
\times\left(2 \pi \sigma_{x_{i}}^{2}\right)^{-n_{i} T / 2} \exp \left\{-\frac{1}{2 \sigma_{x_{i}}^{2}} \sum_{j=1}^{n_{i}} \sum_{t=1}^{T}\left(x_{i, j, t}-g\left(z_{i, j, t}\right)\right)^{2}\right\} \\
\times\left(\sigma_{y_{i}}^{2}\right)^{-\alpha_{1}-1} \exp \left\{-\frac{\beta_{1}}{\sigma_{y_{i}}^{2}}\right\} \times\left(\sigma_{x_{i}}^{2}\right)^{-\alpha_{2}-1} \exp \left\{-\frac{\beta_{2}}{\sigma_{x_{i}}^{2}}\right\},
\end{array}
$$

em que $y_{i, t}^{*}=y_{i, t}-R_{i, t}$, para $i=1,2, \cdots, N$.

A distribuição a posteriori acima não tem forma conhecida. Entretanto, as distribuições condicionais completas a posteriori de cada parâmetro são fáceis de serem obtidas, como pode-se observar a seguir:

(i) Distribuição condicional completa a posteriori para $x_{i, j, t}$ :

$$
\begin{aligned}
p\left(x_{i, j, t} \mid \cdot\right) & \propto \exp \left\{-\frac{1}{2 \sigma_{y_{i}}^{2}}\left(y_{i, t}^{*}-\sum_{j=1}^{n_{i}} x_{i, j, t}\right)^{2}\right\} \\
& \times \exp \left\{-\frac{1}{2 \sigma_{x_{i}}^{2}} \sum_{j=1}^{n_{i}}\left(x_{i, j, t}-g\left(z_{i, j, t}\right)\right)^{2}\right\}
\end{aligned}
$$

segue que 


$$
p\left(x_{i, j, t} \mid \cdot\right) \propto \exp \left\{-\frac{1}{2}\left[x_{i, j, t}^{2}\left(\frac{1}{\sigma_{y_{i}}^{2}}+\frac{1}{\sigma_{x_{i}}^{2}}\right)-2 x_{i, j, t}\left(\frac{y_{i, t}^{*}-\sum_{k=1, k \neq j}^{n_{i}} x_{i, k, t}}{\sigma_{y_{i}}^{2}}+\frac{g\left(z_{i, j, t}\right)}{\sigma_{x_{i}}^{2}}\right)\right]\right\} .
$$

Logo,

$$
\begin{gathered}
\left(x_{i, j, t} \mid \cdot\right) \sim N\left(v^{-1} m, v^{-1}\right), \text { em que } \\
v=\left(\frac{1}{\sigma_{y_{i}}^{2}}+\frac{1}{\sigma_{x_{i}}^{2}}\right) \text { e } m=\left(\frac{y_{i, t}^{*}-\sum_{k=1, k \neq j}^{n_{i}} x_{i, k, t}}{\sigma_{y_{i}}^{2}}+\frac{g\left(z_{i, j, t}\right)}{\sigma_{x_{i}}^{2}}\right) .
\end{gathered}
$$

(ii) Distribuição condicional completa a posteriori para $\sigma_{y_{i}}^{2}$ :

$$
p\left(\sigma_{y_{i}}^{2} \mid \cdot\right) \propto\left(\sigma_{y_{i}}^{2}\right)^{-T / 2-\alpha_{1}-1} \exp \left\{-\frac{1}{\sigma_{y_{i}}^{2}}\left[\beta_{1}+\frac{1}{2} \sum_{t=1}^{T}\left(y_{i, t}^{*}-\sum_{j=1}^{n_{i}} x_{i, j, t}\right)^{2}\right]\right\} .
$$

Logo,

$$
\left(\sigma_{y_{i}}^{2} \mid \cdot\right) \sim I G\left(\alpha_{1}+\frac{T}{2}, \beta_{1}+\frac{1}{2} \sum_{t=1}^{T}\left(y_{i, t}^{*}-\sum_{j=1}^{n_{i}} x_{i, j, t}\right)^{2}\right) .
$$

(iii) Distribuição condicional completa a posteriori para $\sigma_{x_{i}}^{2}$ :

$$
p\left(\sigma_{x_{i}}^{2} \mid \cdot\right) \propto\left(\sigma_{x_{i}}^{2}\right)^{-\frac{n_{i} T}{2}-\alpha_{2}-1} \exp \left\{-\frac{1}{\sigma_{x_{i}}^{2}}\left[\beta_{2}+\frac{1}{2} \sum_{j=1}^{n_{i}} \sum_{t=1}^{T}\left(x_{i, j, t}-g\left(z_{i, j, t}\right)\right)^{2}\right]\right\} .
$$

Logo,

$$
\left(\sigma_{x_{i}}^{2} \mid \cdot\right) \sim I G\left(\alpha_{2}+\frac{n_{i} T}{2}, \beta_{2}+\frac{1}{2} \sum_{j=1}^{n_{i}} \sum_{t=1}^{T}\left(x_{i, j, t}-g\left(z_{i, j, t}\right)\right)^{2}\right) .
$$

Como as distribuições condicionais completas são conhecidas, então pode-se gerar amostras da distribuição a posteriori dos parâmetros do modelo utilizando o método MCMC, em particular pelo Amostrador de Gibbs.

A estimação dos parâmetros sob o enfoque bayesiano pode ser consultada com mais detalhes em Migon et al. (2015).

No Capítulo seguinte o modelo proposto será contextualizado para o setor industrial brasileiro. 


\section{Aplicação do Modelo Proposto}

\section{1}

\section{Mapeamento da indústria brasileira}

O setor industrial brasileiro é composto por onze subsetores de acordo com a atividade desenvolvida, segundo o Balanço Energético Nacional (EPE, 2016a; EPE, 2017), ferro-gusa e aço, metais não-ferrosos e outros de metalurgia, papel e celulose, química, alimentos e bebidas, cimento, ferro ligas, mineração e pelotização, têxtil, cerâmicas e outras indústrias. A Figura 4.1 mostra a evolução do consummo de eletricidade dos subsetores da indústria brasileira, de 2000 até 2016.

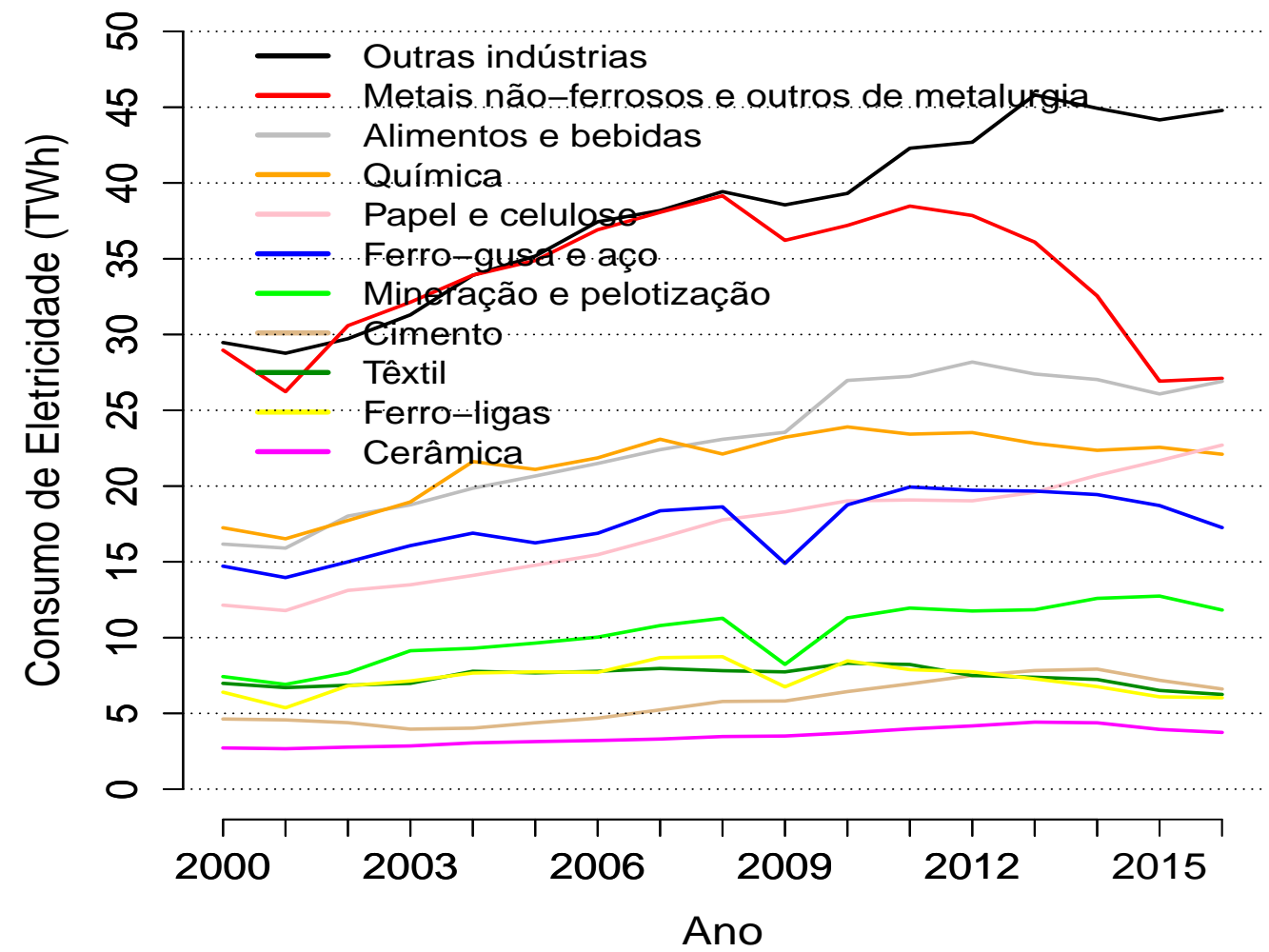

Figura 4.1: Consumo de eletricidade dos subsetores da indústria brasileira.

Neste trabalho, para cada um dos subsetores foram identificados os processos de produção existente e o consumo específico de eletricidade por 
processo. Além disso, para alguns subsetores foram definidas as possíveis medidas de eficiência energética.

A Tabela 4.1 apresenta os 79 processos mapeados na indústria brasileira com os respectivos subsetores. Na indústria química foi identificado o maior número de processos, seguido pela indústria de alimentos e bebidas.

Tabela 4.1: Subsetores e processos da indústria brasileira

\begin{tabular}{|c|c|c|}
\hline & Subsetor & Processos \\
\hline & 1 Ferro gusa e aço & $\begin{array}{l}1 \text { Sinterização } \\
2 \text { Aço oxigenado } \\
3 \text { Aço elétrico } \\
4 \text { Aço laminadoo } \\
5 \text { Gusa coke } \\
6 \text { Redução }\end{array}$ \\
\hline$\underset{\infty}{\longleftarrow}$ & $\begin{array}{l}2 \text { Metais não ferrosos e outros } \\
\text { de metalurgia }\end{array}$ & $\begin{array}{l}1 \text { Alumínio primário } \\
2 \text { Alumínio secundário (sucata) } \\
3 \text { Cobre primário } \\
4 \text { Cobre secundário } \\
5 \text { Cobre refinado } \\
6 \text { Zinco primário } \\
7 \text { Chumbo } \\
8 \text { Estanho } \\
9 \text { Níquel } \\
10 \text { Silício metálico }\end{array}$ \\
\hline 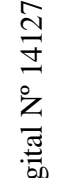 & 3 Papel e celulose & $\begin{array}{l}1 \text { Papel } \\
2 \text { Mecânica de celulose } \\
3 \text { Química de celulose } \\
4 \text { Papel reciclado } \\
\end{array}$ \\
\hline 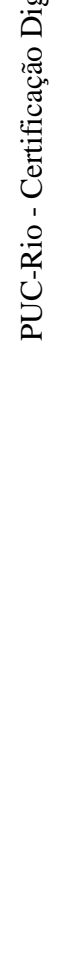 & 4 Química & $\begin{array}{l}1 \text { Amônia } \\
2 \text { Carboneto calcio (acetileno) } \\
3 \text { Cloro, diafragma } \\
4 \text { cloro, membrana } \\
5 \text { Cloro, mercúrio } \\
6 \text { Eteno (etileno) } \\
7 \text { Oxigênio } \\
8 \text { Polietileno } \\
9 \text { Polipropileno } \\
10 \text { Plásticos } \\
11 \text { Resinas termofixas } \\
12 \text { Ácido adípico* } \\
13 \text { Carbono preto* } \\
14 \text { Metanol (álcool metílico*) } \\
15 \text { Ácido nítrico* } \\
16 \text { Policarbonato* } \\
17 \text { Polissulfona* } \\
18 \text { Hidróxido de sódio (soda)* } \\
19 \text { Tolueno (TDI)* } \\
20 \text { Dióxido de titânio* } \\
21 \text { Outros para fertilizantes* } \\
22 \text { Outros químicos inogânicos* } \\
23 \text { Outros petroquímicos básicos* }\end{array}$ \\
\hline
\end{tabular}




\begin{tabular}{|c|c|}
\hline & $\begin{array}{l}24 \text { Outros fibras sintéticas* } \\
25 \text { Solventes industriais* } \\
26 \text { Outros produtos químicos orgânicos* } \\
27 \text { Outros resinas termoplásticas* } \\
28 \text { Elastômeros* }\end{array}$ \\
\hline 5 Alimentos e bebidas & $\begin{array}{l}1 \text { Açúcares } \\
2 \text { Leite e derivados } \\
3 \text { Bebidas } \\
4 \text { Produtos derivados de carne } \\
5 \text { Panificação } \\
6 \text { Café, chá, cereais } \\
7 \text { Óleos e gorduras } \\
8 \text { Frutas e legumes } \\
9 \text { Óleos e gorduras* } \\
10 \text { Chocolate, cacau e balas* } \\
11 \text { Conservas de pescados* }\end{array}$ \\
\hline 6 Cimento & $\begin{array}{l}1 \text { Preparação de matérias-primas } \\
\text { (moagem cru) } \\
2 \text { Clinquerização do cimento } \\
3 \text { Moagem do cimento CPI } \\
4 \text { Moagem do cimento CPII } \\
5 \text { Moagem do cimento CPIII } \\
6 \text { Moagem do cimento CPIV } \\
7 \text { Moagem do cimento CPV }\end{array}$ \\
\hline 7 Ferro ligas & $\begin{array}{l}1 \text { Preparação de matéria prima } \\
2 \text { Fusão e redução da carga } \\
3 \text { Preparação do produto final }\end{array}$ \\
\hline 8 Mineração e pelotização & $\begin{array}{l}1 \text { Mineração } \\
2 \text { Pelotização }\end{array}$ \\
\hline 9 Têxtil & $\begin{array}{l}1 \text { Fiação } \\
2 \text { Tecelagem } \\
3 \text { Malharia } \\
4 \text { Confecção } \\
5 \text { Beneficiamento }\end{array}$ \\
\hline 10 Cerâmica & $\begin{array}{l}1 \text { Revestimentos cerâmicos } \\
2 \text { Cerâmicas vermelha }\end{array}$ \\
\hline 11 Outras indústrias & 1 Outros \\
\hline
\end{tabular}

A Figura 4.2 mostra a classificação dos processos em relação ao consumo de eletricidade em 2012. Essa figura mostra os processos eletro-intensivos da indústria brasileira, pode-se observar que 30 processos consumiram aproximadamente $90 \%$ de eletricidade do setor industrial, e 21 processos apresentaram um consumo superior a $80 \%$ do total de eletricidade da indústria brasileira. 


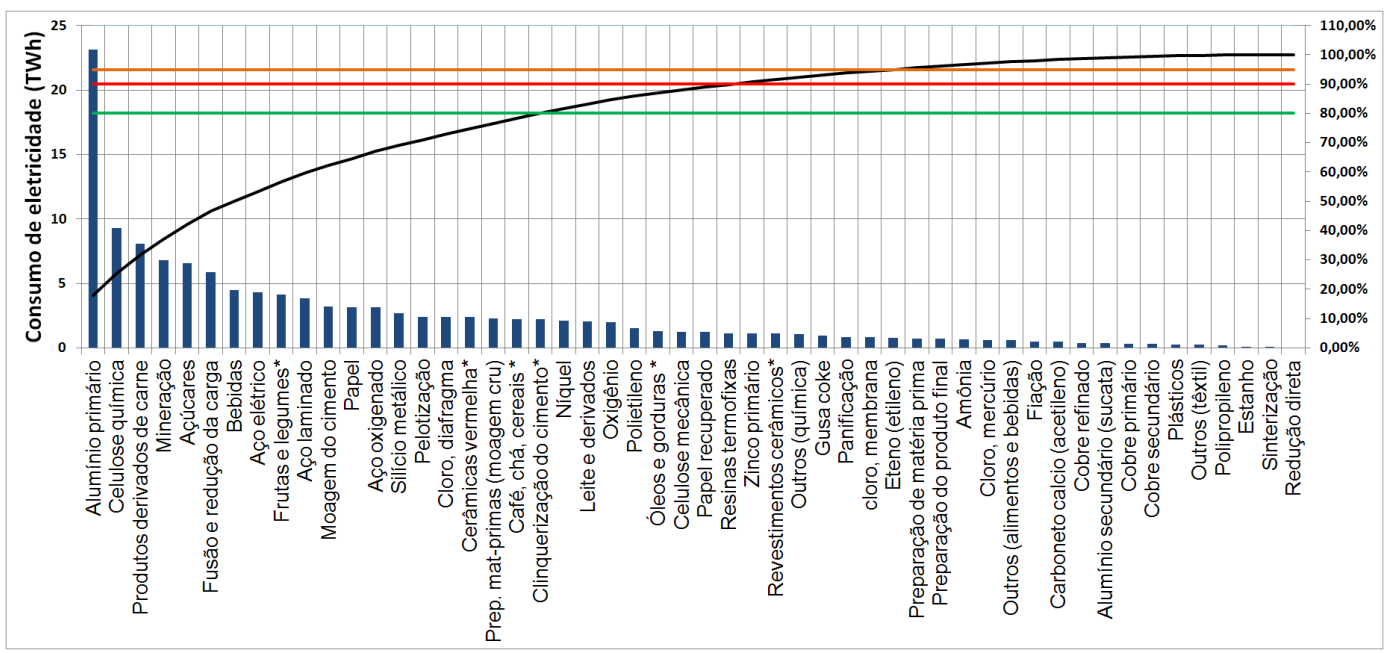

Figura 4.2: Consumo de eletricidade (TWh) dos processos da indústria brasileira em 2012 (Tabela B.2).

\section{2}

\section{Medidas de Eficiência Energética (MEEs)}

As medidas de eficiência energética são utilizadas para reduzir o consumo de eletricidade ao longo do tempo. Essas medidas podem ser aplicadas aos processos da indústria e as tecnologias transversais que são equipamentos comuns a todos os setores da indústria (FLEITER et al., 2012), como pode ser observado na estrutura da Figura 4.3. Com base em Fleiter et al. (2012) e no FORECAST, as tecnologias transversais definidas neste trabalho foram as seguintes: ventilação, refrigeração, bombas, outros motores, iluminação e ar comprimido.

As MEEs foram obtidas principalmente a partir de estudos desenvolvidos pelo Instituto Fraunhofer ${ }^{1}$ e por outros trabalhos que serão apresentados na Seção 4.2.2. Para mais detalhes sobre a metodologia das MEEs consultar Beer et al. (1997), Worrell e Price (2001), Kramer et al. (2009a) e Fleiter et al. (2011), Fleiter et al. (2012).

De acordo com Fleiter et al. (2011), Fleiter et al. (2012) e no FORECAST, para cada medida de eficiência energética tem-se um cenário de referência e três cenários de difusão tecnológica, que são os seguintes: cenário frozen que é livre de medidas de eficiência; o cenário de difusão autônoma que permite o mínimo de medidas de eficiência; cenário de difusão máxima que permite o máximo de medidas de eficiência; e o cenário de difusão cost-effective que considera o custo de investimento das medidas de eficiência energética. Esses cenários são construídos com base nos valores das curvas de difusão (FLEITER

\footnotetext{
${ }^{1}$ http://www.forecast-model.eu/forecast-en/index.php
} 
et al., 2012; MATHEWS; BARONI, 2013).

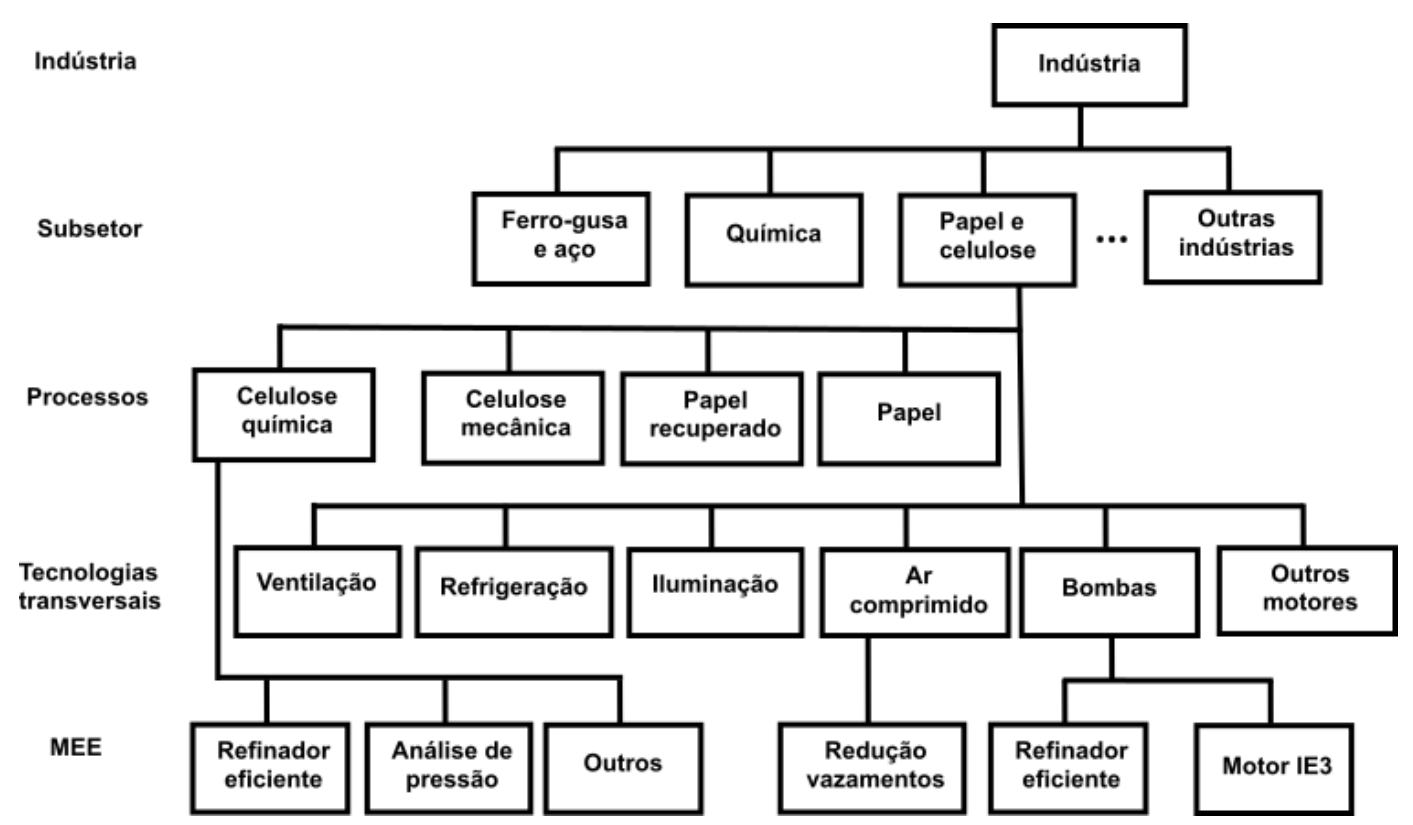

Figura 4.3: Estrutura hierárquica do setor industrial com algumas medidas de eficiência energética de um subsetor.

Segundo Jaffe e Stavins (1994), Rao e Kishore (2010), e Mathews e Baroni (2013) os valores de uma curva de difusão podem ser estimados por uma função logística. Neste estudo, a função logística foi definida por

$$
d_{x}(t)=\frac{D_{x, 0} D_{x, f} e^{\lambda_{x}\left(t-t_{x, 0}\right)}}{D_{x, f}+D_{x, 0}\left[e^{\lambda_{x}\left(t-t_{x, 0}\right)}-1\right]}
$$

onde $x$ é o tipo de difusão, $t$ é o ano de interesse, $\lambda$ é o parâmetro de inclinação da curva logística, $t_{x, 0}$ é o ano inicial, $t_{x, f}$ é o ano final, $D_{x, 0}$ é o valor inicial da curva de difusão em $t_{x, 0}$ e $D_{x, f}$ é o valor final da curva de difusão em $t_{x, f}$.

Na Seção 4.3 será apresentada a metodologia utilizada para construção dos cenários de difusão tecnológica.

\subsection{1}

\section{MEEs para o subsetor de papel e celulose}

No subsetor de papel e celulose foram consideradas onze medidas de eficiência energética para reduzir o consumo de eletricidade dos processos. Essas medidas de eficiência foram consideradas com base nos trabalhos de Kramer et al. (2009a), Fleiter et al. (2012), pelo estudo desenvolvido pelo Instituto Fraunhofer e presente no FORECAST, informações da indústria brasileira contidas no Balanço Energético Útil (BEU) (MME, 2005) e PROCEL-Indústria (PROCEL/INFO, 2010). A Tabela 4.2 mostra as MEEs definidas neste estudo para os processos do subsetor de papel e celulose, e algumas características/informações importantes para modelagem. 
Tabela 4.2: Resumo das medidas de eficiência energética aplicadas aos processos da indústria de papel e celulose.

\begin{tabular}{l|l|c|c}
\hline Processos & MEEs & $\begin{array}{c}\text { EEE } \\
\text { (GJ/t) }\end{array}$ & $\begin{array}{c}\text { Tempo de vida } \\
\text { (ano) }\end{array}$ \\
\hline Papel & Refinadores eficientes & 0.118 & 10 \\
& Otimização dos refinadores & 0.075 & 10 \\
& Melhoramento na química de fibras & 0.164 & 10 \\
\hline Química de celulose & Gaseificação de licor negro & 2.000 & 10 \\
\hline Mecânica de celulose & Eficiência elevada (GW) & 2.590 & 10 \\
& Pré-tratamento enzimático & 1.860 & 10 \\
& Refinadores eficientes (TMP) & 1.550 & 10 \\
\hline Papel reciclado & Polpação de alta consistência & 0.020 & 10 \\
& Rastreamento eficiente & 0.065 & 10 \\
& Otimização de flotação De-Inking & 0.050 & 10 \\
& Dispersor eficiente & 0.022 & 10 \\
\hline
\end{tabular}

$\mathrm{EEE}=$ Economia Específica de Eletricidade

$\mathrm{Na}$ modelagem de eficiência energética para as tecnologias tranversais, este estudo considerou dezesseis medidas de eficiência. Elas foram definidas com base nas informações encontradas no BEU (MME, 2005), PROCEL-Indústria (PROCEL/INFO, 2010), EPE (2014), Electrical Engineerning Portal (EEP, 2015a; EEP, 2015b), the Institute for Industrial Productivity (IETD, 2006), Ernest Orlando Lawrence Berkeley National Laboratory (KRAMER et al., 2009b), e pelo estudo desenvolvido pelo Instituto Fraunhofer e presente no FORECAST. As informações são mostradas na Tabela 4.3. 
Tabela 4.3: Resumo das medidas de eficiência energética aplicadas às tecnologias transversais da indústria de papel e celulose.

\begin{tabular}{|c|c|c|c|}
\hline $\begin{array}{l}\text { Tecnologias } \\
\text { transversais }\end{array}$ & MEEs & $\begin{array}{c}\mathrm{EEE} \\
(\mathrm{GJ} / \mathrm{t})\end{array}$ & $\begin{array}{c}\text { Tempo de vida } \\
\text { (ano) }\end{array}$ \\
\hline \multirow[t]{7}{*}{ Ventilação } & Ventiladores de alta eficiência & 0.050 & 15 \\
\hline & Manutenção regular & 0.013 & 1 \\
\hline & Motores IE2 & 0.009 & 20 \\
\hline & Controlador de velocidade & 0.096 & 20 \\
\hline & Motores IE3 & 0.004 & 20 \\
\hline & $\begin{array}{l}\text { Movimentação direta em } \\
\text { vez de V-Belt }\end{array}$ & 0.029 & 15 \\
\hline & Avoid oversizing & 0.033 & 20 \\
\hline \multirow[t]{7}{*}{ Bombas } & Bombas de alta eficiência & 0.029 & 15 \\
\hline & Avoid oversizing & 0.025 & 20 \\
\hline & Manutenção regular & 0.013 & 1 \\
\hline & Motores IE2 & 0.009 & 20 \\
\hline & Controlador de velocidade & 0.113 & 20 \\
\hline & Motores IE3 & 0.004 & 20 \\
\hline & $\begin{array}{l}\text { Movimentação direta em } \\
\text { vez de V-Belt }\end{array}$ & 0.029 & 15 \\
\hline \multirow[t]{7}{*}{ Ar comprimido } & Compressor de alta eficiência & 0.047 & 15 \\
\hline & Manutenção regular & 0.177 & 1 \\
\hline & Motores IE2 & 0.009 & 20 \\
\hline & Controlador de velocidade & 0.026 & 20 \\
\hline & Motores IE3 & 0.004 & 20 \\
\hline & Avoid oversizing & 0.025 & 20 \\
\hline & $\begin{array}{l}\text { Movimentação direta em } \\
\text { vez de V-Belt }\end{array}$ & 0.020 & 15 \\
\hline \multirow[t]{7}{*}{ Refrigeração } & Compressores eficientes & 0.022 & 20 \\
\hline & Manutenção regular & 0.044 & 20 \\
\hline & Motores IE2 & 0.009 & 20 \\
\hline & Controlador de velocidade & 0.026 & 20 \\
\hline & Motores IE3 & 0.009 & 20 \\
\hline & Avoid oversizing & 0.025 & 20 \\
\hline & $\begin{array}{l}\text { Movimentação direta em } \\
\text { vez de V-Belt }\end{array}$ & 0.029 & 15 \\
\hline \multirow[t]{5}{*}{ Outros motores } & IE2 Motors & 0.009 & 20 \\
\hline & Motores IE3 & 0.004 & 20 \\
\hline & Controlador de velocidade & 0.047 & 20 \\
\hline & Avoid oversizing & 0.025 & 20 \\
\hline & $\begin{array}{l}\text { Movimentação direta em } \\
\text { vez de V-Belt }\end{array}$ & 0.029 & 15 \\
\hline \multirow[t]{3}{*}{ Iluminação } & Manutenção regular & 0.068 & 1 \\
\hline & LEDs & 0.136 & 20 \\
\hline & Luminárias eficientes & 0.041 & 10 \\
\hline
\end{tabular}

$\overline{\mathrm{EEE}}=$ Economia Específica de Eletricidade

\subsection{2}

\section{MEEs para o subsetor de metais não ferrosos e outros de metalurgia}

No subsetor de metais não ferrosos e outros de metalurgia, foram consideradas dezesseis medidas de eficiência energética (Tabela 4.4) para reduzir o consumo de eletricidade dos processos. Essas medidas de eficiência foram consideradas com base nos trabalhos desenvolvido pelo Instituto 
Fraunhofer e presente no FORECAST, Schwarz (2008), informações da indústria brasileira contidas no BEU (MME, 2005) e PROCEL-Indústria (PROCEL/INFO, 2010).

Para as tecnologias transversais foram consideradas as MEEs apresentadas na Tabela 4.3.

Tabela 4.4: Resumo das medidas de eficiência energética aplicadas aos processos da indústria de metais não-ferrosos e outros de metalurgia.

\begin{tabular}{l|l|c|c}
\hline Processos & MEEs & $\begin{array}{c}\text { EEE } \\
(\mathrm{GJ} / \mathrm{t})\end{array}$ & $\begin{array}{c}\text { Tempo de vida } \\
\text { (ano) }\end{array}$ \\
\hline Alumínio primário & Anodos inertes & 3,60 & 2 \\
& Wetted Cathode & 7,34 & 8,52 \\
& PFPB & 3,60 & 20 \\
& Controle de eletrólise de otimização & 5 \\
& Design de célula de otimização & 2,52 & 6 \\
\hline Cobre primário & Gerenciamento de otimização & 0,25 & 20 \\
& Recuperação de calor residual & 0,05 & 20 \\
\hline Cobre secundário & Recuperação de calor residual & 0,45 & 20 \\
& Derretimento reverbatório: & 0,29 & 20 \\
& controle de processo melhorado & & \\
& Forno de eixo: refinaria melhorada & 0,08 & 20 \\
& Forno de eixo: recuperadores & 0,11 & 20 \\
& Forno de eixo: pré-aquecimento & 0,26 & 20 \\
& de sucata & & 20 \\
\hline Cobre refinado & Pacote de eficiência & 0,04 & 20 \\
& Novos tipos de queimadores & 0,38 & 20 \\
\hline Zinco primário & Aquecimento rápido & 0,60 & 20 \\
\hline
\end{tabular}

$\mathrm{EEE}=$ Economia Específica de Eletricidade

\section{3}

\section{Definição dos cenários de difusão tecnológica}

Os cenários de difusão tecnológica são construídos considerando as políticas de eficiência, as barreiras à inovação e os custos com as MEEs (KOOPMANS; VELD, 2001; WORRELL et al., 2003; ABDELAZIZ et al., 2011; FLEITER et al., 2012; HUANG et al., 2016)

Primeiramente, pode-se construir dois cenários de difusão variando os valores dos parâmetros da função logística (equação (4-1)). Assim, os cenários limites (inferior e superior) podem ser definidos como sugerido por Fleiter et al. (2012), e Koopmans e Veld (2001). Esses limites consideram apenas as barreiras tecnológicas, isto é, não incluem nenhum custo com as MEEs. O limite inferior pressupõe que essas barreiras permaneçam altas e que a difusão da tecnologia é baseada no desenvolvimento passado e sem políticas de incentivo. Para o limite superior, assume-se que as barreiras são muito baixas.

Um cenário real considera os custos e outras componentes. Assim, tem-se o cenário de difusão cost-effective (ou induzido) que é construído com base no 
custo das MEEs e certas suposições de decisão de investimento (KOOPMANS; VELD, 2001; WORRELL et al., 2003; FLEITER et al., 2012; HUANG et al., 2016). Nesse cenário assume-se que as empresas investem com base no tempo de resposta das MEEs. Portanto, maior o tempo de resposta, mais perto do limite inferior, e reduzindo o tempo de resposta, ele se aproxima do limite superior.

Para avaliar as economias de energia que um cenário oferece considera-se uma linha de base que é obtida onde não há melhoria na eficiência energética. Essa linha de base foi nomeada de cenário frozen (ou congelado) por Hirst e Brown (1990), Farla et al. (1997), Fleiter et al. (2012) e Huang et al. (2016). A distância de qualquer cenário para o cenário frozen em um determinado ano é definida como o potencial de economia de energia do cenário. Os cenários de difusão inferior e superior, denominados autônoma (auto, ou tendencial) e máxima (max) respectivamente, foram obtidos pelas curvas de difusão geradas através da função logística apresentada na equação (4-1). O cenário de difusão cost-effective (cost) teve sua curva de difusão definida com base nessas duas curvas por

$$
d_{\text {cost }}(t)=d_{\text {auto }}(t)+\psi(t)\left(d_{\text {max }}(t)-d_{\text {auto }}(t)\right),
$$

onde $d_{\text {auto }}(t)$ é o valor da difusão autônoma, $d_{\max }(t)$ é o valor da difusão máxima e $\psi$ é um parâmetro que depende do preço de energia ${ }^{2}$, do custo de investimento, do potencial específico de economia de eletricidade e do tempo de vida para cada medida de eficiência (Apêndice C). Os valores de $\psi$ variam no intervalo $[0,1]$. Para mais detalhes sobre o cálculo de $\psi$, ver Worrell et al. (2003). Neste estudo, os valores de $\psi$ foram calculados usando as informações apresentadas por Fleiter et al. (2012), por estudos desenvolvidos pelo Instituto Fraunhofer ${ }^{3}$, Kramer et al. (2009a), e pelo The Institute for Industrial Productivity (IETD, 2006). Os valores das curvas de difusão foram calculados pelo FORECAST. A Figura 4.4 ilustra as curvas de difusão.

$\mathrm{Na}$ próxima Seção, apresenta-se a modelagem proposta neste trabalho aplicada ao setor industrial brasileiro que segue a estrutura hierárquica mostrada na Seção 3.1.

\footnotetext{
${ }^{2}$ Preço de energia foi projetado pelo modelo de despacho hidrotérmico estocástico com restrições de rede, https://www.psr-inc.com/softwares/?current $=$ p4026

${ }^{3}$ http://www.forecast-model.eu/forecast-en/index.php
} 


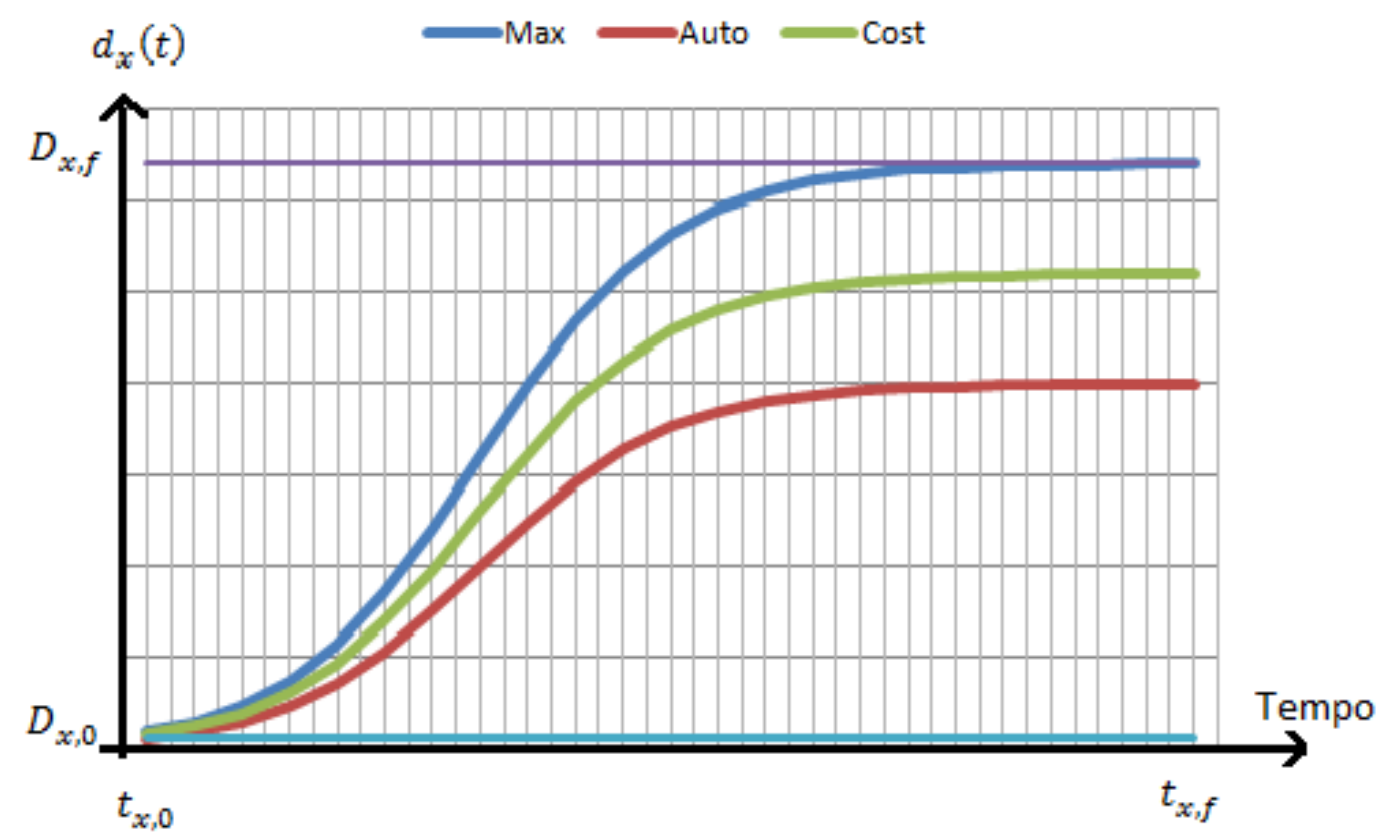

Figura 4.4: Ilustração das curvas de difusão tecnológica, onde Auto representa a curva de difusão autonôma, Max é curva de difusão Máxima, e Cost é a curva de difusão cost-effective.

\section{4}

\section{Modelo para o setor industrial}

Considere a estrutura hierárquica apresentada na Figura 4.5, em que $S_{i, t}$ representa o consumo de eletricidade do subsetor $i$, no tempo $t$, da indústria brasileira, $P_{i, j, t}$ representa o consumo de eletricidade do processo $j$ do subsetor $i$ no tempo $t, \operatorname{Prod}_{i, j, t}$ é produção em toneladas do processo $j$ relacionado ao subsetor $i$ no tempo $t$, e $R_{i, t}$ é uma componente que não foi identificada $a$ priori no histórico dos dados para o subsetor $i$ no tempo $t$.

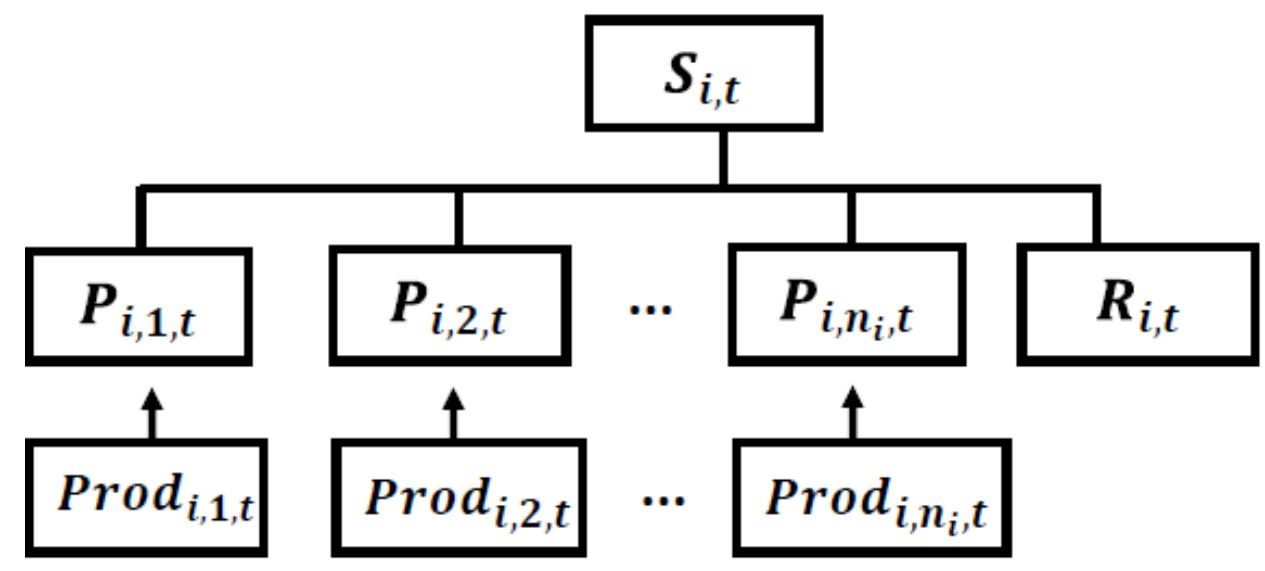

Figura 4.5: Estrutura hierárquica do consumo de eletricidade dos subsetores da indústria brasileira. 
Assuma agora que $S_{i, 1}, S_{i, 2}, \cdots, S_{i, T}$ é uma série temporal hierárquica do consumo de eletricidade de cada subsetor $i$, para $i=1,2, \cdots, 11$, da indústria brasileira. Seguindo o modelo descrito nas equações (3-4) e na Figura 4.5, o modelo linear hierárquico proposto para o consumo de eletricidade de cada subsetor é dado por

$$
\begin{aligned}
S_{i, t} & =\sum_{j=1}^{n_{i}} P_{i, j, t}+R_{i, t}+\epsilon_{i, t}, & \epsilon_{i, t} & \sim N\left(0, \sigma_{s_{i}}^{2}\right), \\
P_{i, j, t} & =g\left(\operatorname{Prod}_{i, j, t}\right)+\delta_{i, j, t}, & & \delta_{i, j, t} \sim N\left(0, \sigma_{p_{i}}^{2}\right), \\
g\left(\operatorname{Prod}_{i, j, t}\right) & =S E C_{i, j, t} \times \operatorname{Prod}_{i, j, t}, & &
\end{aligned}
$$

para $t=1,2, \cdots, T, j=1,2, \cdots, n_{i}$ e $i=1,2, \cdots, 11$, em que $S E C_{i, j, t}$ é o consumo específico de eletricidade do processo $j$ pertencente ao subsetor $i$ no tempo $t ; \epsilon_{i, t}$ segue uma distribuição normal com média zero e variância $\sigma_{s_{i}}^{2}$, e $\delta_{i, j, t}$ segue uma distribuição normal com média zero e variância $\sigma_{p_{i}}^{2}$. Além disso, é assumido que os erros $\epsilon_{i, t}$ e $\delta_{i, j, t}$ são internamente e mutuamente independentes.

Baseado no material metodológico do FORECAST, propõe-se que a parcela não identificada a priori $\left(R_{i, t}\right)$ seja obtida por

$$
R_{i, t}= \begin{cases}S_{i, t}-\sum_{j=1}^{n_{i}} P_{i, j, t}, & t=1, \cdots, T \\ R_{i, T} \times\left[1+\left(\frac{V A_{i, t}}{V A_{i, T}}-1\right) \times \rho\right], & t=T+1, T+2, \cdots ;\end{cases}
$$

em que $V A_{i, t}$ é o valor adicionado do subsetor $i$ no tempo $t$ e $\rho$ é um fator de correlação da demanda de energia com o valor adicionado.

O procedimento de cálculo do consumo específico de eletricidade (SEC) utilizado na modelagem será apresentado abaixo (Seção 4.4.1).

\subsection{1}

\section{Consumo específico de eletricidade}

Segundo Farla et al. (1997), o consumo específico de eletricidade do processo $j$ pertencente ao subsetor $i$ no tempo $t$ é definido por

$$
S E C_{i, j, t}=\frac{P_{i, j, t}}{\operatorname{Prod}_{i, j, t}} .
$$

No Brazil, alguns valores de SEC dos processos da indústria brasileira foram obtidos através dos relatórios do PROCEL-Indústria (PROCEL/INFO, 2010) e EPE (EPE, 2015). Mas para os outros processos foram necessários propor outros métodos para obter os valores de SEC devido a falta de informação do consumo de energia e a produção específica de alguns processos da indústria. 
O primeiro método, baseado em Farla et al. (1997), simplesmente considera o SEC dos processos igual ao do subsetor, quando possível. Desta forma, supondo que a produção $\left(\sum_{j=1}^{n_{i}} \operatorname{Prod}_{i, j, t}\right)$ e consumo de energia $\left(\sum_{j=1}^{n_{i}} P_{i, j, t}\right)$ do subsetor sejam conhecidas, então o consumo específico de energia pode ser calculado por

$$
S E C_{i, j, t}=S E C_{i, t}=\frac{\sum_{j=1}^{n_{i}} P_{i, j, t}}{\sum_{j=1}^{n_{i}} \operatorname{Prod}_{i, j, t}}
$$

No segundo método, a ideia é utilizar os valores do SEC dos processos de subsetores de outro país $C$, que sejam conhecidos e com características equivalentes aos processos do país cujos valores de SEC são desconhecidos. Além disso, suponha que o consumo anual de energia do subsetor do país em análise $\left(S_{i, t, L}\right)$ e a produção anual dos seus processos $\left(\operatorname{Prod}_{i, j, t, L}\right)$ sejam conhecidos. Pode-se calcular o consumo específico de energia de cada processo $j$ pertencente ao subsector $i$, no tempo $t$, do país $L\left(S E C_{i, j, t, L}\right)$ usando os valores conhecidos do $\mathrm{SEC}$ dos processos do país $C\left(S E C_{i, j, t, C}\right)$ por

$$
S E C_{i, j, t, L}=\theta \times S E C_{i, j, t, C}
$$

onde

$$
\begin{gathered}
\theta=\frac{S_{i, t, L}-R_{i, t, L}}{\tilde{S}_{i, t, C}}, \\
\tilde{S}_{i, t, C}=\sum_{j=1}^{n_{i}}\left(S E C_{i, j, t, C} \times \operatorname{Prod}_{i, j, t, L}\right), \\
R_{i, t, L}=S_{i, t, L}-\sum_{j=1}^{n_{i}}\left(S E C_{i, j, t, C} \times \operatorname{Prod}_{i, j, t, L}\right) .
\end{gathered}
$$

O segundo método permitiu calcular os valores de SEC necessários exigidos pela abordagem, quando não estavam disponíveis em fontes oficiais, com base em informações oficiais encontradas. Assim, os dados utilizados na metodologia foram obtidos de dados do próprio país, não usando diretamente os dados de outros países.

Segue abaixo o procedimento de inferência utilizado para estimar os parâmetros envolvidos no modelo (4-3).

\subsection{2}

\section{Estimação dos parâmetros do modelo proposto para o setor industrial}

Para cada subsetor industrial $i$, o interesse é estimar o vetor paramétrico do modelo proposto que é dado por $\Theta=\left(\sigma_{s_{i}}^{2}, \sigma_{p_{i}}^{2}, \mathbf{P}_{i}\right)$, em que $\mathbf{P}_{i}=$ $\left(\mathbf{P}_{i, 1}, \cdots, \mathbf{P}_{i, T}\right)$, com $\mathbf{P}_{i, t}=\left(P_{i, 1, t}, \cdots, P_{i, n_{i}, t}\right)$. Seguindo o modelo (4-3), a função de verossimilhança é dada por 


$$
\begin{aligned}
l\left(\sigma_{s_{i}}^{2}, \sigma_{p_{i}}^{2}, \mathbf{P}_{i} \mid \mathbf{S}_{i}\right) & =p\left(\mathbf{S}_{i} \mid \sigma_{s_{i}}^{2}, \sigma_{p_{i}}^{2}, \mathbf{P}_{i}\right) \\
& =\left(2 \pi \sigma_{s_{i}}^{2}\right)^{-T / 2} \exp \left\{-\frac{1}{2 \sigma_{s_{i}}^{2}} \sum_{t=1}^{T}\left(S_{i, t}^{*}-\sum_{j=1}^{n_{i}} P_{i, j, t}\right)^{2}\right\}
\end{aligned}
$$

tais que $S_{i, t}^{*}=S_{i, t}-R_{i, t}$ e $\mathbf{S}_{i}=\left(S_{i, 1}, \cdots, S_{i, T}\right)$.

Os parâmetros do modelo linear hierárquico serão estimados utilizando a abordagem bayesiana. Seja $p\left(\sigma_{s_{i}}^{2}, \sigma_{p_{i}}^{2}, \mathbf{P}_{i}\right)$ a distribuição a priori do vetor paramétrico $\Theta$. Assume-se independência a priori das componentes do vetor paramétrico. Para os parâmetros $\sigma_{s_{i}}^{2}$ e $\sigma_{p_{i}}^{2}$ é usual especificar a distribuição a priori Inversa Gama, como dito na Seção 3.2. Assim, foram atribuídas as distribuições a priori independentes e pouco informativas: $\sigma_{s_{i}}^{2} \sim I G\left(\alpha_{1}, \beta_{1}\right)$, com $\alpha_{1}$ e $\beta_{1}$ conhecidos, e $\sigma_{p_{i}}^{2} \sim I G\left(\alpha_{2}, \beta_{2}\right)$, com $\alpha_{2}$ e $\beta_{2}$ conhecidos.

O modelo completo para o consumo de eletricidade de cada subsetor $i$ da indústria é especificado por

$$
\begin{aligned}
\left(S_{i, t} \mid \sigma_{s_{i}}^{2}, \sigma_{p_{i}}^{2}, \mathbf{P}_{i, t}\right) & \sim N\left(\sum_{j=1}^{n_{i}} P_{i, j, t}+R_{i, t}, \sigma_{s_{i}}^{2}\right) \\
\left(P_{i, j, t} \mid \sigma_{p_{i}}^{2}, \operatorname{Prod}_{i, j, t}\right) & \sim N\left(g\left(\operatorname{Prod}_{i, j, t}\right), \sigma_{p_{i}}^{2}\right) \\
\sigma_{s_{i}}^{2} & \sim I G\left(\alpha_{1}, \beta_{1}\right) \\
\sigma_{p_{i}}^{2} & \sim I G\left(\alpha_{2}, \beta_{2}\right)
\end{aligned}
$$

em que $\alpha_{1}, \beta_{1}$, $\alpha_{2}$ e $\beta_{2}$ representam os hiperparâmetros considerados como conhecidos a priori. Os valores de $\operatorname{Prod}_{i, j, t}$ e $R_{i, t}$ serão gerados exogenamente até o horizonte de previsão. O método de previsão utilizado neste trabalho para projetar a produção será apresentado mais adiante (Seção 4.7).

Sendo assim, a distribuição a posteriori para $\Theta$ é obtida da seguinte forma

$$
\begin{aligned}
p\left(\sigma_{s_{i}}^{2}, \sigma_{p_{i}}^{2}, \mathbf{P}_{i} \mid \mathbf{S}_{i}\right) & \propto l\left(\sigma_{s_{i}}^{2}, \sigma_{p_{i}}^{2}, \mathbf{P}_{i} \mid \mathbf{S}_{i}\right) p\left(\sigma_{s_{i}}^{2}, \sigma_{p_{i}}^{2}, \mathbf{P}_{i}\right) \\
& =p\left(\mathbf{S}_{i} \mid \sigma_{s_{i}}^{2}, \sigma_{p_{i}}^{2}, \mathbf{P}_{i}\right) p\left(\sigma_{s_{i}}^{2}, \sigma_{p_{i}}^{2}, \mathbf{P}_{i}\right) \\
& \propto p\left(\mathbf{S}_{i} \mid \sigma_{s_{i}}^{2}, \sigma_{p_{i}}^{2}, \mathbf{P}_{i}\right) p\left(\mathbf{P}_{i} \mid \sigma_{p_{i}}^{2}\right) p\left(\sigma_{s_{i}}^{2}, \sigma_{p_{i}}^{2}\right) \\
& \propto p\left(\mathbf{S}_{i} \mid \sigma_{s_{i}}^{2}, \mathbf{P}_{i}\right) p\left(\mathbf{P}_{i} \mid \sigma_{p_{i}}^{2}\right) p\left(\sigma_{p_{i}}^{2}\right) p\left(\sigma_{s_{i}}^{2}\right)
\end{aligned}
$$

assumindo-se independência a priori das componentes do vetor paramétrico. Portanto, a distribuição a posteriori dos parâmetros do modelo proposto para 
o consumo de eletricidade é dado por

$$
\begin{aligned}
p\left(\Theta \mid \mathbf{S}_{i}\right) & \propto\left(2 \pi \sigma_{s_{i}}^{2}\right)^{-T / 2} \exp \left\{-\frac{1}{2 \sigma_{s_{i}}^{2}} \sum_{t=1}^{T}\left(S_{i, t}^{*}-\sum_{j=1}^{n_{i}} P_{i, j, t}\right)^{2}\right\} \\
& \times\left(2 \pi \sigma_{p_{i}}^{2}\right)^{-n_{i} T / 2} \exp \left\{-\frac{1}{2 \sigma_{p_{i}}^{2}} \sum_{j=1}^{n_{i}} \sum_{t=1}^{T}\left(P_{i, j, t}-g\left(\operatorname{Prod}_{i, j, t}\right)\right)^{2}\right\} \\
& \times\left(\sigma_{s_{i}}^{2}\right)^{-\alpha_{1}-1} \exp \left\{-\frac{\beta_{1}}{\sigma_{s_{i}}^{2}}\right\} \times\left(\sigma_{p_{i}}^{2}\right)^{-\alpha_{2}-1} \exp \left\{-\frac{\beta_{2}}{\sigma_{p_{i}}^{2}}\right\} .
\end{aligned}
$$

A distribuição a posteriori conjunta não tem forma conhecida. Entretanto, as distribuições condicionais completas a posteriori de cada parâmetro são fáceis de serem obtidas, como mostrado a seguir:

(i) Distribuição condicional completa a posteriori de $P_{i, j, t}$ :

$$
\begin{aligned}
p\left(P_{i, j, t} \mid \cdot\right) \propto & \exp \left\{-\frac{1}{2 \sigma_{s_{i}}^{2}}\left(S_{i, t}^{*}-\sum_{j=1}^{n_{i}} P_{i, j, t}\right)^{2}\right\} \\
& \times \exp \left\{-\frac{1}{2 \sigma_{p_{i}}^{2}} \sum_{j=1}^{n_{i}}\left(P_{i, j, t}-g\left(\operatorname{Prod}_{i, j, t}\right)\right)^{2}\right\}
\end{aligned}
$$

segue que

$$
p\left(P_{i, j, t} \mid \cdot\right) \propto \exp \left\{-\frac{1}{2}\left[P_{i, j, t}^{2}\left(\frac{1}{\sigma_{s_{i}}^{2}}+\frac{1}{\sigma_{p_{i}}^{2}}\right)-2 P_{i, j, t}\left(\frac{S_{i, t}^{*}-\sum_{k=1, k \neq j}^{n_{i}} P_{i, k, t}}{\sigma_{s_{i}}^{2}}+\frac{g\left(\operatorname{Prod}_{i, j, t}\right)}{\sigma_{p_{i}}^{2}}\right)\right]\right\} .
$$

Logo,

$$
\left(P_{i, j, t} \mid \cdot\right) \sim N\left(v^{-1} m, v^{-1}\right), \text { em que }
$$

$$
v=\left(\frac{1}{\sigma_{s_{i}}^{2}}+\frac{1}{\sigma_{p_{i}}^{2}}\right) \text { e } m=\left(\frac{S_{i, t}^{*}-\sum_{k=1, k \neq j}^{n_{i}} P_{i, k, t}}{\sigma_{s_{i}}^{2}}+\frac{g\left(\operatorname{Prod}_{i, j, t}\right)}{\sigma_{p_{i}}^{2}}\right)
$$

(ii) Distribuição condicional completa a posteriori de $\sigma_{s_{i}}^{2}$ :

$$
p\left(\sigma_{s_{i}}^{2} \mid \cdot\right) \propto\left(\sigma_{s_{i}}^{2}\right)^{-T / 2-\alpha_{1}-1} \exp \left\{-\frac{1}{\sigma_{s_{i}}^{2}}\left[\beta_{1}+\frac{1}{2} \sum_{t=1}^{T}\left(S_{i, t}^{*}-\sum_{j=1}^{n_{i}} P_{i, j, t}\right)^{2}\right]\right\} .
$$

Logo,

$$
\left(\sigma_{s_{i}}^{2} \mid \cdot\right) \sim I G\left(\alpha_{1}+\frac{T}{2}, \beta_{1}+\frac{1}{2} \sum_{t=1}^{T}\left(S_{i, t}^{*}-\sum_{j=1}^{n_{i}} P_{i, j, t}\right)^{2}\right) .
$$

(iii) Distribuição condicional completa a posteriori de $\sigma_{p_{i}}^{2}$ : 


$$
\begin{aligned}
p\left(\sigma_{p_{i}}^{2} \mid \cdot\right) & \propto\left(\sigma_{p_{i}}^{2}\right)^{-\frac{n_{i} T}{2}-\alpha_{2}-1} \\
& \times \exp \left\{-\frac{1}{\sigma_{p_{i}}^{2}}\left[\beta_{2}+\frac{1}{2} \sum_{j=1}^{n_{i}} \sum_{t=1}^{T}\left(P_{i, j, t}-g\left(\operatorname{Prod}_{i, j, t}\right)\right)^{2}\right]\right\} .
\end{aligned}
$$

Logo,

$$
\left(\sigma_{p_{i}}^{2} \mid \cdot\right) \sim I G\left(\alpha_{2}+\frac{n_{i} T}{2}, \beta_{2}+\frac{1}{2} \sum_{j=1}^{n_{i}} \sum_{t=1}^{T}\left(P_{i, j, t}-g\left(\operatorname{Prod}_{i, j, t}\right)\right)^{2}\right) .
$$

Como as distribuições condicionais completas a posteriori são conhecidas, então pode-se gerar amostras da distribuição a posteriori dos parâmetros do modelo utilizando o método MCMC, em particular, pelo Amostrador de Gibbs.

\section{5}

\section{Modelo proposto para o setor industrial com as medidas de eficiência energética}

Considere a estrutura hierárquica apresentada na Figura $4.6 \mathrm{com}$ as medidas de eficiência energética. Nessa figura, os fatores $\alpha$ e $\beta$ representam o percentual de redução do consumo de eletricidade do subsetor $S_{i, t}$ (ou do processo $P_{i, j, t}$ ) obtido por uma (ou mais) medida (s) de eficiência. Essa figura mostra que as medidas de eficiência podem ser aplicadas nos subsetores e nos processos.

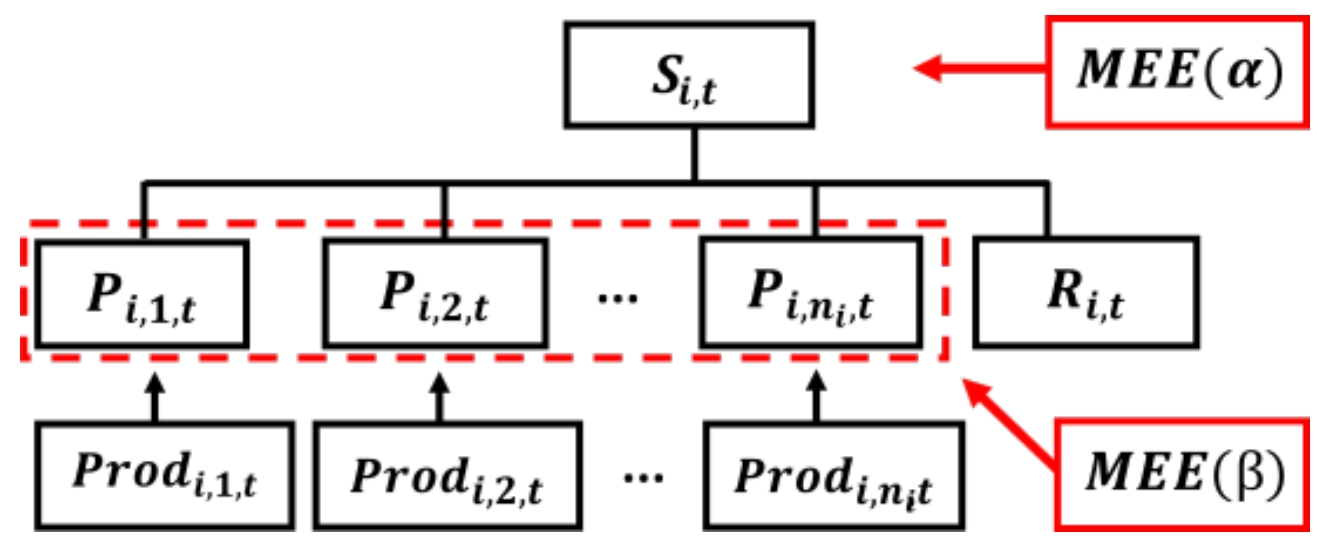

Figura 4.6: A estrutura hierárquica com as medidas de eficiência energética.

Primeiramente, propõe-se um modelo determinístico para a estrutura hierárquica (Figura 4.6) considerando as medidas de eficiência energética e, em seguida, será apresentado o modelo estocástico seguindo a estrutura das equações (3-4) e (4-3).

Com base nos trabalhos de Farla et al. (1997), Fleiter et al. (2012), Huang et al. (2016) e nas equações (3-1), pode-se definir um modelo determinístico para prever o consumo de eletricidade de longo prazo por 


$$
\begin{aligned}
S_{i, t} & =\sum_{j=1}^{n_{i}} P_{i, j, t}+R_{i, t}-E_{i, t}, \\
P_{i, j, t} & =g\left(\operatorname{Prod}_{i, j, t}\right)-E_{i, j, t},
\end{aligned}
$$

para $i=1,2, \cdots, N$ e $j=1,2, \cdots, n_{i}$, em que $S_{i, t}$ representa o consumo de eletricidade do subsetor $i$ no tempo $t, P_{i, j, t}$ representa o consumo de eletricidade do processo $j$ pertencente ao subsetor $i$ no tempo $t, R_{i, t}$ é uma estimativa obtida através do valor adicionado de cada subsetor, $\operatorname{Prod}_{i, j, t}$ é a produção em toneladas do processo $j$ relacionado ao subsetor $i$ no tempo $t, E_{i, t}$ corresponde a economia de energia obtida pelas MEEs aplicadas ao subsetor $i$ no tempo $t$, $E_{i, j, t}$ corresponde a economia de energia do processo $j$ pertencente ao subsetor $i$ no tempo $t$ obtida pelas MEEs. A economia de energia obtida pelas medidas de eficiência energética podem ser calculadas a partir das seguintes equações:

i)

$$
E_{i, t}=\sum_{k=1}^{z}\left(\phi_{i, k, t} \times \Delta_{i, k, t}\right), \quad \Delta_{i, k, t}=\sum_{e_{k}=1}^{m_{k}}\left(s p_{i, k, e_{k}} \times \alpha_{i, e_{k}, t, x}\right)
$$

onde $k$ representa a tecnologia transversal, z é o número de tecnologias, $e_{k}$ representa a MEE, $m_{k}$ é número de MEEs, $\phi_{i, k, t}$ é o de consumo de eletricidade da tecnologia transversal $k$ no subsetor $i, \Delta_{i, k, t}$ é o percentual de redução de eletricidade obtido pelas medidas de eficiência para a tecnologia transversal $k$ no tempo $t, s p_{i, k, e_{k}}$ é potencial específico de redução do consumo de eletricidade da MEE $e_{k}$ aplicada a tecnologia transversal $k$, e $\alpha_{i, e_{k}, t, x}$ é o percentual de redução do consumo de eletricidade no tempo $t$ obtido pela $\operatorname{MEE} e_{k}$ para a curva de difusão $x$.

ii)

$$
E_{i, j, t}=\sum_{e_{j}=1}^{m_{j}}\left(s p_{i, j, e_{j}} \times \beta_{i, j, e_{j}, t, x} \times \operatorname{Prod}_{i, j, t}\right),
$$

onde $e_{j}$ representa a MEE aplicada ao processo $j, m_{j}$ é o número de MEEs, $s p_{i, j, e_{j}}$ é um potencial específico de redução do consumo de eletricidade da medida de eficiência energética $e_{j}, \beta_{i, j, e_{j}, t, x}$ é o percentual de redução do consumo de eletricidade no tempo $t$ obtido pela medida de eficiência $e_{j}$ para a curva de difusão $x$.

Os parâmetros $\alpha$ e $\beta$ presentes nas equações (4-22) e (4-23) foram obtidos, usando a equação (4-1) da curva de difusão e a equação (4-2), por

$$
\begin{aligned}
& \alpha_{i, e_{k}, t, x}=d_{e_{k}, x}(t)-d_{e_{k}, x}\left(t_{x, 0}\right) \\
& \beta_{i, j, e_{j}, t, x}=d_{e_{j}, x}(t)-d_{e_{j}, x}\left(t_{x, 0}\right)
\end{aligned}
$$


O consumo de eletricidade da tecnologia transversal $k$ no subsetor $i\left(\phi_{i, k, t}\right)$ foi obtido a partir do percentual de consumo de eletricidade por tecnologia calculado pelo método proposto na Seção 4.6.

A partir dos modelos (4-3) e (4-21), o modelo linear hierárquico proposto para prever o consumo de eletricidade de longo prazo do subsetor $i$ no tempo $t$, usando as medidas de eficiência energética, é definido por

$$
\begin{aligned}
S_{i, t} & =\sum_{j=1}^{n_{i}} P_{i, j, t}+R_{i, t}-E_{i, t}+\epsilon_{i, t}, & \epsilon_{i, t} & \sim N\left(0, \sigma_{s_{i}}^{2}\right), \\
P_{i, j, t} & =g\left(\operatorname{Prod}_{i, j, t}\right)-E_{i, j, t}+\delta_{i, j, t}, & & \delta_{i, j, t} \sim N\left(0, \sigma_{p_{i}}^{2}\right),
\end{aligned}
$$

para $t=1,2, \cdots, T, i=1,2, \cdots, N$ e $j=1,2, \cdots, n_{i}$.

\section{6}

\section{Cálculo do percentual de consumo de eletricidade por tecnologia transversal}

No Brasil, o PROCEL ${ }^{4}$ juntamente com a CNI ${ }^{5}$ (Confederação Nacional das Indústrias) publicaram vários relatórios citando as tecnologias utilizadas pelos subsetores da indústria nacional. Esses relatórios não distinguem as tecnologias específicas de processos das tecnologias transversais; eles consideram um único tipo. Os relatórios mostram que seis tecnologias são utilizadas pela indústria brasileira, força motriz, iluminação, refrigeração, aquecimento direto, calor de processo e eletroquímica. Analisando os relatórios do PROCEL, as tecnologias de aquecimento direto, calor de processo e eletroquímica foram classificadas como tecnologias específicas de processo, e os aparelhos de força motriz, iluminação e refrigeração como tecnologias transversais.

Neste estudo, as tecnologias transversais que foram consideradas são as seguintes: ventilação, refrigeração, bombas, outros motores, iluminação e ar comprimido. As tecnologias de iluminação e refrigeração são correspondentes as tecnologias definidas pela indústria brasileira. Então, foi considerado que a tecnologia de força motriz reunia todos os tipos de motores utilizados na indústria, bombas, ventiladores e ar comprimido, ou seja, está associada a quatro tecnologias distintas na modelagem. Assim, propõe-se um método para calcular a parte de cada tecnologia contida na força motriz. Primeiramente, tem-se que

$$
E_{s p t, S, B r}+E_{c c t, S, B r}=100 \%
$$

onde $\mathrm{Br}$ representa o Brasil, $S$ é o setor da indústria, spt representa a tecnologia específica de processo, cct representa a tecnologia transversal,

\footnotetext{
${ }^{4}$ http://www.procelinfo.com.br

${ }^{5} \mathrm{http}: / /$ www.portaldaindustria.com.br/cni/
} 
$E_{s p t, S, B r}$ representa o percentual de consumo de eletricidade pelas tecnologias específicas de processos, $E_{c c t, S, B r}$ representa o percentual de consumo de eletricidade pelas tecnologias transversais. Portanto, o percentual de consumo das tecnologias transversais podem ser obtidas por

$$
E_{c c t, S, B r}=100 \%-E_{s p t, S, B r}
$$

Considere que o percentual de consumo de eletricidade pelas tecnologias transversais pode ser reescrito por

$$
E_{c c t, S, B r}=E_{F M, B r}+E_{I R, B r}
$$

onde $E_{F M, B r}$ representa o percentual de consumo de eletricidade da força motriz $(\mathrm{FM}), E_{I R, B r}$ representa o percentual de consumo de eletricidade das tecnologias tansversais de iluminação e refrigeração (IR) que são conhecidos.

Supondo que o percentual de consumo de eletricidade de cada tecnologia que compõe a força motriz, de algum país com características semelhantes, seja conhecido. Então pode-se calcular um fator de ajuste $\left(\varphi_{F M}\right)$ com base na força motriz por

$$
\varphi_{F M}=\frac{E_{F M, S, B r}}{E_{F M, S, C}}=\frac{\sum_{i=1}^{\tau} E_{i, S, B r}}{\sum_{i=1}^{\tau} E_{i, S, C}},
$$

onde $C$ representa o país que o percentual de consumo de cada tecnologia seja conhecido e $\tau$ é o número de tecnologias, $E_{i, S, C}$ é o percentual de consumo de cada tecnologia $i$ do subsetor $S$ do país $C, E_{i, S, B r}$ é o percentual desconhecido de consumo da tecnologia $i$ do subsetor $S$ do país $B r$. Mas, $E_{F M, S, B r}$ é um percentual conhecido. Portanto, o percentual individual de consumo de eletricidade das tecnologias transversais brasileiras que compõem a força motriz é dado por

$$
E_{i, S, B r}=\varphi_{F M} \times E_{i, S, C}
$$

O procedimento acima permitiu calcular o percentual (Tabelas D.1, D.2 no Apêndice) de consumo de eletricidade de cada tecnologia transversal brasileira que compõe a força motriz, com base em dados da indústria alemã obtidos em Fleiter et al. (2012) e presente no FORECAST.

\section{7}

\section{Previsão da produção e do valor adicionado da indústria brasileira}

Os dados de produção anual, em toneladas, para os processos da indústria brasileira foram obtidos em diversas fontes, para mais detalhes consultar a Tabela B.1 no Apêndice. E o valor adicionado anual, em milhões de reais, foi obtido para cada subsetor da indústria (IBGE, 2015). 
Uma condição suficiente e necessária para a modelagem proposta poder ser aplicada é a projeção da produção e do valor adicionado.

As séries temporais anuais de produção e do valor adicionado obtidas possuem um histórico com tamanho reduzido, o que dificulta a implementação de alguns métodos de previsão. A partir dessas séries, o interesse é obter a previsão da produção dos processos e do valor adicionado real de cada subsetor até 2050 .

Neste contexto, foram propostos os modelos de regressão dinâmica para gerar a previsão anual da produção e do valor adicionado real. Esses modelos combinam a estrutura de dependência de uma série temporal com o efeito de variáveis explicativas.

Neste trabalho, os modelos de regressão dinâmica que foram ajustados aos dados seguem a seguinte estrutura

$$
\begin{aligned}
& y_{t}=\theta y_{t-1}+\beta x_{t}+\eta_{t}, \\
& \eta_{t}=\gamma \eta_{t-1}+\epsilon_{t} \\
& \epsilon_{t} \sim N I D\left(0, \sigma^{2}\right)
\end{aligned}
$$

onde $y_{t}$ é a produção do processo (ou o valor adicionado real do subsetor) no tempo $t, x_{t}$ é o PIB projetado até 2050 , $\theta$ é o coeficiente relacionado a variável dependente, $\beta$ é o coeficiente da variável explicativa, $\eta_{t}$ é o resíduo da regressão, $\gamma$ é o coeficiente relacionado ao resíduo da regressão e $\epsilon_{t}$ é um ruído branco.

A equação (4-32) decompõe o valor de $y_{t}$ em três termos: o primeiro termo mostra que a variável depende do seu passado imediato, o segundo termo captura a dinâmica sistemática devido à influência das variáveis explicativas, enquanto que o último termo reflete a dinâmica residual que não é explicada pelas variáveis explicativas no modelo. Para mais detalhes, ver Cochrane e Orcutt (1949), Pankratz (1991), e Hyndman e Athanasopoulos (2013).

O cenário de PIB considerado para da indústria brasileira foi baseado na taxa de crescimento publicado pelo Banco Central do Brasil (BACEN) (BACEN, 2015).

As Tabelas 4.5 e 4.6 apresentam as projeções anuais, para alguns anos do horizonte de previsão, da produção e do valor adicionado fornecidos pelos modelos construídos. Esses valores completam as informações necessárias, de modo que a abordagem para calcular o consumo de eletricidade pode ser aplicada. 
Tabela 4.5: Produção anual (em milhões de toneladas) por processo e o valor adicionado anual (em milhões de Reais) do subsetor de papel e celulose no Brasil.

\begin{tabular}{l|l|llllllll}
\hline & Processo & 2014 & 2020 & 2025 & 2030 & 2035 & 2040 & 2045 & 2050 \\
\hline Produção & Papel & 5,88 & 6,36 & 7,39 & 8,36 & 9,27 & 10,11 & 10,86 & 11,58 \\
$\left(10^{6} \mathrm{t}\right)$ & Química de celulose & 15,91 & 18,43 & 21,42 & 24,23 & 26,86 & 29,32 & 31,49 & 33,56 \\
& Mecânica de celulose & 0,50 & 0,53 & 0,61 & 0,69 & 0,77 & 0,84 & 0,90 & 0,96 \\
& Papel reciclado & 4,52 & 5,08 & 5,90 & 6,68 & 7,40 & 8,08 & 8,68 & 9,25 \\
\hline \hline Subsetor & 2014 & 2020 & 2025 & 2030 & 2035 & 2040 & 2045 & 2050 \\
\hline \multicolumn{2}{l}{ Valor adicionado real $\left(10^{6}\right.$ Reais $)$} & 22624 & 25558 & 30048 & 34252 & 38182 & 41826 & 45059 & 48115 \\
\hline
\end{tabular}

Tabela 4.6: Produção anual (em $10^{5}$ toneladas) por processo e o valor adicionado anual (em milhões de Reais) do subsetor de metais não-ferrosos e outros de metalurgia no Brasil.

\begin{tabular}{l|l|llllllll}
\hline & Processo & 2014 & 2020 & 2025 & 2030 & 2035 & 2040 & 2045 & 2050 \\
\hline Produção & Alumínio primário & 9,62 & 8,12 & 9,11 & 10,27 & 11,57 & 12,93 & 14,33 & 15,91 \\
$\left(10^{6}\right.$ t) & Alumínio secundário & 4,90 & 6,44 & 7,23 & 8,15 & 9,18 & 10,26 & 11,37 & 12,62 \\
& Cobre primário & 2,13 & 2,05 & 2,30 & 2,60 & 2,93 & 3,27 & 3,63 & 4,02 \\
& Cobre secundário & 1,41 & 1,39 & 1,59 & 1,84 & 2,12 & 2,43 & 2,76 & 3,14 \\
& Cobre refinado & 2,41 & 2,52 & 2,83 & 3,19 & 3,60 & 4,02 & 4,46 & 4,94 \\
& Zinco primário & 2,46 & 2,50 & 2,87 & 3,32 & 3,83 & 4,38 & 4,98 & 5,66 \\
& Estanho & 0,22 & 0,19 & 0,22 & 0,24 & 0,28 & 0,31 & 0,34 & 0,38 \\
& Níquel & 0,58 & 0,46 & 0,52 & 0,58 & 0,66 & 0,74 & 0,82 & 0,91 \\
& Silício metálico & 2,30 & 1,58 & 1,77 & 1,99 & 2,25 & 2,51 & 2,79 & 3,09 \\
\hline \hline Subsetor & & 2014 & 2020 & 2025 & 2030 & 2035 & 2040 & 2045 & 2050 \\
\hline \multicolumn{1}{l|}{ Valor adicionado real (106 Reais) } & 7920 & 8142 & 8890 & 9468 & 9915 & 10261 & 10529 & 10736 \\
\hline
\end{tabular}




\section{5 \\ Resultados e Discussão}

Neste capítulo serão apresentados os resultados obtidos através da simulação do modelo proposto no Capítulo 4 aplicado aos dados dos subsetores de papel e celulose, e de metais não-ferrosos e outros de metalurgia da indústria brasileira. Desta forma, será omitido o índice $i$ que representa o subsetor $i$, dado que os resultados serão apresentados para cada subsetor separadamente.

\section{1}

\section{Subsetor de papel e celulose}

O subsetor de papel e celulose foi responsável por 11,6\% do consumo de eletricidade da indústria brasileira em 2016 (EPE, 2017). De acordo com a EPE (2016b), no setor industrial brasileiro, o subsetor de papel e celulose apresenta boas perspectivas econômicas de longo prazo devido principalmente adaptação do eucalipto ao solo e ao clima brasileiro. Esse subsetor foi modelado considerando os 4 processos mapeados. A produção dos processos foi projetada pelo modelo de regressão dinâmica.

Baseado no modelo especificado em (4-3), o modelo completo para o consumo de eletricidade de longo prazo do subsetor de papel e celulose é dado por

$$
\begin{aligned}
\left(S_{t} \mid \sigma_{s}^{2}, \sigma_{p}^{2}, \mathbf{P}_{t}\right) & \sim N\left(\sum_{j=1}^{4} P_{j, t}+R_{t}, \sigma_{s}^{2}\right) \\
\left(P_{j, t} \mid \sigma_{p}^{2}, \operatorname{Prod}_{j, t}\right) & \sim N\left(g\left(\operatorname{Prod}_{j, t}\right), \sigma_{p}^{2}\right) \\
\sigma_{s}^{2} & \sim I G(0,1 ; 0,1) \\
\sigma_{p}^{2} & \sim I G(2 ; 1)
\end{aligned}
$$

em que $\mathbf{P}_{t}=\left(P_{1, t}, P_{2, t}, P_{3, t}, P_{4, t}\right)$ representa o consumo de eletricidade dos processos deste subsetor. Os valores de produção $\operatorname{Prod}_{j, t}$ foram gerados exogenamente até o horizonte de previsão pelo modelo de regressão dinâmica. Os valores da componente $R_{t}$ foram obtidos aplicando-se a equação (4-4).

Para validar o processo de estimação dos parâmetros envolvidos no modelo proposto nesse capítulo, foi realizado um estudo de simulação (Apêndice F). Os resultados mostraram que o algoritmo consegue recuperar 
os valores verdadeiros dos parâmetros utilizados na simulação.

Neste trabalho, foram utilizados os dados de consumo de eletricidade de 2000 até 2016 dos subsetores da indústria brasileira, sendo que os últimos 2 anos (2015 e 2016) foram retirados da amostra a fim de avaliar a qualidade da previsão por simulação, e para compor a amostra até 2050 os valores foram projetados pelo modelo bottom-up determinístico. Utilizou-se os dados de 2008 até 2014 para avaliar o ajuste do modelo por simulação. O tamanho reduzido da amostra utilizada para o ajuste foi limitada pela escassez de dados, por exemplo como o valor adicionado do subsetor que está disponível apenas entre 2008-2014 (IBGE, 2015), o consumo específico de eletricidade que foi obtido para o ano de 2007 e, também, pelo tamanho reduzido das séries temporais de produção por processo. Mas, é importante ressaltar que o objetivo principal deste estudo é inserir a incerteza nas previsões de longo prazo obtida por um modelo bottom-up determinístico para garantir a precisão.

Primeiramente, para cada processo foi gerada uma cadeia de 30000 iterações pelo método de MCMC, das quais 10000 iterações foram consideradas como período de aquecimento e descartadas. Desta forma, as iterações restantes, e com raleamento de 40 iterações, foram utilizadas para compor as amostras a posteriori dos parâmetros do modelo. A Figura 5.1 mostra algumas cadeias do consumo de eletricidade por processo do subsetor de papel e celulose para os anos de 2015 e 2016. A convergência das cadeias foi avaliada a partir de inspeção gráfica (Figura 5.1).

Na Figura 5.2 são apresentados os histogramas das distribuições $a$ posteriori dos parâmetros $\mathbf{P}_{t}$ do modelo, com os seus respectivos intervalos de $95 \%$ de credibilidade para os anos de 2015 e 2016. Portanto, para cada ano do horizonte de previsão será possível obter uma distribuição de probabilidade para o consuno de eletricidade. 

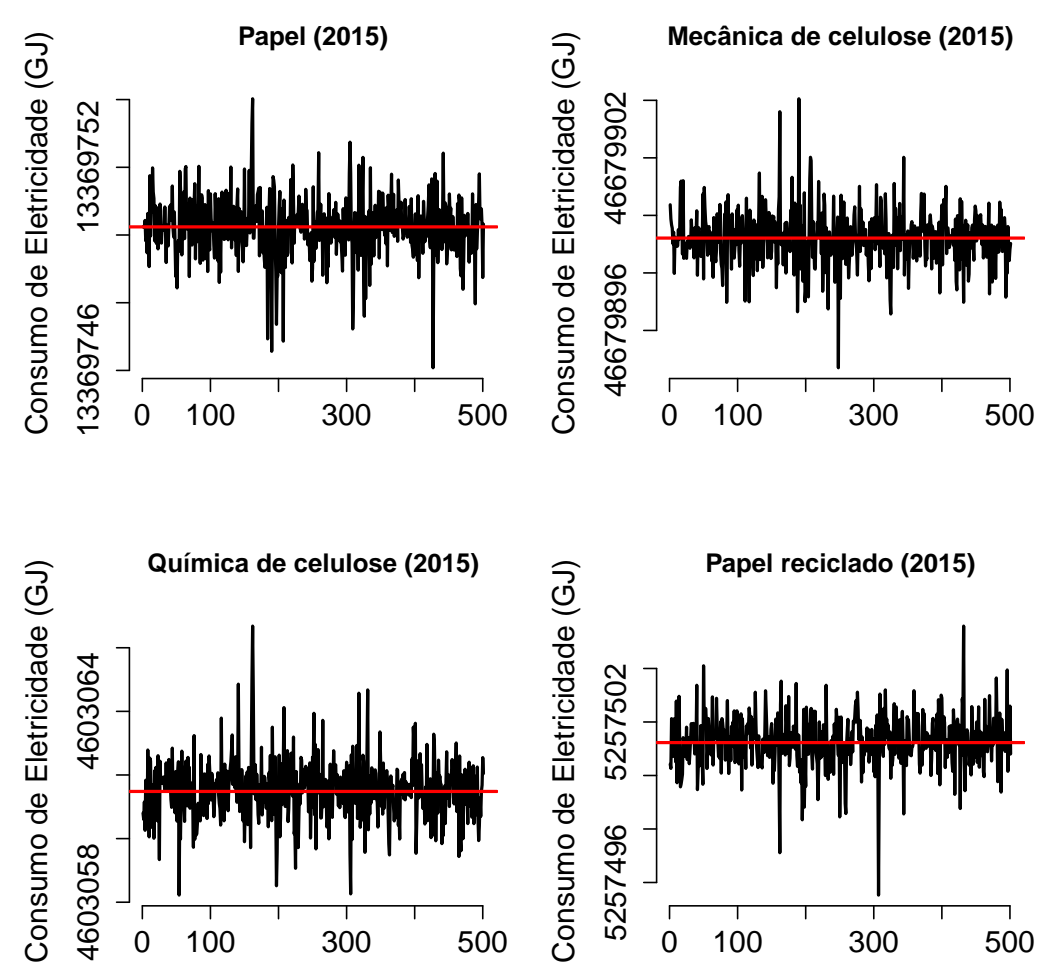

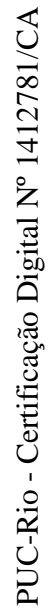
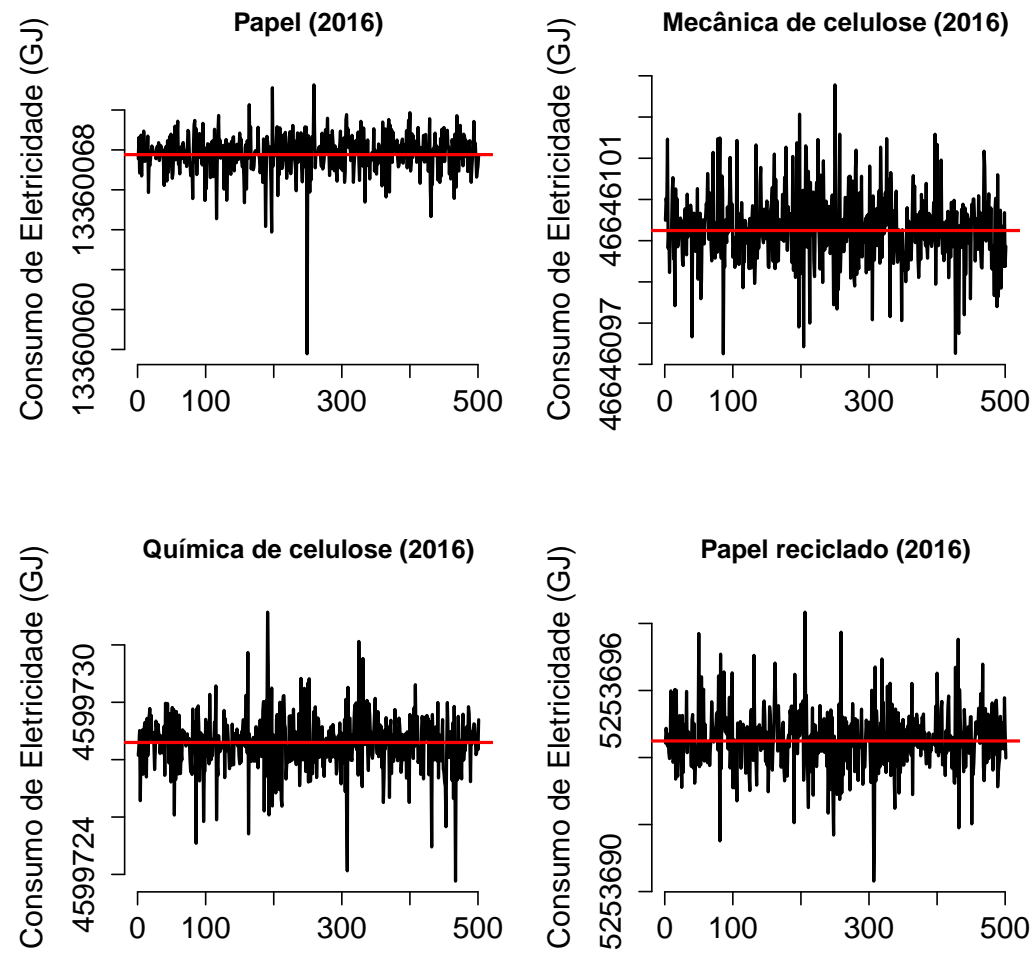

Figura 5.1: Cadeia do consumo de eletricidade de cada processo do subsetor de papel e celulose para o ano de 2015 e 2016, em que a linha vermelha é a média da cadeia. 


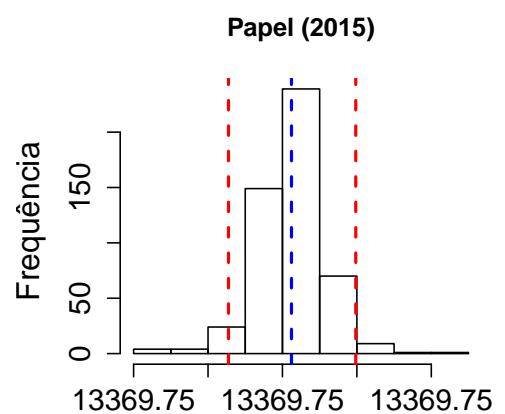

Consumo de eletricidade (TJ)

Química de celulose (2015)

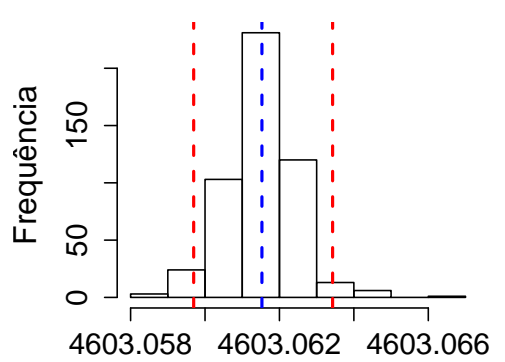

Consumo de eletricidade (TJ)

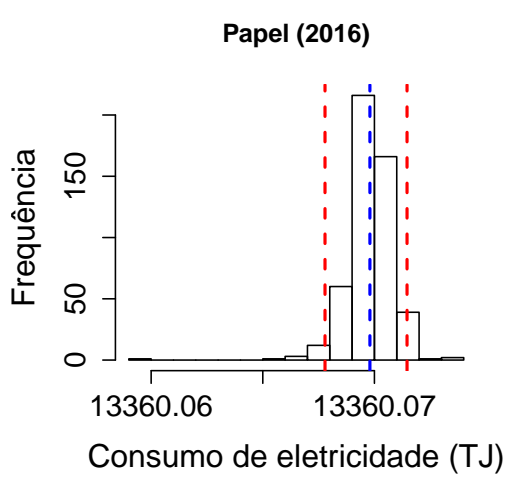

Química de celulose (2016)

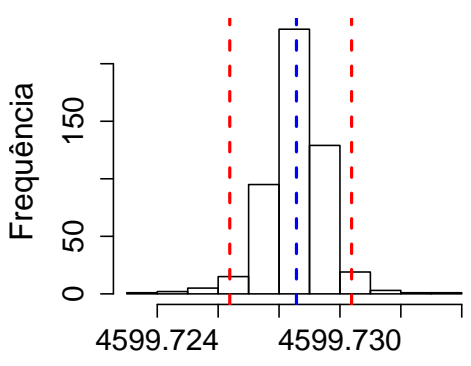

Consumo de eletricidade (TJ)

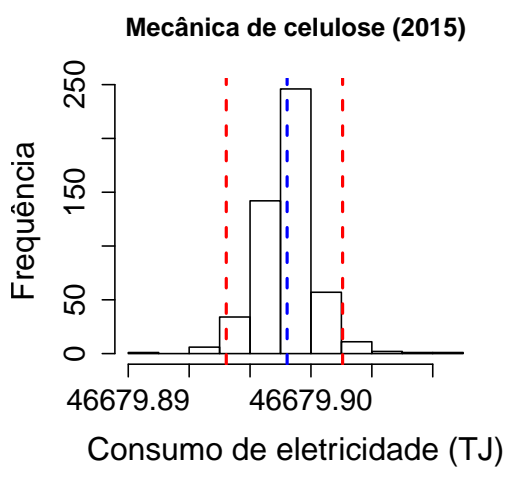

Papel reciclado (2015)
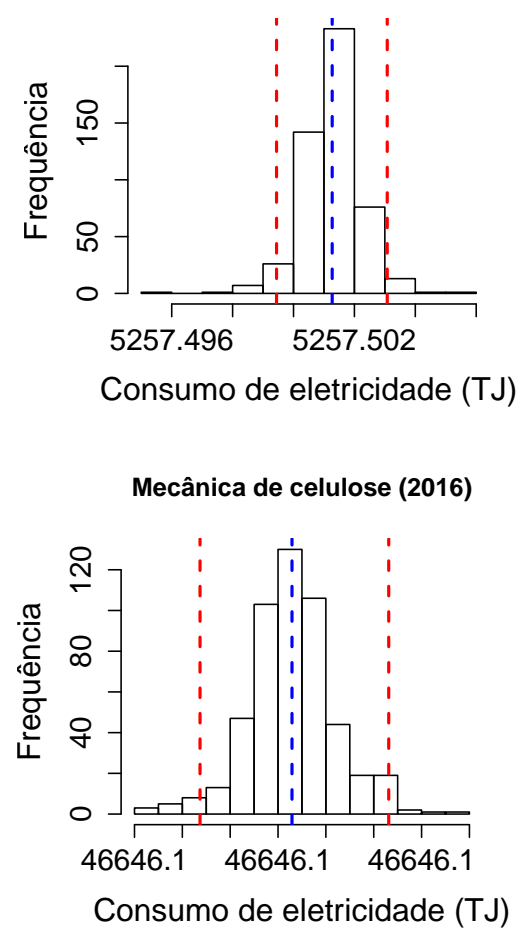

Papel reciclado (2016)

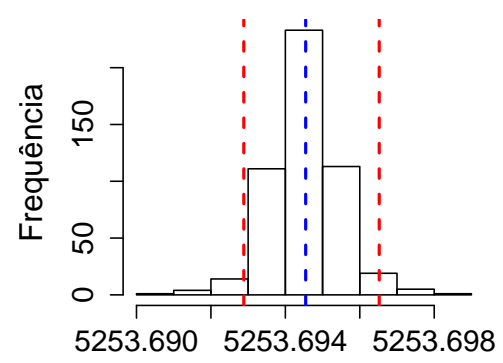

Consumo de eletricidade (TJ)

Figura 5.2: Histograma do consumo de eletricidade de cada processo do subsetor de papel e celulose para o ano de 2015 e 2016, em que a linha tracejada em azul é a média a posteriori e a linha tracejada em vermelho é o intervalo de credibilidade de $95 \%$. 
O resultado apresentado na Figura 5.3 mostra que o modelo proposto consegue capturar o comportamento do consumo de eletricidade observado no subsetor de papel e celulose entre 2008 e 2014. Neste período, a medida de erro de previsão MAPE (erro médio absoluto percentual) é de $2 \%$. Além disso, é apresentada a previsão anual do consumo de eletricidade de longo prazo até 2050. Essa figura apresenta, também, a comparação entre a previsão do consumo de eletricidade obtida pelo modelo proposto e o FORECAST. A curva do consumo de eletricidade da EPE, apresentada nesta figura, foi projetada usando a taxa de crescimento do consumo fornecida pela EPE (EPE, 2015; EPE, 2016b). A diferença observada na figura entre as projeções da EPE (2016b) e o modelo proposto está relacionada principalmente pelo cenário de crescimento da produção industrial considerado pela EPE (2016b) antes do período de crise na indústria iniciado em 2014.

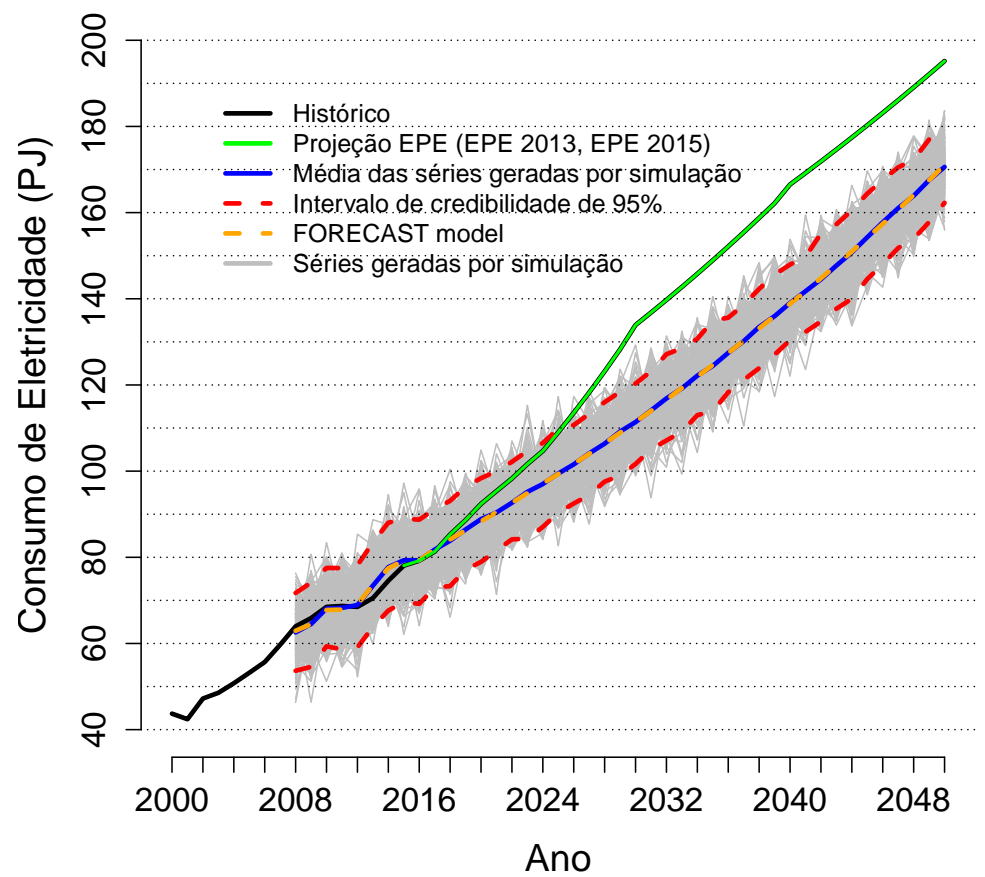

Figura 5.3: Resumo a posteriori da distribuição preditiva do consumo de eletricidade de longo prazo do subsetor de papel e celulose com as medidas de eficiência congeladas, isto é, um cenário frozen.

No horizonte de longo prazo, estima-se que o consumo total de eletricidade, para o cenário frozen, no subsetor de papel e celulose evolua de 82 PJ para 171 PJ entre 2016 e 2050 (Tabela 5.1), com uma taxa média de crescimento de 2,19\% ao ano (Tabela 5.2). Neste estudo, também, foi estimado um intervalo de credibilidade de $95 \%$ entre 162 a 182 PJ para o consumo de eletricidade em 2050 (Tabela 5.1). 
Na Figura 5.3 não foi possível observar a diferença existente entre os valores gerados pelo modelo proposto e pelo FORECAST. Mas, na Figura 5.4 pode-se observar a diferença entre as duas projeções. Ao longo do horizonte de previsão a diferença entre as duas abordagens foi inferior a $1 \%$.

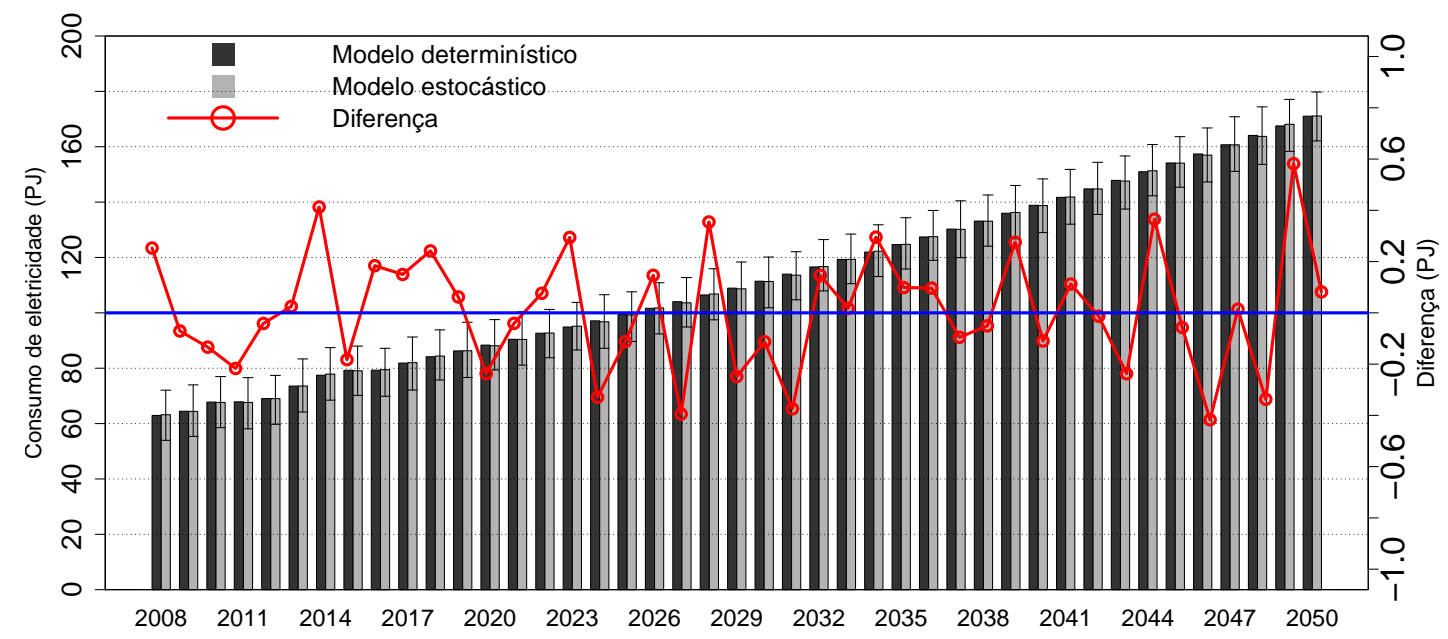

Figura 5.4: Consumos de eletricidade gerados pelos modelos proposto e o FORECAST para o subsetor de papel e celulose.

A Figura 5.5 apresenta os histogramas com os valores replicados da projeção do consumo de eletricidade para os anos de 2015 e 2016, e ,também, os valores reais observados pela EPE (2017). Os valores replicados foram obtidos a partir dos valores dos parâmetros gerados de cada iteração obtida pelo método de MCMC. Por exemplo, para ano de 2015 o consumo médio de eletricidade estimado foi de 79 PJ, com um intervalo de credibilidade de $95 \%$ entre 70 e 88 PJ. Pode-se observar na figura que os valores estimados pelo modelo estão próximos dos valores reais observados pela EPE, além disso os valores reais pertencem ao intervalo de credibilidade de 95\% (Tabela 5.1).

A Figura 5.6 mostra a evolução do consumo de eletricidade do subsetor de papel e celulose com a introdução de medidas de eficiência energética. Essa figura apresenta os cenários de difusão tecnológica autônoma e cost-effective. Pode-se observar nessa figura, que o modelo proposto consegue capturar o comportamento do consumo de eletricidade previsto pelo FORECAST, além de medir a incerteza, através de um intervalo de credibilidade, que pode auxiliar na tomada de decisões sobre as medidas de eficiência.

No cenário de difusão autônoma, o consumo de eletricidade cresceu de 82 PJ para 157 PJ entre 2016 e 2050 (Tabela 5.1), com uma taxa média de crescimento de 1,94\% (Tabela 5.2). E, também, foi estimado um intervalo para o consumo de eletricidade entre 148 e 166 PJ em 2050 (Tabela 5.1). 
Para o cenário de difusão cost-effective, o consumo de eletricidade evoluiu de 82 PJ para 129 PJ entre 2016 e 2050 (Tabela 5.1), com uma taxa média de crescimento de 1,33\% ao ano (Tabela 5.2). E, também, foi estimado um intervalo para o consumo de eletricidade entre 120 e 138 PJ em 2050 (Tabela $5.1)$.

Na Tabela 5.2, os valores negativos da taxa média de crescimento do consumo de eletricidade estão relacionados com a desaceleração da produção industrial causada pela crise econômica iniciada em 2014.
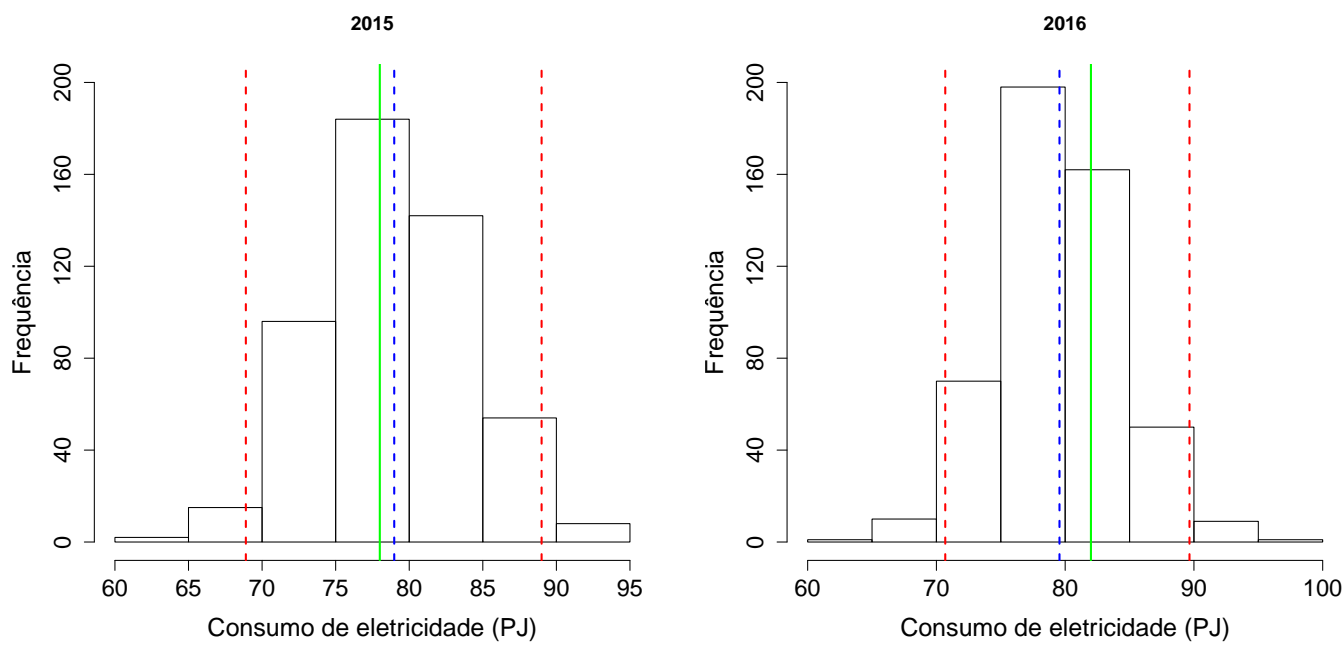

Figura 5.5: Histogramas do consumo de eletricidade do subsetor de papel e celulose para os anos de 2015 e 2016. A linha cheia verde representa o valor real obtido pela EPE, a linha tracejada azul representa a média e as linhas tracejadas em vermelho representam o intervalo de credibilidade de $95 \%$ do consumo de eletricidade.
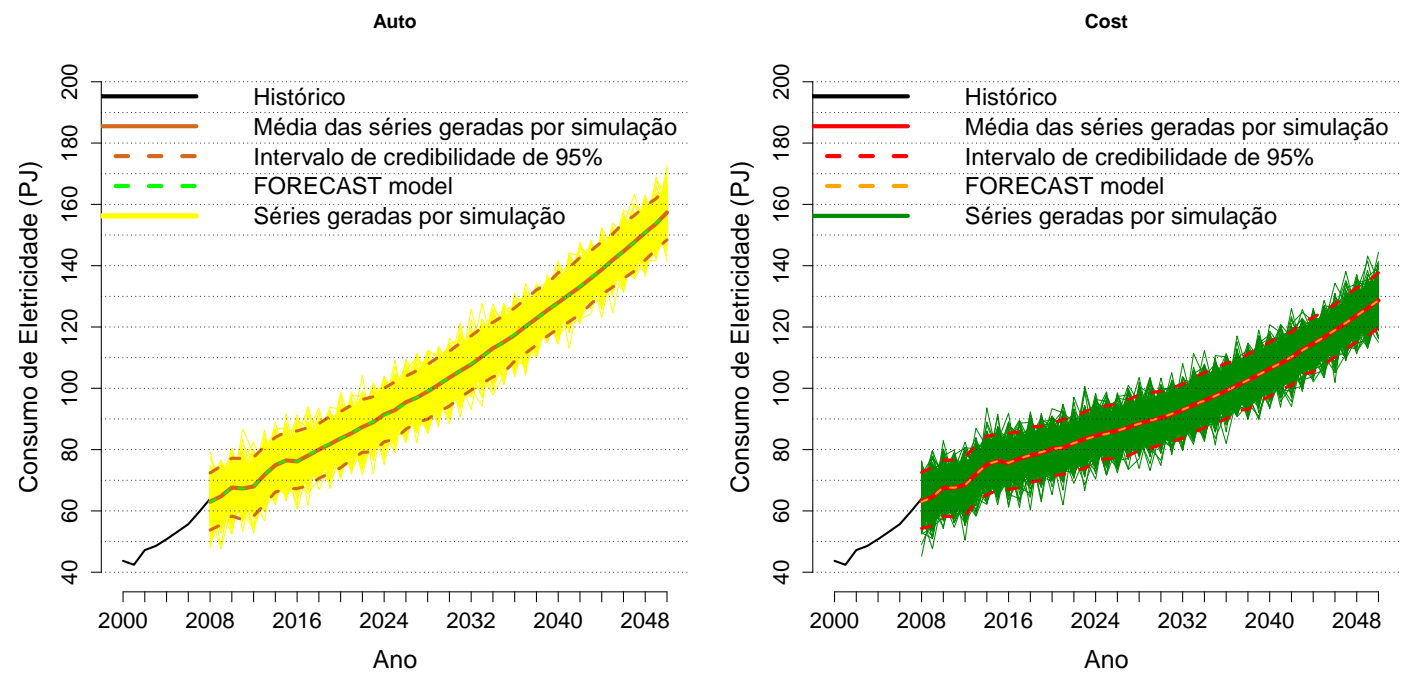

Figura 5.6: Consumo de eletricidade de longo prazo do subsetor de papel e celulose considerando os cenários de difusão autônoma e cost-effective. 
Tabela 5.1: Evolução do consumo de eletricidade, com o intervalo de credibilidade de 95\%, para o subsetor de papel e celulose. E, a redução percentual (\%) do consumo de eletricidade, a partir da utilização de medidas de eficiência energética, em comparação com o cenário frozen para os anos de 2015, 2016, 2020, 2030, 2040 e 2050.

\begin{tabular}{|c|c|c|c|c|c|c|c|}
\hline \multirow{3}{*}{ Ano } & \multicolumn{6}{|c|}{ Cenários } & \\
\hline & Frozen & \multicolumn{2}{|l|}{ Auto } & \multicolumn{2}{|l|}{ Max } & \multicolumn{2}{|l|}{ Cost } \\
\hline & $\begin{array}{l}\text { Consumo } \\
\text { (PJ) }\end{array}$ & $\begin{array}{l}\text { Consumo } \\
(\mathrm{PJ})\end{array}$ & $\begin{array}{c}\text { Red. } \\
(\%)\end{array}$ & $\begin{array}{l}\text { Consumo } \\
(\mathrm{PJ})\end{array}$ & $\begin{array}{c}\text { Red. } \\
(\%)\end{array}$ & $\begin{array}{l}\text { Consumo } \\
(\mathrm{PJ})\end{array}$ & $\begin{array}{l}\text { Red. } \\
(\%)\end{array}$ \\
\hline 2015 & $\begin{array}{c}79,28 \\
{[70,08 ; 88,25]}\end{array}$ & $\begin{array}{c}76,47 \\
{[67,16 ; 85,83]}\end{array}$ & 3,56 & $\begin{array}{c}72,67 \\
{[63,16 ; 81,16]}\end{array}$ & 8,35 & $\begin{array}{c}76,31 \\
{[66,76 ; 85,08]}\end{array}$ & 3,75 \\
\hline 2016 & $\begin{array}{c}79,23 \\
{[69,33 ; 89,00]}\end{array}$ & $\begin{array}{c}76,15 \\
{[67,31 ; 85,83]}\end{array}$ & 3,89 & $\begin{array}{c}71,12 \\
{[61,71 ; 80,24]}\end{array}$ & 10,24 & $\begin{array}{c}75,63 \\
{[66,98 ; 85,41]}\end{array}$ & 4,55 \\
\hline 2020 & $\begin{array}{c}88,64 \\
{[78,64 ; 97,88]}\end{array}$ & $\begin{array}{c}83,65 \\
{[74,09 ; 92,42]}\end{array}$ & 5,63 & $\begin{array}{c}69,68 \\
{[60,55 ; 79,09]}\end{array}$ & 21,34 & $\begin{array}{c}80,30 \\
{[71,44 ; 88,53]}\end{array}$ & 9,40 \\
\hline 2030 & $\begin{array}{c}111,58 \\
{[102,58 ; 120,49]}\end{array}$ & $\begin{array}{c}103,48 \\
{[94,20 ; 112,11]}\end{array}$ & 7,26 & $\begin{array}{c}74,01 \\
{[64,07 ; 83,37]}\end{array}$ & 33,67 & $\begin{array}{c}90,36 \\
{[81,63 ; 99,00]}\end{array}$ & 19,02 \\
\hline 2040 & $\begin{array}{c}138,74 \\
{[129,44 ; 148,61]}\end{array}$ & $\begin{array}{c}127,96 \\
{[119,48 ; 137,70]}\end{array}$ & 7,77 & $\begin{array}{c}85,25 \\
{[76,22 ; 93,99]} \\
\end{array}$ & 38,56 & $\begin{array}{c}106,45 \\
{[97,42 ; 115,10]}\end{array}$ & 23,28 \\
\hline 2050 & $\begin{array}{c}171,46 \\
{[161,51 ; 181,64]}\end{array}$ & $\begin{array}{c}157,35 \\
{[148,44 ; 165,82]}\end{array}$ & 8,23 & $\begin{array}{c}97,39 \\
{[88,53 ; 106,47]}\end{array}$ & 43,20 & $\begin{array}{c}128,68 \\
{[119,93 ; 137,68]}\end{array}$ & 24,95 \\
\hline
\end{tabular}

Red. = Redução.

Tabela 5.2: Taxa de crescimento médio, com o intervalo de credibilidade de $95 \%$, do consumo total de eletricidade no subsetor de papel e celulose da indústria brasileira (\%).

\begin{tabular}{l|c|c|c|c|c}
\hline Cenários & $2016^{*}-2050$ & $2016^{*}-2020$ & $2020-2030$ & $2030-2040$ & $2040-2050$ \\
\hline \multirow{2}{*}{ Frozen } & 2,19 & 1,96 & 2,32 & 2,20 & 2,14 \\
& {$[2,01 ; 2,37]$} & {$[-1,04 ; 4,53]$} & {$[1,47 ; 3,12]$} & {$[1,50 ; 2,91]$} & {$[1,53 ; 2,73]$} \\
\hline \multirow{2}{*}{ Auto } & 1,94 & 0,50 & 2,15 & 2,15 & 2,09 \\
& {$[1,76 ; 2,09]$} & {$[-2.50 ; 3.04]$} & {$[1,20 ; 2,97]$} & {$[1,45 ; 2,90]$} & {$[1,50 ; 2,63]$} \\
\hline \multirow{2}{*}{ Max } & 0,51 & $-3,99$ & 0,61 & 1,42 & 1,34 \\
& {$[0,23 ; 0,77]$} & {$[-7,30 ;-0,90]$} & {$[-0,69 ; 1,64]$} & {$[0,29 ; 2,42]$} & {$[0,38 ; 2,25]$} \\
\hline \multirow{2}{*}{ Cost } & 1,33 & $-0,52$ & 1,19 & 1,65 & 1,91 \\
& {$[1,12 ; 1,54]$} & {$[-3,39 ; 1,93]$} & {$[0,16 ; 2,11]$} & {$[0,75 ; 2,45]$} & {$[1,20 ; 2,61]$} \\
\hline * Valor real
\end{tabular}

* Valor real observado pela EPE $(2017), \approx 82$ PJ.

Na Figura 5.7 são apresentados os resultados para os cenários de difusão tecnológica frozen, autônoma e cost-effective. Nessa figura, pode-se observar que existem regiões de interseção entre as séries simuladas e o intervalo de credibilidade. Além disso, é sabido que o consumo de eletricidade no cenário frozen é sempre maior do que qualquer outro cenário de eficiência quando os pressupostos econômicos são iguais. No cenário frozen, que não considera a eficiência energética, o consumo de eletricidade aumentará em cerca de 36,07\% entre 2016 e 2030, e de 109,10\% entre 2016 e 2050. Mas, quando são aplicadas as medidas de eficiência energética, o consumo de eletricidade é reduzido consideravelmente (Tabela 5.1). A Tabela 5.1 mostra o percentual de redução do consumo de eletricidade quando as medidas de eficiência são empregadas em comparação com o cenário que as medidas são congeladas. Para o cenário de difusão cost-effective, o consumo de eletricidade crescerá em cerca de 10,20\% entre 2016 e 2030, e de 56,93\% entre 2016 e 2050. 


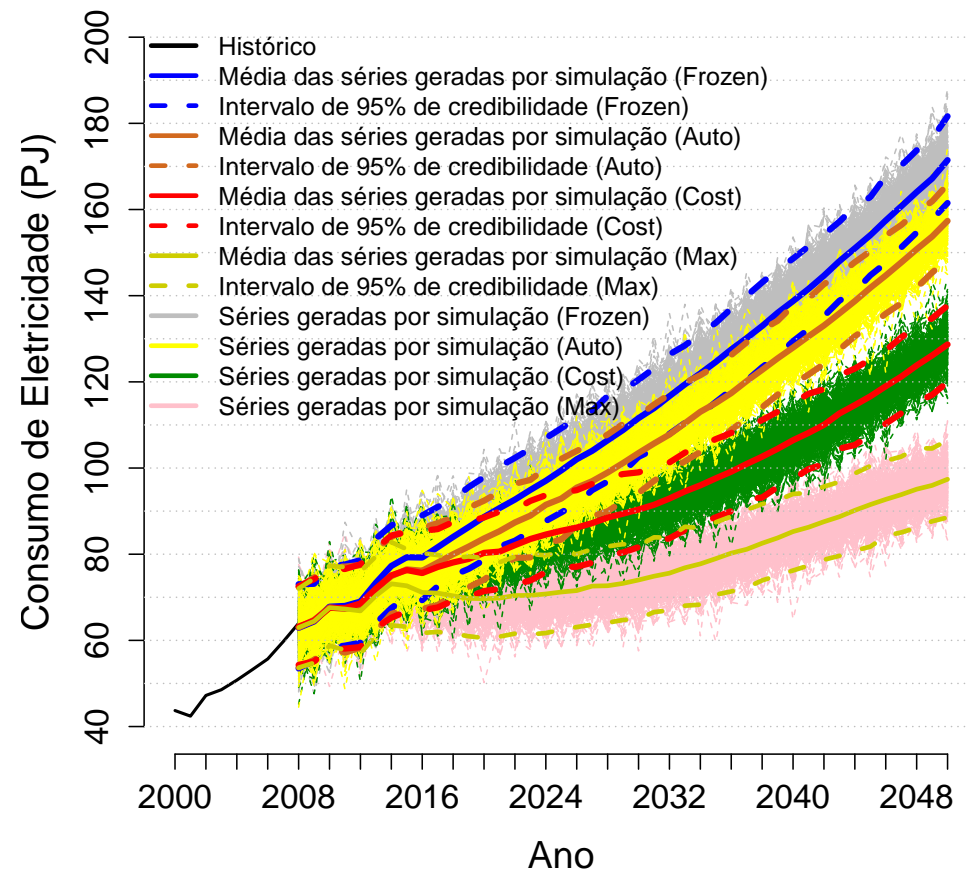

Figura 5.7: Consumo de eletricidade de longo prazo do subsetor de papel e celulose comparando os cenários de difusão frozen, autônoma, cost-effective e máxima.

A Figura 5.8 mostra a evolução do consumo de eletricidade por tecnologia transversal, considerando os cenários frozen e cost-effective. Nessas tecnologias, as bombas são responsáveis em média por $54 \%$ do consumo de eletricidade, seguido pelo consumo de $21 \%$ da ventilação (Tabela D.1). No horizonte de longo prazo, analisando o cenário frozen, estima-se que o consumo de eletricidade pelas bombas evolua de 44 PJ para 93 PJ entre 2016 e 2050, com uma taxa média de crescimento de $2,23 \%$ ao ano. Por outro lado, no cenário de difusão cost-effective foi estimado uma evolução de 44 PJ para 67 PJ, representando uma taxa média de crescimento de 1,24\% ao ano. Pelos resultados apresentados, as bombas do subsetor de papel e celulose podem economizar em média $27 \%$, cerca de 26 PJ, no consumo de eletricidade em 2050 (Tabela 5.3). A Tabela 5.3 mostra a evolução do consumo médio de eletricidade, com seu respectivo intervalo de credibilidade de $95 \%$, e a redução percentual para cada tecnologia transversal até 2050 . 


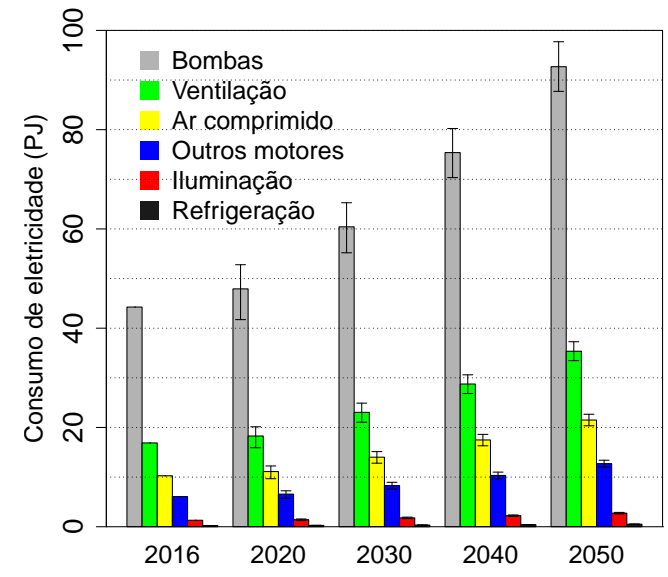

5.8(a): Cenário frozen.

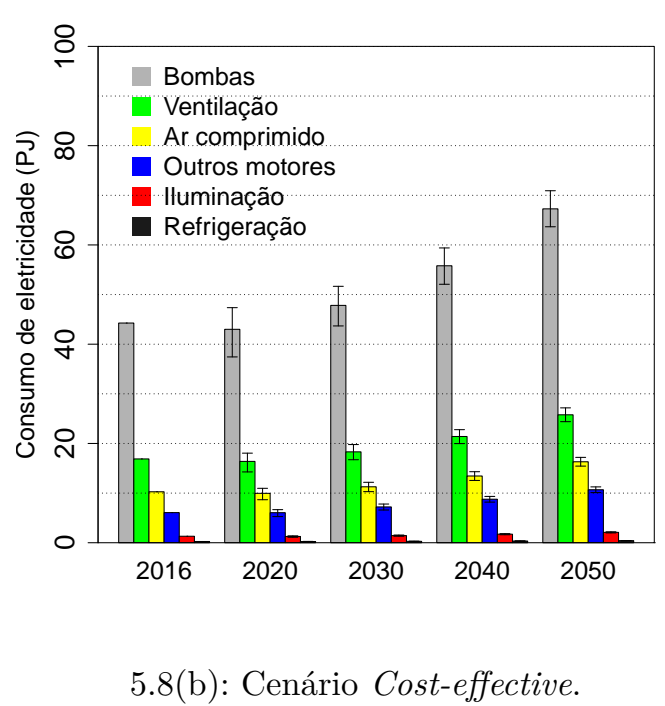

5.8(b): Cenário Cost-effective.

Figura 5.8: Evolução do consumo de eletricidade e o intervalo de credibilidade de $95 \%$ por tecnologia transversal do subsetor de papel e celulose no Brasil.

Tabela 5.3: Evolução do consumo de eletricidade, com o intervalo de credibilidade de 95\%, e o percentual de redução do consumo, quando comparado ao cenário frozen, por tecnologia transversal utilizada no subsetor de papel e celulose.

\begin{tabular}{|c|c|c|c|c|c|c|}
\hline \multirow{4}{*}{ Tecnologia } & \multirow{4}{*}{ Ano } & \multicolumn{4}{|c|}{ Cenários } & \\
\hline & & \multirow{2}{*}{\multicolumn{2}{|c|}{$\begin{array}{c}\text { Frozen } \\
\text { Consumo (PJ) }\end{array}$}} & \multicolumn{3}{|c|}{ Cost } \\
\hline & & & & & umo (PJ) & Redução (\%) \\
\hline & & Média & Intervalo & Média & Intervalo & Média \\
\hline \multirow{4}{*}{ Bombas } & 2020 & 48,01 & {$[43,13 ; 53,39]$} & 43,11 & {$[38,68 ; 47,40]$} & 10,28 \\
\hline & 2030 & 60,48 & $55,67 ; 65,59]$ & 47,76 & {$[43,61 ; 51,60]$} & 20,86 \\
\hline & 2040 & 75,10 & $70,58 ; 80,37]$ & 55,61 & {$[51,61 ; 59,19]$} & 25,97 \\
\hline & 2050 & 92,75 & {$[87,01 ; 97,99]$} & 67,18 & {$[60,05 ; 70,74]$} & 27,42 \\
\hline \multirow{4}{*}{ Ventilação } & 2020 & 18,31 & 16,$45 ; 20,37$ & 16,43 & {$[14,74 ; 18,06]$} & 10,37 \\
\hline & 2030 & 23,07 & {$[21,24 ; 25,02]$} & 18,29 & {$[16,70 ; 19,76]$} & 20,55 \\
\hline & 2040 & 28,65 & $26,93 ; 30,66]$ & 21,33 & {$[19,79 ; 22,70]$} & 25,56 \\
\hline & 2050 & 35,38 & $33,19 ; 37,38]$ & 25,74 & {$[24,54 ; 27,11]$} & 27,10 \\
\hline \multirow{4}{*}{ Ar comprimido } & 2020 & 11,14 & $10,01 ; 12,38]$ & 9,98 & {$[8,95 ; 10,97]$} & 10,46 \\
\hline & 2030 & 14,03 & $12,91 ; 15,21]$ & 11,26 & {$[10,28 ; 12,16]$} & 19,57 \\
\hline & 2040 & 17,42 & $16,37 ; 18,64]$ & 13,40 & {$[12,43 ; 14,26]$} & 23,09 \\
\hline & 2050 & 21,51 & {$[20,18 ; 22,73]$} & 16,29 & {$[15,53 ; 17,15]$} & 24,12 \\
\hline \multirow{4}{*}{ Outros motores } & 2020 & 6,58 & {$[5,91 ; 7,32]$} & 6,07 & {$[5,45 ; 6,67]$} & 7,89 \\
\hline & 2030 & 8,29 & {$[7,63 ; 8,99]$} & 7,21 & {$[6,58 ; 7,79]$} & 12,91 \\
\hline & 2040 & 10,30 & {$[9,68 ; 11,02]$} & 8,74 & {$[8,11 ; 9,30]$} & 15,20 \\
\hline & 2050 & 12,72 & {$[11,93 ; 13,44]$} & 10,66 & {$[10,17 ; 11,23]$} & 16,01 \\
\hline \multirow{4}{*}{ Iluminação } & 2020 & 1,42 & {$[1,27 ; 1,57]$} & 1,26 & {$[1,13 ; 1,39]$} & 10,92 \\
\hline & 2030 & 1,79 & {$[1,64 ; 1,94]$} & 1,43 & {$[1,31 ; 1,55]$} & 19,60 \\
\hline & 2040 & 2,22 & {$[2,09 ; 2,37]$} & 1,72 & {$[1,59 ; 1,83]$} & 22,61 \\
\hline & 2050 & 2,74 & {$[2,57 ; 2,90]$} & 2,09 & {$[1,99 ; 2,20]$} & 23,60 \\
\hline \multirow{4}{*}{ Refrigeração } & 2020 & 0,27 & {$[0,24 ; 0,30]$} & 0,25 & {$[0,22 ; 0,27]$} & 7,95 \\
\hline & 2030 & 0,34 & {$[0,31 ; 0,36]$} & 0,29 & {$[0,27 ; 0,31]$} & 14,50 \\
\hline & 2040 & 0,42 & {$[0,39 ; 0,45]$} & 0,34 & {$[0,32 ; 0,36]$} & 17,39 \\
\hline & 2050 & 0,51 & {$[0,48 ; 0,54]$} & 0,42 & {$[0,40 ; 0,44]$} & 18,26 \\
\hline
\end{tabular}




\section{2}

\section{Subsetor de metais não-ferrosos e outros de metalurgia}

O subsetor de metais não-ferrosos e outros de metalurgia foi responsável por 13, 9\% do consumo de eletricidade da indústria brasileira em 2016 (EPE, 2017). De acordo com a EPE (2016b), o processo de produção do alumínio é eletrointensivo e contribui para o elevado consumo total de eletricidade do subsetor. Esse subsetor foi modelado considerando os 9 processos mapeados.

Baseado no modelo especificado em (4-3), o modelo completo para o consumo de eletricidade de longo prazo do subsetor de metais não-ferrosos e outros de metalurgia é dado por

$$
\begin{aligned}
\left(S_{t} \mid \sigma_{s}^{2}, \sigma_{p}^{2}, \mathbf{P}_{t}\right) & \sim N\left(\sum_{j=1}^{9} P_{j, t}+R_{t}, \sigma_{s}^{2}\right) \\
\left(P_{j, t} \mid \sigma_{p}^{2}, \operatorname{Prod}_{j, t}\right) & \sim N\left(g\left(\operatorname{Prod}_{j, t}\right), \sigma_{p}^{2}\right) \\
\sigma_{s}^{2} & \sim I G(0,1 ; 0,1) \\
\sigma_{p}^{2} & \sim I G(2 ; 1)
\end{aligned}
$$

em que $\mathbf{P}_{t}=\left(P_{1, t}, P_{2, t}, P_{3, t}, P_{4, t}, P_{5, t}, P_{6, t}, P_{7, t}, P_{8, t}, P_{9, t}\right)$ representa o consumo de eletricidade dos processos deste subsetor. Os valores de produção $\operatorname{Prod}_{j, t}$ foram gerados exogenamente até o horizonte de previsão pelo modelo de regressão dinâmica. Os valores da componente $R_{t}$ foram obtidos aplicando-se a equação (4-4).

Os resultados obtidos para o subsetor de metais não-ferrosos e outros de metalurgia seguem as mesmas especificações para o método de MCMC utilizado no subsetor de metais não-ferrosos e outros de metalurgia. As Figuras 5.9 e 5.10 mostram as cadeias do consumo de eletricidade por processo do subsetor de metais não-ferrosos e outros de metalurgia para os anos de 2015 e 2016 .

Nas Figuras 5.11 e 5.12 são apresentados os histogramas das distribuições a posteriori dos parâmetros $\mathbf{P}_{t}$ do modelo, com os seus respectivos intervalos de $95 \%$ de credibilidade para os anos de 2015 e 2016. Portanto, para cada ano do horizonte de previsão será possível obter uma distribuição de probabilidade para o consuno de eletricidade. 


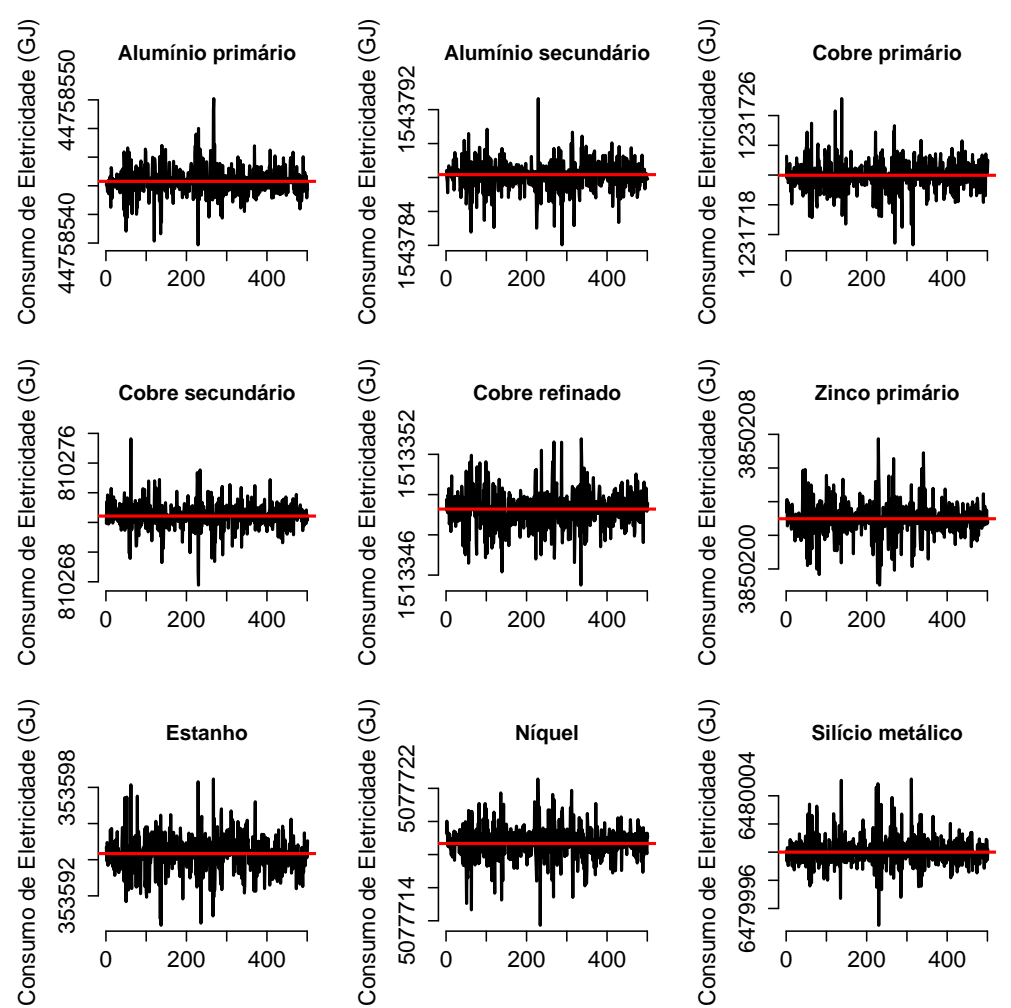

Figura 5.9: Cadeia do consumo de eletricidade de cada processo do subsetor de metais não-ferrosos e outros de metalurgia para o ano de 2015, em que a linha vermelha é a média da cadeia.
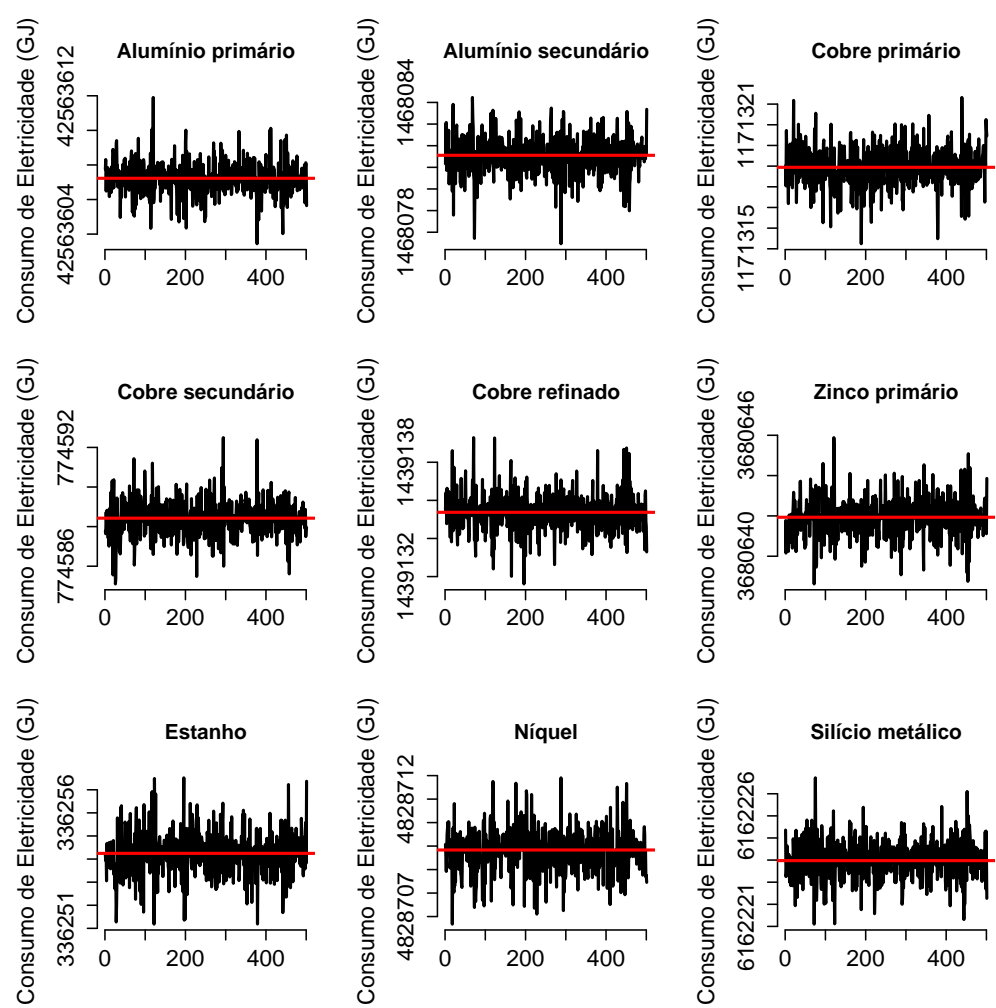

Figura 5.10: Cadeia do consumo de eletricidade de cada processo do subsetor de metais não-ferrosos e outros de metalurgia para o ano de 2016, em que a linha vermelha é a média da cadeia. 

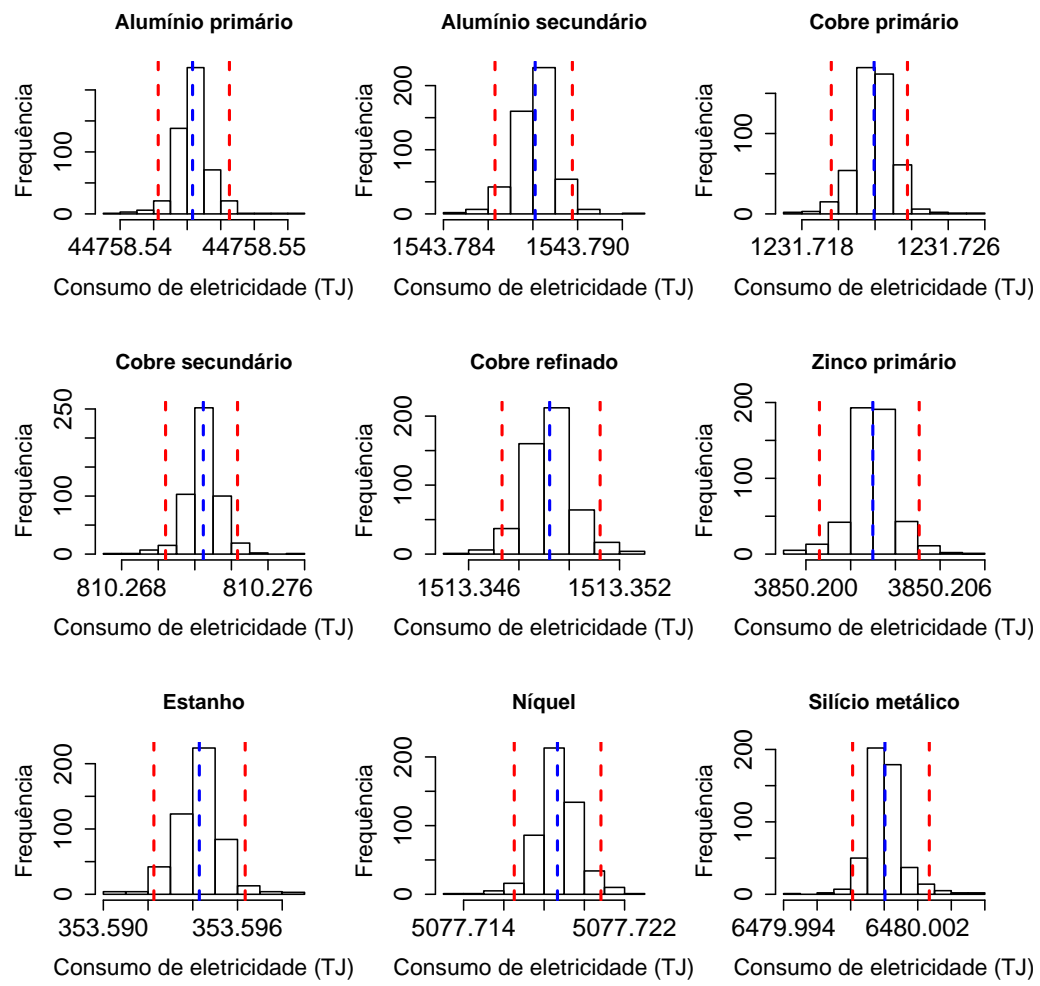

Figura 5.11: Histograma do consumo de eletricidade de cada processo do subsetor de metais não-ferrosos e outros de metalurgia para o ano de 2015, em que a linha tracejada em azul é a média a posteriori e a linha tracejada em vermelho é o intervalo de credibilidade de $95 \%$.
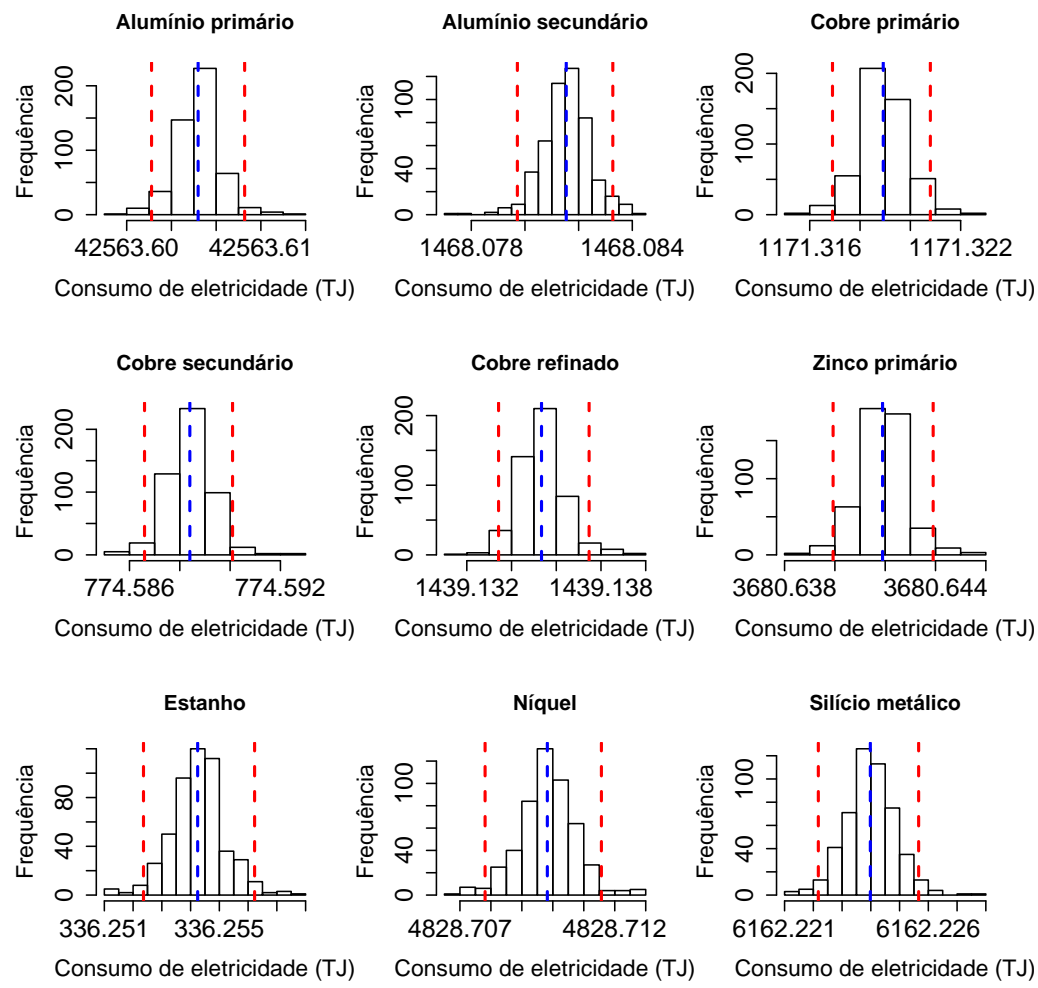

Figura 5.12: Histograma do consumo de eletricidade de cada processo do subsetor de metais não-ferrosos e outros de metalurgia para o ano de 2016, em que a linha tracejada em azul é a média a posteriori e a linha tracejada em vermelho é o intervalo de credibilidade de $95 \%$. 
A Figura 5.13 mostra que o modelo proposto consegue capturar o comportamento do consumo de eletricidade observado no subsetor de metais não-ferrosos e outros de metalurgia entre 2008 e 2014. Além disso, é apresentada a previsão anual do consumo de eletricidade de longo prazo até 2050. Essa figura apresenta, também, a comparação entre a previsão do consumo de eletricidade obtida pelo modelo proposto e o FORECAST. A curva do consumo de eletricidade da EPE, apresentada nesta figura, foi projetada usando a taxa de crescimento do consumo fornecida pela EPE (2016b), EPE (2015). A diferença observada na figura entre as projeções da EPE e o modelo proposto está relacionada principalmente pelo cenário de crescimento da produção industrial considerado pela EPE (EPE, 2015; EPE, 2016b).

No horizonte de longo prazo, estima-se que o consumo total de eletricidade, para o cenário frozen, no subsetor de metais não-ferrosos e outros de metalurgia evolua de 98 PJ para 172 PJ entre 2016 e 2050 (Tabela 5.4), com uma taxa média de crescimento de 1,68\% ao ano (Tabela 5.5). No estudo, também, foi estimado um intervalo de credibilidade de 95\% entre 153 a 192 PJ para o consumo de eletricidade em 2050 (Tabela 5.4).

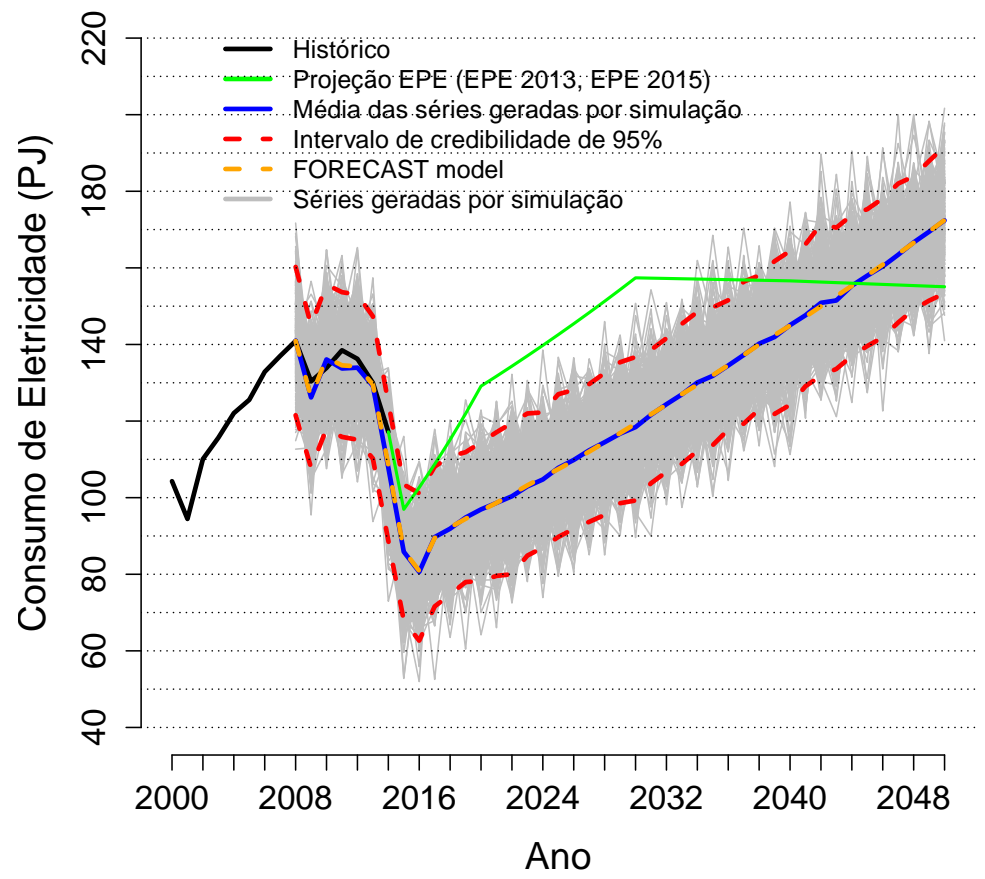

Figura 5.13: Resumo a posteriori da distribuição preditiva do consumo de eletricidade de longo prazo do subsetor de metais não-ferrosos e outros de metalurgia com as medidas de eficiência congeladas, isto é, um cenário frozen.

Na Figura 5.13 não foi possível observar a diferença existente entre os 
valores gerados pelo modelo proposto e pelo FORECAST. Mas, na Figura 5.14 pode-se observar a diferença entre as duas projeções. A diferença entre os valores previstos pelos dois modelos foi inferior a $1 \%$.

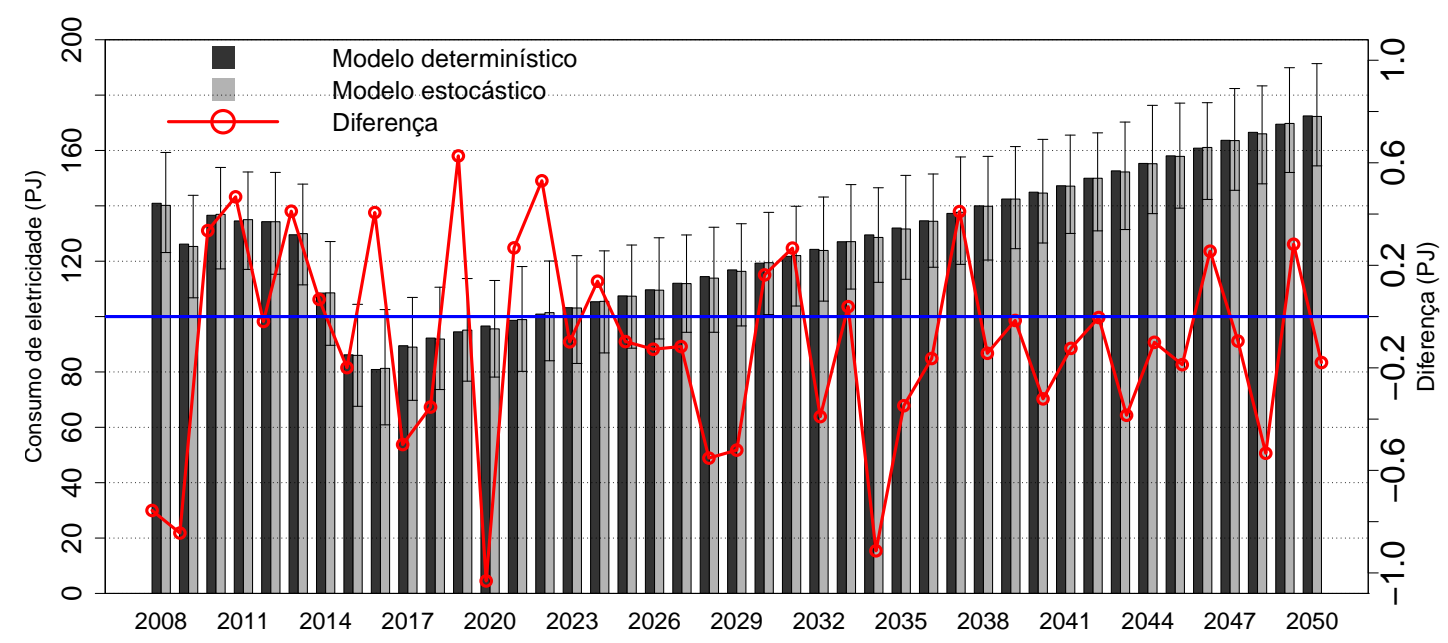

Figura 5.14: Consumos de eletricidade gerados pelos modelos proposto e o FORECAST para o subsetor de metais não-ferrosos e outros de metalurgia.

A Figura 5.15 apresenta os histogramas com os valores replicados da projeção do consumo de eletricidade para os anos de 2015 e 2016. Os valores replicados foram obtidos a partir dos valores dos parâmetros gerados de cada iteração obtida pelo método de MCMC. Por exemplo, para ano de 2015 o consumo médio de eletricidade estimado foi de 86 PJ, com um intervalo de credibilidade de $95 \%$ entre 67 e 104 PJ (Tabela 5.4).

A Figura 5.16 mostra a evolução do consumo de eletricidade do subsetor de papel e celulose com a introdução de medidas de eficiência energética. Essa figura apresenta os cenários de difusão tecnológica autônoma e cost-effective. Pode-se observar nessa figura, que o modelo proposto consegue capturar o comportamento do consumo de eletricidade previsto pelo FORECAST, além de medir a incerteza, através de um intervalo de credibilidade, que pode auxiliar na tomada de decisões sobre as medidas de eficiência.

No cenário de difusão autônoma, o consumo de eletricidade cresceu de 98 PJ para 166 PJ entre 2016 e 2050 (Tabela 5.4), com uma taxa média de crescimento de 1,57\% (Tabela 5.5). E, também, foi estimado um intervalo para o consumo de eletricidade entre 149 e 185 PJ em 2050 (Tabela 5.4). Para o cenário de difusão cost-effective, o consumo de eletricidade evoluiu de 98 PJ para 160 PJ entre 2016 e 2050 (Tabela 5.4), com uma taxa média de crescimento de 1,46\% ao ano (Tabela 5.5). E, também, foi estimado um intervalo para o consumo de eletricidade entre 143 e 177 PJ em 2050 (Tabela 
5.4). A taxa de crescimento baixa observada para o período entre 2016 e 2020 pode ser explicada pela crise, iniciada em 2014, que atingiu o setor industrial (Tabela 5.5).
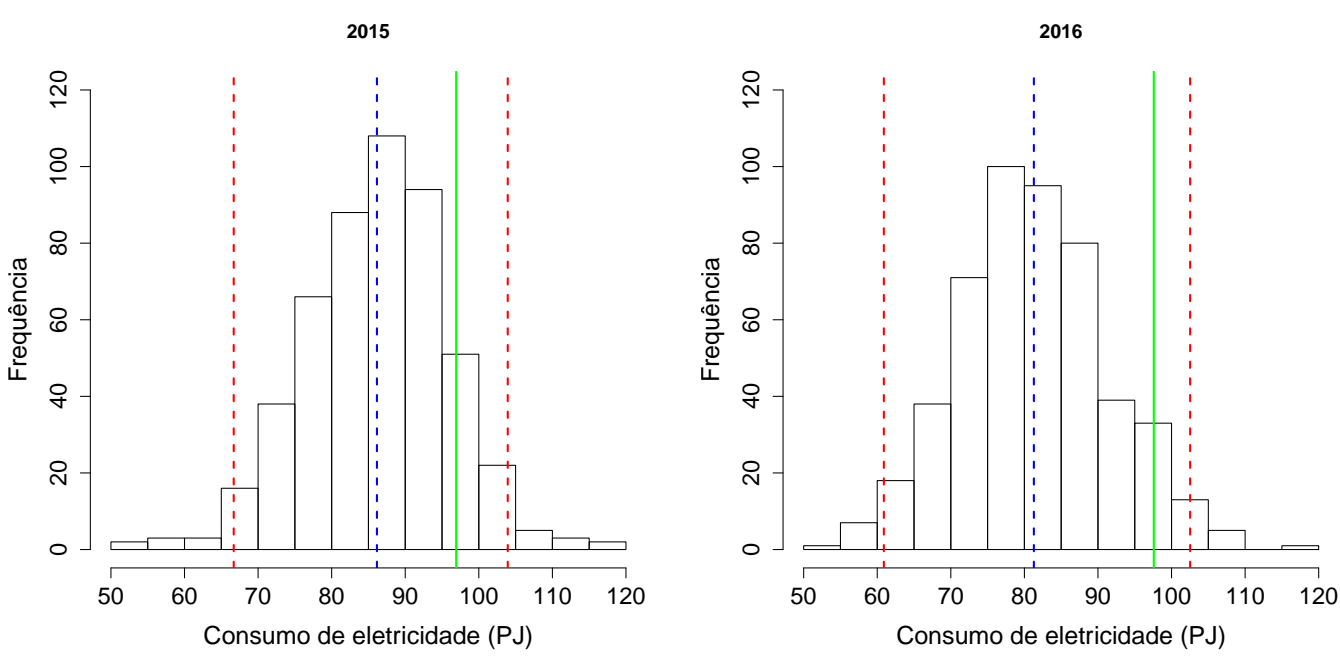

Figura 5.15: Histogramas do consumo de eletricidade do subsetor de metais não-ferrosos e outros de metalurgia para os anos de 2015 e 2016. A linha cheia verde representa o valor real obtido pela EPE, a linha tracejada azul representa a média e as linhas tracejadas em vermelho representam o intervalo de credibilidade de $95 \%$ do consumo de eletricidade.
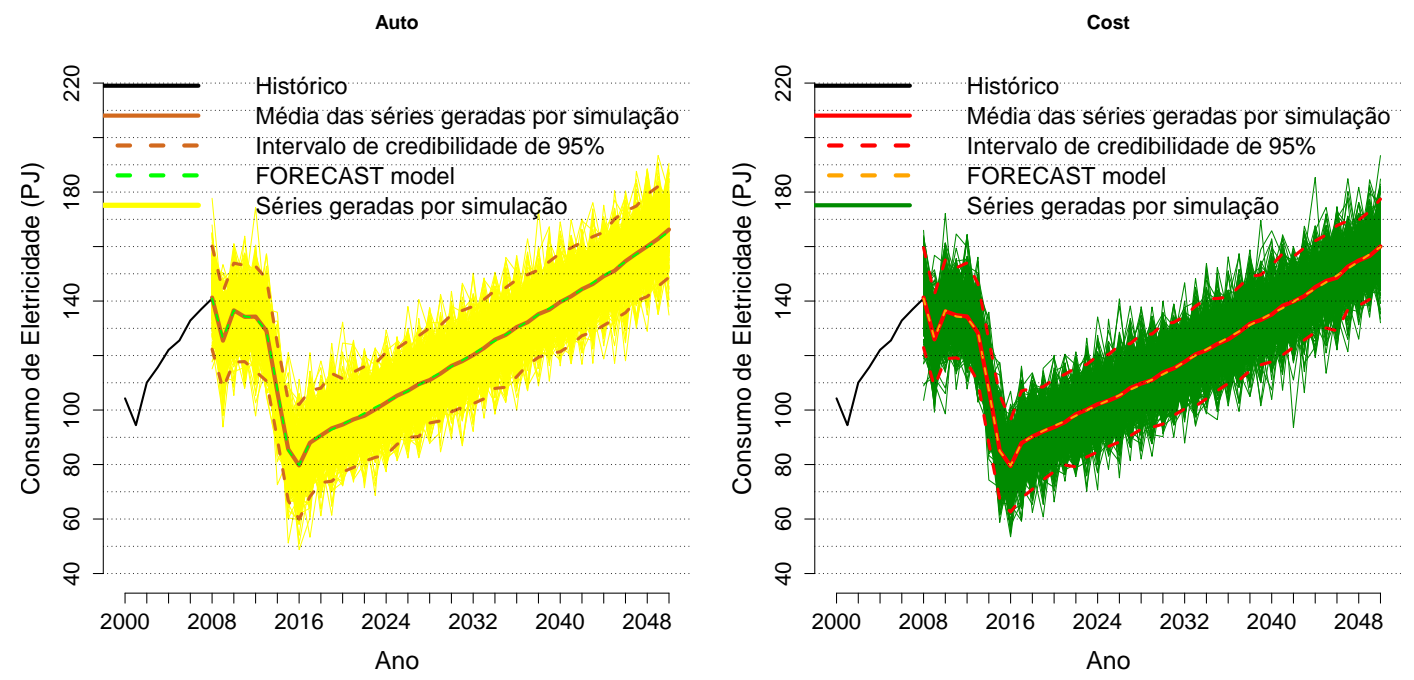

Figura 5.16: Consumo de eletricidade de longo prazo do subsetor de metais não-ferrosos e outros de metalurgia considerando os cenários de difusão autônoma e cost-effective. 
Tabela 5.4: Evolução do consumo de eletricidade, com o intervalo de credibilidade de 95\%, para o subsetor de metais não-ferrosos e outros de metalurgia. E, a redução percentual (\%) do consumo de eletricidade, a partir da utilização de medidas de eficiência energética, em comparação com o cenário frozen para os anos de 2015, 2016, 2020, 2030, 2040 e 2050.

\begin{tabular}{|c|c|c|c|c|c|c|c|}
\hline \multirow{3}{*}{ Ano } & \multicolumn{6}{|c|}{ Cenários } & \\
\hline & Frozen & \multicolumn{2}{|l|}{ Auto } & \multicolumn{2}{|l|}{ Max } & \multicolumn{2}{|l|}{ Cost } \\
\hline & $\begin{array}{l}\text { Consumo } \\
(\mathrm{PJ})\end{array}$ & $\begin{array}{l}\text { Consumo } \\
(\mathrm{PJ})\end{array}$ & $\begin{array}{c}\text { Red. } \\
(\%)\end{array}$ & $\begin{array}{l}\text { Consumo } \\
(\mathrm{PJ})\end{array}$ & $\begin{array}{c}\text { Red. } \\
(\%)\end{array}$ & $\begin{array}{l}\text { Consumo } \\
(\mathrm{PJ})\end{array}$ & $\begin{array}{l}\text { Red. } \\
(\%)\end{array}$ \\
\hline 2015 & $\begin{array}{c}86,25 \\
{[67,41 ; 103,96]}\end{array}$ & $\begin{array}{c}85,64 \\
{[66,77 ; 103,40]}\end{array}$ & 0,71 & $\begin{array}{c}84,82 \\
{[66,16 ; 102,95]}\end{array}$ & 1,66 & $\begin{array}{c}85,21 \\
{[67,31 ; 105,50]}\end{array}$ & 1,21 \\
\hline 2016 & $\begin{array}{c}81,29 \\
{[60,90 ; 102,53]}\end{array}$ & $\begin{array}{c}79,27 \\
{[61,68 ; 99,11]}\end{array}$ & 2,48 & $\begin{array}{c}78,17 \\
{[59,97 ; 97,45]}\end{array}$ & 3,84 & $\begin{array}{c}79,76 \\
{[62,14 ; 99,13]}\end{array}$ & 1,88 \\
\hline 2020 & $\begin{array}{c}96,03 \\
{[77,93 ; 113,28]}\end{array}$ & $\begin{array}{c}94,67 \\
{[77,28 ; 111,51]}\end{array}$ & 1,41 & $\begin{array}{c}92,18 \\
{[75,76 ; 110,23]}\end{array}$ & 4,02 & $\begin{array}{c}93,71 \\
{[77,41 ; 111,47]}\end{array}$ & 2,42 \\
\hline 2030 & $\begin{array}{c}119,13 \\
{[101,10 ; 138,38]}\end{array}$ & $\begin{array}{c}116,18 \\
{[99,34 ; 134,94]}\end{array}$ & 2,48 & $\begin{array}{c}108,96 \\
{[92,73 ; 127,32]}\end{array}$ & 8,54 & $\begin{array}{c}113,79 \\
{[94,84 ; 131,53]}\end{array}$ & 4,49 \\
\hline 2040 & $\begin{array}{c}145,16 \\
{[128,39 ; 163,51]}\end{array}$ & $\begin{array}{c}139,65 \\
{[121,39 ; 157,57]}\end{array}$ & 3,80 & $\begin{array}{c}127,03 \\
{[111,36 ; 143,50]}\end{array}$ & 12,49 & $\begin{array}{c}135,05 \\
{[117,74 ; 153,03]}\end{array}$ & 6,96 \\
\hline 2050 & $\begin{array}{c}172,09 \\
{[153,14 ; 191,33]}\end{array}$ & $\begin{array}{c}166,25 \\
{[148,71 ; 184,73]}\end{array}$ & 3,39 & $\begin{array}{c}147,24 \\
{[132,10 ; 162,92]}\end{array}$ & 14,44 & $\begin{array}{c}160,04 \\
{[142,69 ; 177,42]}\end{array}$ & 6,99 \\
\hline
\end{tabular}

Red. = Redução.

Tabela 5.5: Taxa de crescimento médio, com o intervalo de credibilidade de $95 \%$, para o consumo total de eletricidade no subsetor de metais não-ferrosos e outros de metalurgia da indústria brasileira (\%).

\begin{tabular}{l|c|c|c|c|c}
\hline Cenários & $2016^{*}-2050$ & $2016^{*}-2020$ & $2020-2030$ & $2030-2040$ & $2040-2050$ \\
\hline \multirow{2}{*}{ Frozen } & 1,68 & $-0,40$ & 2,18 & 1,99 & 1,72 \\
& {$[1,33 ; 2,00]$} & {$[-5,47 ; 3,80]$} & {$[0,52 ; 3,72]$} & {$[0,75 ; 3,22]$} & {$[0,54 ; 2,80]$} \\
\hline \multirow{2}{*}{ Auto } & 1,57 & $-0,75$ & 2,07 & 1,86 & 1,76 \\
& {$[1,25 ; 1,89]$} & {$[-5,67 ; 3,40]$} & {$[0,48 ; 3,61]$} & {$[0,44 ; 3,09]$} & {$[0,63 ; 2,84]$} \\
\hline \multirow{2}{*}{ Max } & 1,22 & $-1,41$ & 1,69 & 1,55 & 1,49 \\
& {$[0,89 ; 152]$} & {$[-6,13 ; 3,09]$} & {$[0,06 ; 3,28]$} & {$[0,22 ; 2,79]$} & {$[0,39 ; 2,52]$} \\
\hline \multirow{2}{*}{ Cost } & 1,46 & $-1,09$ & 1,96 & 1,73 & 1,71 \\
& {$[1,12 ; 1,77]$} & {$[-5,63 ; 3,38]$} & {$[0,12 ; 3,45]$} & {$[0,34 ; 3,01]$} & {$[0,55 ; 2,77]$} \\
\hline * Valor
\end{tabular}

* Valor real observado pela EPE (2017) de 97,59 PJ.

Na Figura 5.17 são apresentados os resultados para os cenários de difusão tecnológica frozen, autônoma e cost-effective. Nessa figura, pode-se observar que existem regiões de interseção entre as séries simuladas e o intervalo de credibilidade. No cenário frozen, que não considera a eficiência energética, o consumo de eletricidade aumentará em cerca de 22,07\% entre 2016 e 2030, e de 76,34\% entre 2016 e 2050. Mas, quando são aplicadas as medidas de eficiência energética, o consumo de eletricidade é reduzido consideravelmente (Tabela 5.4). A Tabela 5.4 mostra o percentual de redução do consumo de eletricidade quando as medidas de eficiência são empregadas em comparação com o cenário que as medidas são congeladas. Para o cenário de difusão cost-effective, o consumo de eletricidade crescerá em cerca de 16,60\% entre 2016 e 2030, e de $63,99 \%$ entre 2016 e 2050. 


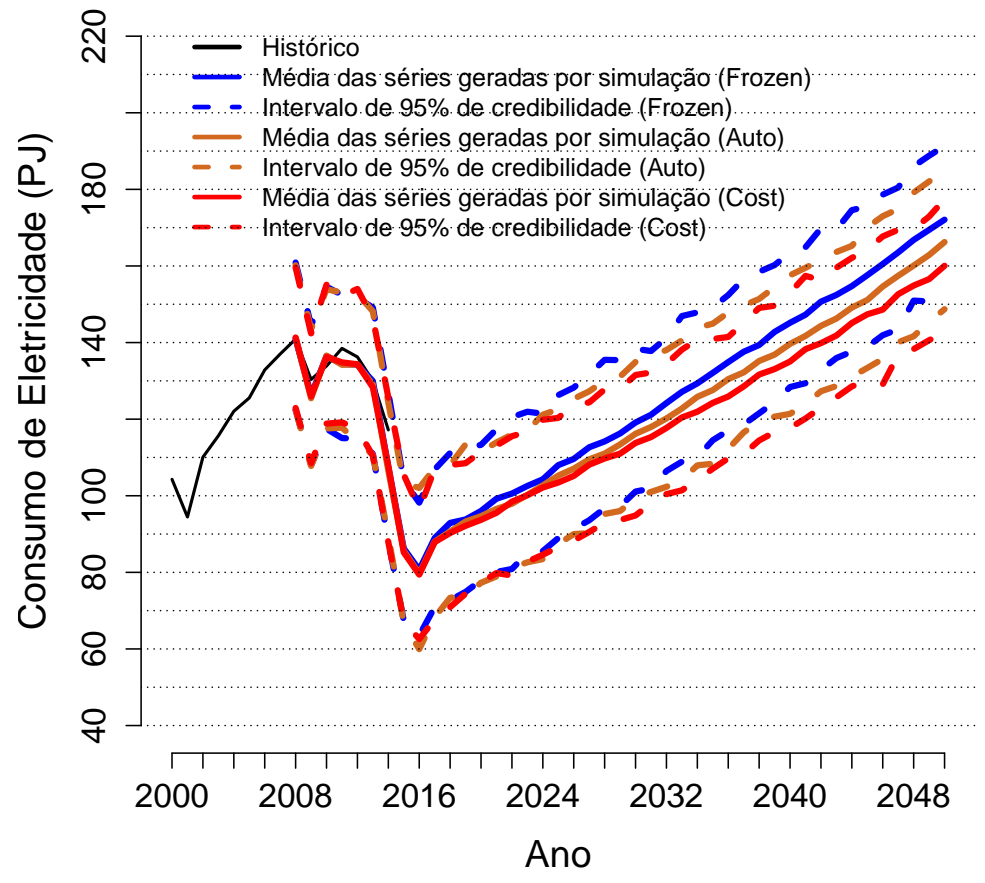

Figura 5.17: Consumo de eletricidade de longo prazo do subsetor de metais não-ferrosos e outros de metalurgia comparando os cenários de difusão frozen, autônoma e cost-effective.

A Figura 5.18 mostra a evolução do consumo de eletricidade por tecnologia transversal, considerando os cenários de difusão frozen e cost-effective. Nessas tecnologias, a ventilação é responsável em média por $6 \%$ do consumo de eletricidade, e outros motores com o consumo de $20 \%$ (Tabela D.2). No horizonte de longo prazo, analisando o cenário frozen, estima-se que o consumo de eletricidade pelos motores evolua de 20 PJ para 35 PJ entre 2016 e 2050, com uma taxa média de crescimento de $1,66 \%$ ao ano. Por outro lado, no cenário de difusão cost-effective foi estimado uma evolução de $20 \mathrm{PJ}$ para 30 PJ, representando uma taxa média de crescimento de 1,20\% ao ano. Pelos resultados apresentados, os motores do subsetor de metais não-ferrosos e outros de metalurgia podem economizar em média 14\%, cerca de 5 PJ, no consumo de eletricidade em 2050 (Tabela 5.6). A Tabela 5.6 mostra a evolução do consumo médio de eletricidade, com seu respectivo intervalo de credibiidade de $95 \%$, e a redução percentual para cada tecnologia transversal até 2050 . 


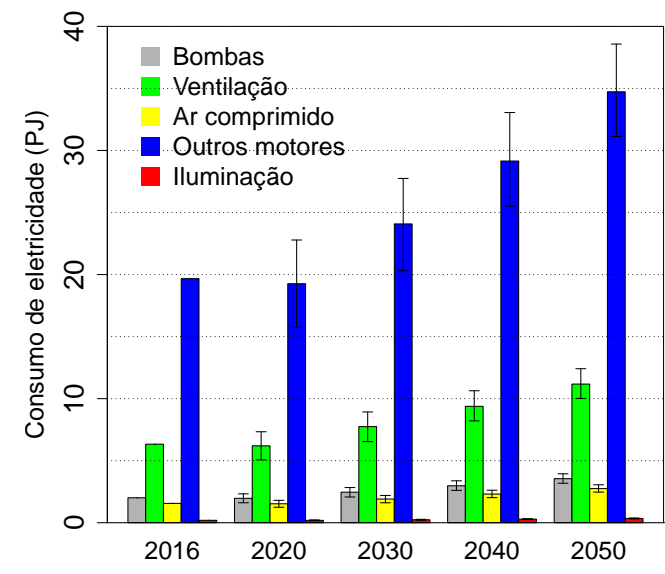

5.18(a): Cenário frozen.

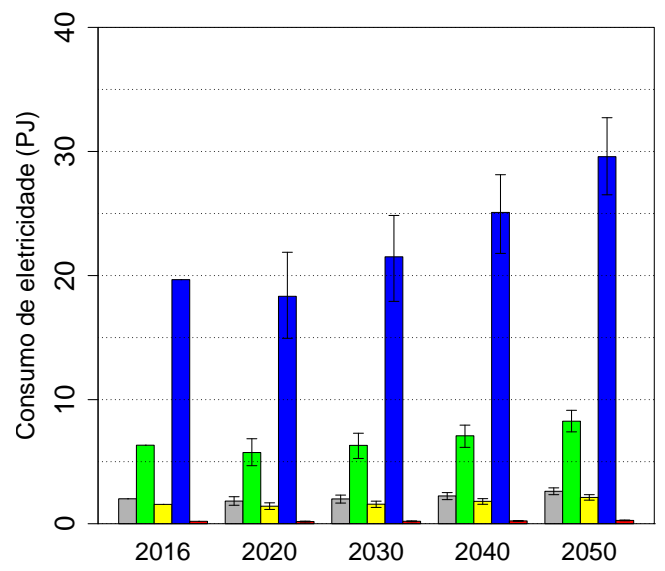

5.18(b): Cenário Cost-effective.

Figura 5.18: Evolução do consumo de eletricidade com o intervalo de credibilidade de $95 \%$ por tecnologia transversal do subsetor de metais não-ferrosos e outros de metalurgia no Brasil.

Tabela 5.6: Evolução do consumo de eletricidade, com o intervalo de credibilidade de 95\%, e o percentual de redução do consumo, quando comparado ao cenário frozen, por tecnologia transversal utilizada no subsetor de metais não-ferrosos e outros de metalurgia.

\begin{tabular}{|c|c|c|c|c|c|c|}
\hline \multirow{4}{*}{ Tecnologia } & \multirow{4}{*}{ Ano } & \multicolumn{4}{|c|}{ Cenários } & \\
\hline & & \multirow{2}{*}{\multicolumn{2}{|c|}{$\frac{\text { Frozen }}{\text { Consumo (PJ) }}$}} & \multicolumn{3}{|c|}{ Cost } \\
\hline & & & & $\mathrm{Co}$ & umo (PJ) & Redução (\%) \\
\hline & & Média & Intervalo & Média & Intervalo & Média \\
\hline \multirow{4}{*}{ Bombas } & 2020 & 1,99 & {$[1,61 ; 2,33]$} & 1,81 & {$[1,47 ; 2,14]$} & 8,31 \\
\hline & 2030 & 2,45 & {$[2,08 ; 2,85]$} & 1,99 & {$[1,69 ; 2,31]$} & 19,02 \\
\hline & 2040 & 2,99 & {$[2,64 ; 3,37]$} & 2,25 & {$[1,99 ; 2,54]$} & 24,69 \\
\hline & 2050 & 3,55 & {$[3,15 ; 3,94]$} & 2,61 & {$[2,32 ; 2,90]$} & 26,33 \\
\hline \multirow{4}{*}{ Ventilação } & 2020 & 6,23 & {$[5,05 ; 7,35]$} & 5,71 & {$[4,63 ; 6,73]$} & 8,41 \\
\hline & 2030 & 7,73 & {$[6,56 ; 7,35]$} & 6,28 & {$[5,33 ; 7,30]$} & 18,72 \\
\hline & 2040 & 9,42 & {$[8,32 ; 10,61]$} & 7,13 & {$[6,31 ; 8,03]$} & 24,28 \\
\hline & 2050 & 11,16 & {$[9,93 ; 12,41]$} & 8,26 & {$[7,35 ; 9,18]$} & 26,00 \\
\hline \multirow{4}{*}{ Ar comprimido } & 2020 & 1,53 & {$[1,24 ; 1,81]$} & 1,4 & {$[1,14 ; 1,66]$} & 8,50 \\
\hline & 2030 & 1,90 & {$[1,62 ; 2,21]$} & 1,57 & {$[1,33 ; 1,82]$} & 17,71 \\
\hline & 2040 & 2,32 & {$[2,05 ; 2,61]$} & 1,81 & {$[1,60 ; 2,04]$} & 21,76 \\
\hline & 2050 & 2,75 & {$[2,45 ; 3,06]$} & 2,12 & {$[1,88 ; 2,35]$} & 22,97 \\
\hline \multirow{4}{*}{ Outros motores } & 2020 & 19,36 & {$[15,71 ; 22,83]$} & 18,22 & {$[14,79 ; 21,49]$} & 5,87 \\
\hline & 2030 & 24,01 & {$[20,38 ; 27,89]$} & 21,39 & {$[18,16 ; 24,85]$} & 10,90 \\
\hline & 2040 & 29,26 & {$[25,87 ; 32,96]$} & 25,24 & {$[22,32 ; 28,43]$} & 13,74 \\
\hline & 2050 & 34,69 & {$[30,87 ; 38,56]$} & 29,57 & {$[26,31 ; 32,87]$} & 14,76 \\
\hline \multirow{4}{*}{ Iluminação } & 2020 & 0,19 & {$[0,16 ; 0,23]$} & 0,17 & {$[0,14 ; 0,21]$} & 8,97 \\
\hline & 2030 & 0,24 & {$[0,20 ; 0,28]$} & 0,20 & {$[0,17 ; 0,23]$} & 17,75 \\
\hline & 2040 & 0,29 & {$[0,26 ; 0,33]$} & 0,23 & {$[0,20 ; 0,26]$} & 21,27 \\
\hline & 2050 & 0,34 & {$[0,31 ; 0,38]$} & 0,27 & {$[0,24 ; 0,30]$} & 22,46 \\
\hline
\end{tabular}




\section{Conclusão}

Neste trabalho foi apresentada uma proposta de metodologia de modelagem que permite a combinação da abordagem bottom-up com modelos lineares hierárquicos para obter a previsão de longo prazo (36 anos à frente até 2050) do consumo de eletricidade da indústria brasileira. Nessa metodologia foi utilizada a inferência bayesiana para a estimação dos parâmetros.

O emprego da inferência bayesiana permitiu que fosse gerada uma amostra de valores para cada parâmetro de interesse, com tamanho adequado, e, consequentemente, pode-se obter sua distribuição de probabilidade a posteriori. Para gerar tais amostras dos parâmetros, foi utilizado o método de MCMC, mais especificamente o amostrador de Gibbs.

Essa abordagem estocástica é inspirada no modelo bottom-up determinístico proposto por Farla et al. (1997), Fleiter et al. (2012) e Huang et al. (2016). O modelo aqui proposto consegue medir a incerteza da previsão do consumo de eletricidade, através da estimação de uma distribuição de probabilidade para cada ano do horizonte de previsão. Com isso, ele permite a geração de previsões de longo prazo do consumo de eletricidade, para cada ano do horizonte de previsão desejado, com um intervalo de credibilidade associado. A previsão de longo prazo traz consigo um alto grau de incerteza nos seus resultados, o modelo proposto pode, assim, contribuir com novas informações que permitam a tomada de decisões em bases mais sólidas.

Nas pesquisas realizadas na literatura pertinente, não se encontrou nenhum modelo disponível com essas características, o que permite dizer que o modelo aqui desenvolvido é uma novidade para a área.

O modelo desenvolvido permite, também, avaliar o efeito da adoção de MEEs no consumo futuro, devido a utilização da abordagem bottom-up. Como foi visto, as MEEs estão relacionadas com os cenários de difusão tecnológica. Esses cenários implementados e definidos neste estudo, pode-se dizer que é algo inovador na modelagem de energia e simulação de cenários de eficiência energética para o Brasil.

A abordagem bottom-up requer uma quantidade de informação muito grande e com boa qualidade, então foi necessário fazer um mapeamento da indústria brasileira. Esse mapeamento foi uma tarefa árdua que exigiu um 
grande esforço e um tempo considerável para obtenção e consolidação das informações necessárias para realizar a modelagem. A maioria dos dados foi obtida através de fontes oficiais. A partir das informações disponíveis foram definidos 79 processos divididos entre os 11 subsetores da indústria e, através deste mapeamento, foram obtidos os processos mais eletro-intensivos da indústria brasileira. Para informações faltantes, foram desenvolvidos alguns procedimentos, permitindo que a modelagem fosse aplicada com base em informações oficiais encontradas. Nesse caso, estava o consumo específico de eletricidade de alguns processos e a parcela de cada tecnologia transversal dos subsetores da indústria. Essa é, assim, outra contribuição desse trabalho. O detalhamento do setor industrial desenvolvido neste estudo pode contribuir para futuros estudos sobre a demanda de energia e as políticas de eficiência energética.

Para avaliar o desempenho do modelo nesse trabalho, dois setores da indústria brasileira foram selecionados: o de papel e celulose e o de metais não-ferrosos e outros da metalurgia.

Os resultados obtidos pelo modelo estocástico proposto para esses dois subsetores foram bastante satisfatórios. Pois, as distribuições de probabilidade conseguidas para as previsões forneceram valores esperados similares aos resultantes do modelo determinístico (FORECAST) equivalente (empregado em previsões desse tipo) utilizado aqui para comparação dos resultados (Cap. 5, Figuras 5.3 e 5.13). A diferença entre os valores dos dois modelos foi menor do que $1 \%$ ao longo do horizonte de previsão. Por essas figuras, pode ser observado que os dados oriundos do modelo proposto trazem mais informações do que aqueles provenientes do modelo determinístico, fornecendo mais solidez para a tomada de decisão pelos órgãos e companhias responsáveis pelo planejamento energético no horizonte futuro.

Uma outra demonstração que os resultados obtidos pelo modelo estocástico contêm mais informação, foi observado nos anos da crise brasileira de 2015 e 2016. Para esses anos, os intervalos de credibilidade construídos contemplam os valores reais observados fornecidos pela EPE (2017), enquanto que o modelo deteminístico apresenta apenas uma medida pontual (Cap. 5, Figuras 5.5 e 5.15 ).

No contexto de eficiência energética, foi apresentado um conjunto de MEEs para os subsetores da indústria brasileira modelados neste trabalho. Para as tecnologias transversais ligadas aos subsetores, 16 MEEs foram identificadas e detalhadas, enquanto que para as tecnologias de processos, 11 foram definidas para o subsetor de papel e celulose e 16 para o subsetor de metais não ferrosos e outros da metalurgia. A avaliação do impacto 
dessas MEEs no consumo de eletricidade dos subsetores foi feita a partir dos cenários de difusão tecnológica definidos. Essas MEEs são importantes para economizar o consumo de eletricidade, sendo, portanto, uma estratégia para reduzir os custos e aumentar os ganhos fornecidos, especialmente em tempos de volatilidade dos preços da energia.

Para um cenário real, levando em conta aspectos econômicos, pode-se observar a redução no consumo de eletricidade dos subsetores analisados ao longo do horizonte de previsão (Cap. 5, Tabelas 5.1 e 5.4) que chegou a $25 \%$ e $7 \%$ em 2050, representando uma economia de 42 PJ para o setor de papel e celulose e de 12 PJ para o subsetor de metais não ferrosos e outros da metalurgia, respectivamente.

\section{1}

\section{Trabalhos futuros}

Nesse trabalho, o modelo proposto foi aplicado em dois subsetores da indústria brasileira. Uma proposta de estudo seria obter os dados necessários dos outros subsetores, determinar as MEEs e curvas de difusão tecnológica de cada processo e aplicar o modelo, para avaliar o seu consumo de eletricidade no horizonte desejado.

A estrutura hierárquica apresentada na Figura 4.3 mostra que o consumo total de eletricidade do setor industrial como o primeiro nível de uma hierarquia. Desta forma, uma extensão do modelo proposto seria inserir mais um nível hierárquico e avaliar o ganho do compartilhamento de informação entre os subsetores na estimação dos parâmetros e projeções futuras. O esquema da Figura 4.3 apresenta o consumo industrial como apenas uma soma dos consumos dos subsetores, induzindo o modelo abaixo:

$$
\begin{array}{rlrl}
I_{t} & =\sum_{i=1}^{N} S_{i, t} & \\
S_{i, t} & =\sum_{j=1}^{n_{i}} P_{i, j, t}+R_{i, t}-E_{i, t}+\epsilon_{i, t}, & & \epsilon_{i, t} \sim N\left(0, \sigma_{s_{i}}^{2}\right), \\
P_{i, j, t} & =g\left(\operatorname{Prod}_{i, j, t}\right)-E_{i, j, t}+\delta_{i, j, t}, & & \delta_{i, j, t} \sim N\left(0, \sigma_{p}^{2}\right),
\end{array}
$$

em que $I_{t}$ representa o consumo total do setor industrial no tempo $t$, para $t=1,2, \cdots, T, i=1,2, \cdots, N$ e $j=1,2, \cdots, n_{i}$. Nesse caso, não é associada nenhuma incerteza no novo nível o que pode ser discutido em um estudo futuro.

Outro trabalho futuro seria investigar a possibilidade de adaptar o modelo desenvolvido nesta tese para outros setores, residencial, comercial etc.

Integrar a previsão das séries dos níveis inferiores da estrutura hierárquica, levando em conta a correlação entre elas, o que atualmente não é 
considerado no modelo apresentado na Seção 3.1 do Capítulo 3, é outro estudo de interesse que pode trazer mais ganhos ao modelo.

A equação que gera a componente $R_{i, t}$ também pode ser melhor investigada. Desta forma, tem-se a seguinte possibilidade

$$
\begin{aligned}
R_{i, t} & =(1+v) R_{i, t-1}+w_{i, t}, \quad w_{i, t} \sim N(0, W) \\
v & =\left(\frac{V A_{i, t}}{V A_{i, t-1}}-1\right) \rho
\end{aligned}
$$

onde $V A_{i, t}$ é o valor adicionado real do subsetor $i$ no tempo $t$ e $\rho$ é um fator de correlação entre a demanda de eletricidade e o valor adicionado.

A emissão de $\mathrm{CO}_{2}$ tem sido um tema muito importante na indústria. Neste contexto, um outro trabalho futuro seria investigar a possibilidade de incorporar ao modelo proposto a decomposição LMDI (Log Mean Divisia Index) para estudar os efeitos de emissão de $\mathrm{CO}_{2}$ na indústria brasileira. Essa decomposição pode ser vista com maiores detalhes em Ang et al. (2003), Leon e Pessanha (2005) e Xu et al. (2012).

A matriz energética de um país é composta de várias fontes de energia. Expandir o modelo proposto para avaliar o consumo de energia dessas outras fontes, além da eletricidade, é outra pesquisa que desperta interesse. Esse novo modelo permitiria, por exemplo, ter uma noção da evolução dessa matriz ao longo dos anos, indicando as fontes mais exigidas.

A avaliação do efeito de políticas de eficiência energética no consumo de eletricidade também configura um estudo relevante que pode ser feito com o modelo proposto. Esse estudo contemplaria políticas novas e as existentes e possibilitaria mostrar aos órgãos e empresas responsáveis pelo fornecimento de energia a importância de tais políticas na economia de energia e no consequente adiamento de investimentos na expansão do parque gerador para atendimento da demanda.

Outro ponto merecedor de uma análise mais profunda é o que trata do emprego de fontes alternativas de energia, como solar e eólica, na matriz energética. Estudar a possibilidade de adaptar o modelo para considerar essas fontes adequadamente é um tópico que desponta como promissor. 


\section{A \\ Conceitos de Estatística Bayesiana e o Método de Simulação de Monte Carlo via Cadeias de Markov (MCMC)}

A informação sobre uma quantidade de interesse $\theta$ (não observável) é fundamental na estatística. Na estatística bayesiana, o parâmetro $\theta$ é considerado como uma quantidade aleatória. Desta forma, as conclusões obtidas sob essa abordagem são baseadas em distribuições probabilísticas.

Neste capítulo, são apresentados o teorema de Bayes e o método de simulação de Monte Carlo via Cadeias de Markov, que são conceitos fundamentais para a inferência bayesiana. O primeiro serve como base para o desenvolvimento dessa teoria, enquanto que o segundo conceito viabiliza a implementação da inferência.

\section{A.1}

\section{Teorema de Bayes}

Seja $y$ o vetor de observações que segue o modelo $p(y \mid \theta)$, onde $\theta$ é o vetor de parâmetros. Suponha que tem-se a distribuição a priori $p(\theta)$, com uma incerteza inicial antes de $y$ ser observado. Assim, tem-se um modelo probabílistico dado por

$$
p(y, \theta)=p(y \mid \theta) p(\theta) .
$$

Como os dados $y$ possuem informação sobre $\theta$, pode-se utilizar $y$ para atualizar a informação de $\theta$ através da distribuição condicional de $\theta$ dado $y$. Pelo teorema de Bayes, a distribuição a posteriori $p(\theta \mid y)$ é dada por

$$
p(\theta \mid y)=\frac{p(y, \theta)}{p(y)}=\frac{p(y \mid \theta) p(\theta)}{\int p(y, \theta) d \theta} .
$$

$\mathrm{Na}$ maior parte das aplicações, $p(\theta \mid y)$ não possui forma analítica fechada (conhecida). Utilizando o fato que o denominador na equação (A-1) não depende de $\theta$, podemos escrever

$$
p(\theta \mid y) \propto p(y \mid \theta) p(\theta) .
$$

\section{A.2}


Apêndice A. Conceitos de Estatística Bayesiana e o Método de Simulação de

Monte Carlo via Cadeias de Markov (MCMC)

\section{Distribuição a Priori}

A distribuição a priori considerada na inferência bayesiana é uma novidade em relação à inferência clássica. Essa distribuição deve representar o conhecimento a priori sobre uma quantidade de interesse $\theta$ antes de serem observados os resultados do experimento.

Uma distribuição a priori de referência, ou não-informativa, é especificada quando se espera que a informação dos dados seja dominante, ou seja, que a influência da informação a priori na inferência seja reduzida ao mínimo. Entretanto, é necessário derivar a distribuição a priori de referência para o modelo adotado e essa tarefa pode ser árdua.

Neste contexto, surgem as distribuições a priori pouco informativas, que são conhecidas como vagas ou planas. Uma distribuição a priori vaga pode ser obtida a partir de uma distribuição a priori, definindo-se o hiperparâmetro de escala tendendo a zero e mantendo os outros constantes. Por exemplo, uma distribuição a priori Normal com média zero e variância muito alta é relativamente plana (Figura A.1). Nessa figura, a distribuição a priori mostra que a informação dos dados é dominante, isto é, a verossimilhança é dominante. Um parâmetro de variância pode ter distribuição a priori Inversa Gama pouco informativa, se seus hiperparâmetros forem escolhidos com valores suficientemente baixos.

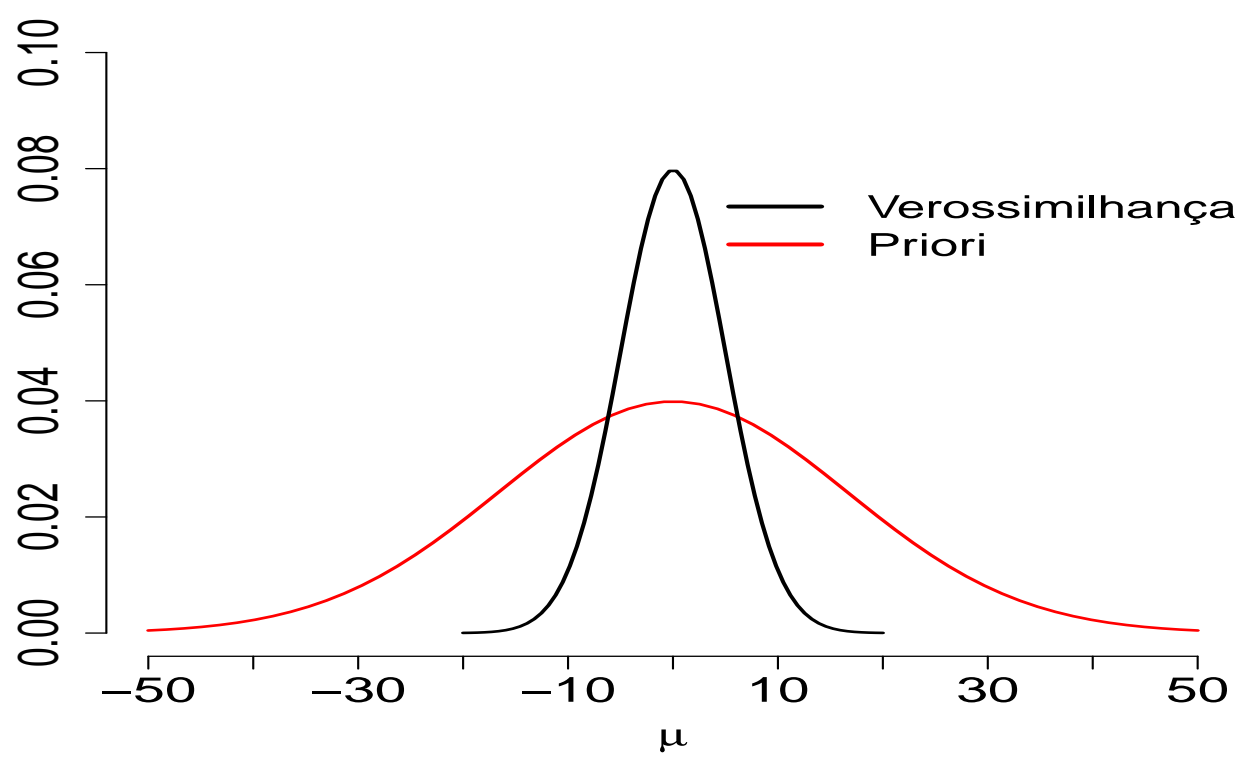

Figura A.1: Distribuição Normal com média 0 e variância baixa (linha cheia preta) e distribuição Normal com média 0 e variância suficientemente grande (linha cheia vermelha). 
Apêndice A. Conceitos de Estatística Bayesiana e o Método de Simulação de Monte Carlo via Cadeias de Markov (MCMC)

Para uma explicação mais detalhada sobre as priori não-informativas ou vagas, consultar Box e Tiao (1973), Berger (1985), e Bernardo e Smith (1994).

Uma forma indireta de se especificar uma distribuição a priori é através de formas funcionais de densidades paramétricas. Os parâmetros destas formas funcionais da distribuição a priori, denominados de hiperparâmetros, são definidos de modo subjetivo de acordo com as informações disponíveis. Um procedimento sistemático de especificar uma distribuição a priori é que a distribuição a posteriori pertençam à mesma família de distribuições, as chamadas de famílias de distribuições conjugadas.

A ideia é que as distribuições a priori e a posteriori pertença a mesma classe de distribuições e, assim, a atualização do conhecimento que se tem do parâmetro de interesse envolva apenas uma mudança nos hiperparâmetros. Neste caso, a forma sequencial do método bayesiano pode ser explorada definindo-se uma regra de atualização dos hiperparâmetros já que as distribuições permanecem as mesmas.

A especificação de uma distribuição a priori conjugada é uma estratégia para se conseguir fazer uma análise bayesiana mais simples, que não exige integrais complexas, porém pode não ser adequada em vários casos.

\section{A.3}

\section{Método de Monte Carlo via Cadeias de Markov (MCMC)}

O método de Monte Carlo via Cadeias de Markov (MCMC) permite gerar amostras de uma variável aleatória $X$ que possua uma distribuição de interesse qualquer. No contexto clássico, esta distribuição pode surgir de um modelo complexo e, no contexto bayesiano, é a distribuição a posteriori do vetor paramétrico.

De acordo com Migon et al. (2015), a ideia central do MCMC é construir uma cadeia de Markov que seja fácil de simular e que tenha a distribuição estacionária dada pela distribuição de interesse. Uma cadeia de Markov é uma família de variáveis aleatórias $\left\{X_{t}: t \in T\right\}$ definidas em um espaço de probabilidade tal que a distribuição de $X_{T+1}$ dados todos os valores anteriores de $\left\{X_{0}, \cdots, X_{t}\right\}$ depende apenas de $X_{t}$, isto é,

$$
P\left(X_{t+1} \in A \mid X_{0}, \cdots, X_{t}\right)=P\left(X_{t+1} \in A \mid X_{t}\right)
$$

para todo $t \geq 0$ e para qualquer subconjunto $A \subset S$. Em que $T$ é um conjunto de índices, $X_{n}$ são os estados, $S$ é o conjunto formado por todos os possíveis estados e é chamado de espaço de estados.

Os métodos de MCMC são uma alternativa aos métodos não iterativos em problemas complexos. A diferença é que aqui usa-se técnicas de simulação 
Apêndice A. Conceitos de Estatística Bayesiana e o Método de Simulação de Monte Carlo via Cadeias de Markov (MCMC)

iterativa, baseadas em cadeias de Markov, e assim os valores gerados não serão mais independentes.

Os métodos de MCMC mais utilizados são o amostrador de Gibbs e o algoritmo de Metropolis-Hastings. Os métodos de MCMC requerem ainda que a cadeia seja homogênea, isto é, as probabilidades de transição de um estado para outro são invariantes; irredutível, isto é, cada estado pode ser atingido a partir de qualquer outro em um número finito de iterações; aperiódica, isto é, não haja estados absorventes. O algoritmo que será abordado aqui satisfaz a estas condições.

$\mathrm{Na}$ literatura, existem várias propostas para avaliar a convergência das cadeias. Uma forma amplamente utilizada, e de fácil aplicação, é a inspeção gráfica através da análise da trajetória de uma ou mais cadeias em períodos distintos de tempo. Outros critérios empíricos são os diagnósticos de Gelman e Rubin (1992) e Geweke (1992). Segundo Tierney (1994), a ideia é que conforme o número de iterações aumenta, a cadeia gradualmente esquece seus valores iniciais e converge para a distribuição estacionária. Em aplicações práticas é comum que as iterações iniciais sejam descartadas, como se formassem uma amostra de aquecimento da cadeia (burn-in). Como a simulação é sequencial, os valores que formam a cadeia apresentam dependência entre si. E, portanto, para evitar o armazenamento de informações redundantes, pode-se optar por selecionar apenas valores a cada certo número de amostras simuladas. Este procedimento é conhecido por raleamento (thinning).

O método MCMC pode ser visto com mais detalhes em Gamerman e Lopes (2006).

\section{A.3.1}

\section{Algoritmo de Metropolis-Hastings}

O algoritmo de Metropolis foi apresentado inicialmente por Metropolis et al. (1953) e generalizado por Hastings (1970) resultando no algoritmo de Metropolis-Hastings.

O algoritmo de Metropolis-Hastings utiliza a ideia dos métodos de rejeição, isto é, um valor é gerado de uma distribuição auxiliar e aceito com uma dada probabilidade. Suponha que a cadeia esteja no estado $\theta$ e um valor $\theta^{*}$ é gerado de uma distribuição proposta $q(\cdot \mid \theta)$. A distribuição proposta pode depender do estado atual da cadeia, por exemplo $q(\cdot \mid \theta)$ poderia ser uma distribuição normal centrada em $\theta$. Assim, o novo valor $\theta^{*}$ é aceito com probabilidade

$$
\alpha\left(\theta, \theta^{*}\right)=\min \left(1, \frac{\pi\left(\theta^{*}\right) q\left(\theta \mid \theta^{*}\right)}{\pi(\theta) q\left(\theta^{*} \mid \theta\right)}\right),
$$


onde $\pi$ é a distribuição de interesse.

O algoritmo de Metropolis-Hastings pode ser especificado pelos seguintes passos:

(i) Inicialize o contador de iterações $i=0$ e especifique um valor inicial $\theta^{(0)}$;

(ii) Gere um novo valor $\theta^{*}$ da distribuição proposta $q\left(\cdot \mid \theta^{(i)}\right)$;

(iii) Calcule a probabilidade de aceitação $\alpha\left(\theta^{(i)}, \theta^{*}\right)$ e gere $u \sim U(0,1)$.

(iv) Se $u<\alpha$ então aceite o novo valor e faça $\theta^{(i+1)}=\theta^{*}$, caso contrário rejeite e faça $\theta^{(i+1)}=\theta^{(i)}$.

(v) Incremente o contador de $i$ para $i+1$ e volte ao passo (ii).

A cadeia de Markov gerada pelo algoritmo de Metropolis-Hastings:

(i) tem $\pi(\theta)$ como sua distribuição estacionária devido ao fato de a cadeia ser reversível;

(ii) é aperiódica, pois permite a ocorrência de eventos tais como $\left\{\theta_{t+1}=\theta_{t}\right\}$, isto é, a probabilidade desses eventos não é zero;

(iii) é irredutível, pois $q(\cdot \mid \cdot)$ satisfaz a seguinte condição

$$
q\left(\theta^{*} \mid \theta\right)>0, \quad \forall \theta, \theta^{*} \in S
$$

(iv) portanto, a distribuição de probabilidade da cadeia converge para a distribuição de interesse $\pi(\theta)$.

À medida que o número de iterações aumenta, a cadeia aproxima-se da sua condição de equilíbrio. Quando a convergência é atingida, o valor resultante $\theta^{(i)}$ é uma observação da distribuição a posteriori de interesse.

Assim, na prática, a cadeia é iterada um número suficientemente grande de iterações (suponha, $J$ ) tal que se possa assmuir que a convergência foi atingida. Este é o chamado período de aquecimento (burn-in). Os valores $\theta^{(J)}, \theta^{(J+1)}, \cdots, \theta^{(M)}$ são tomados como uma amostra da distribuição a posteriori de $\theta$. Como os valores sequenciais nesta amostra são autocorrelacionados, é usual considerar uma sub-amostra sistemática dos valores, por exemplo, a cada $k>1$ iterações (raleamento da amostra), para reduzir este efeito. Na estatística Bayesiana, a distribuição de interesse é igual a própria distribuição a posteriori, isto é, $\pi(\theta)=p(\theta \mid x)$. 
Apêndice A. Conceitos de Estatística Bayesiana e o Método de Simulação de

Monte Carlo via Cadeias de Markov (MCMC)

\section{A.3.2}

\section{Amostrador de Gibbs}

Neste trabalho, será utilizado o amostrador de Gibbs proposto por Geman e Geman (1984) e popularizado por Gelfand e Smith (1990). Esse método é um caso especial do algoritmo de Metropolis-Hastings, com aplicações principalmente em métodos bayesianos.

No amostrador de Gibbs, a cadeia irá sempre se mover para um novo valor e as transições de um estado para outro são feitas de acordo com as distribuições condicionais completas. A distribuição condicional completa é a distribuição da i-ésima componente de $\theta$ condicionada em todas as outras componentes. Se as distribuições condicionais completas forem completamente conhecidas, então podemos utilizar o algoritmo do amostrador de Gibbs. Esse algoritmo pode ser especificado pelos seguintes passos:

(i) Inicialize o contador de iterações da cadeia $i=0$;

(ii) Especifique os valores iniciais de $\theta^{(0)}=\theta_{1}^{(0)}, \cdots, \theta_{d}^{(0)}$;

(iii) Obtenha um novo valor de $\theta^{(i)}$ a partir de $\theta^{(i-1)}$ através da geração sucessiva dos valores de

$\theta_{1}^{(i)} \sim p\left(\theta_{1} \mid \theta_{2}^{(i-1)}, \cdots, \theta_{d}^{(i-1)}\right)$

$\theta_{2}^{(i)} \sim p\left(\theta_{2} \mid \theta_{1}^{(i)}, \theta_{3}^{(i-1)}, \cdots, \theta_{d}^{(i-1)}\right)$

$\theta_{d}^{(i)} \sim p\left(\theta_{d} \mid \theta_{1}^{(i)}, \theta_{2}^{(i)}, \cdots, \theta_{d-1}^{(i)}\right)$

(iv) Incremente o contador de $i$ para $i+1$ e retorne ao passo (iii) até obter convergência. 
B

\section{Fonte dos dados}

Tabela B.1: Fonte dos dados de produção dos processos e do valor adicionado por subsetor da indústria brasileira.

\begin{tabular}{|c|c|}
\hline Subsetor & Processos \\
\hline Ferro gusa e aço & $\begin{array}{l}\text { IBGE, World steel (https://www.worldsteel.org/), } \\
\text { IPEADATA, http : //www.cgee.org.br/eventos/arquivos/ } \\
\text { Período: 2000-2014 }\end{array}$ \\
\hline $\begin{array}{l}\text { Metais não ferrosos } \\
\text { e }\end{array}$ & IBGE, ABAL (http://www.abal.org.br/en/), \\
\hline $\begin{array}{ll}\text { outros } & \text { de } \\
\text { metalurgia } & \end{array}$ & $\begin{array}{l}\text { USGS, Anuário Estatístico do Setor Metalúrgico (2006, 2009, } \\
\text { 2014). } \\
\text { Período: 2000-2014 }\end{array}$ \\
\hline Papel e celulose & $\begin{array}{l}\text { BRACELPA(http://bracelpa.org.br/bra2/index.php), } \\
\text { FAO, (http://faostat3.fao.org/faostat-gateway/go/to/download), } \\
\text { IBGE- Produção Física Industrial; } \\
\text { Período: 2000-2014 }\end{array}$ \\
\hline Química & $\begin{array}{l}\text { ABIQUIM (http://www.abiquim.org.br/home/associacao- } \\
\text { brasileira-da-industria-quimica), ABICLOR } \\
\text { (http://www.abiclor.com.br/), PROCEL/info, IBGE- Produção } \\
\text { Física Industrial; } \\
\text { Período: 2000-2014 }\end{array}$ \\
\hline $\begin{array}{l}\text { Alimentos } \\
\text { bebidas }\end{array}$ & $\begin{array}{l}\text { IBGE- Produção Física Industrial, PROCEL/info } \\
\text { Período: 2000-2014 }\end{array}$ \\
\hline Cimento & SNIC (http://www.snic.org.br/); \\
\hline Ferro ligas & $\begin{array}{l}\text { Anuário Estatístico do Setor Metalúrgico (2006, 2009, 2014), } \\
\text { PROCEL/info } \\
\text { Período: 2000-2014 }\end{array}$ \\
\hline $\begin{array}{l}\text { Mineração } \\
\text { pelotização }\end{array}$ & $\begin{array}{l}\text { DNPM (Departamento Nacional de Produção Mineral), IBGE- } \\
\text { Produção Física Industrial } \\
\text { Período: 2000-2014 }\end{array}$ \\
\hline Têxtil & $\begin{array}{l}\text { IBGE- Produção Física Industrial, PROCEL/info } \\
\text { Período: 2000-2014 }\end{array}$ \\
\hline Cerâmica & $\begin{array}{l}\text { ANFACER (http://www.anfacer.org.br/), Anuário estatístico do } \\
\text { setor de transformação de não metálicos (2006, 2010, 2013, 2014); } \\
\text { Período: 2000-2014 }\end{array}$ \\
\hline Outras indústrias & $\begin{array}{l}\text { Anuário Estatístico ABIFA 2014, PROCEL/info. } \\
\text { Período: 2000-2014 }\end{array}$ \\
\hline $\begin{array}{l}\text { Valor adicionado } \\
\text { dos subsetores da } \\
\text { indústria }\end{array}$ & $\begin{array}{l}\text { IBGE, } \quad \begin{array}{l}\text { Pesquisa } \\
\text { http://www.sidra.ibge.gov.br/bda/pesquisas/pia/ }\end{array} \\
\text { Período: } 2008-2014\end{array}$ \\
\hline
\end{tabular}


Tabela B.2: Classificação dos processos pelo consumo de eletricidade em 2012.

\begin{tabular}{|c|c|c|c|}
\hline & Processos & Eletricidade $2012(\mathrm{GWh})$ & Percentual acumulado (\%) \\
\hline 1 & Alumínio primário & 23132.98 & $18,05 \%$ \\
\hline 2 & Celulose química & 9308.00 & $25,31 \%$ \\
\hline 3 & Produtos derivados de carne & 8054.65 & $31,60 \%$ \\
\hline 4 & Mineração & 6814.31 & $36,92 \%$ \\
\hline 5 & Açúcares & 6548.14 & $42,03 \%$ \\
\hline 6 & Fusão e redução da carga & 5858.99 & $46,60 \%$ \\
\hline 7 & Bebidas & 4480.99 & $50,10 \%$ \\
\hline 8 & Aço elétrico & 4282.54 & $53,44 \%$ \\
\hline 9 & Frutas e legumes* & 4152.68 & $56,68 \%$ \\
\hline 10 & Aço laminado & 3815.88 & $59,66 \%$ \\
\hline 11 & Moagem do cimento & 3226.29 & $62,17 \%$ \\
\hline 12 & Papel & 3138.92 & $64,62 \%$ \\
\hline 13 & Aço oxigenado & 3122.41 & $67,06 \%$ \\
\hline 14 & Silício metálico & 2700.00 & $69,17 \%$ \\
\hline 15 & Pelotização & 2423.38 & $71,06 \%$ \\
\hline 16 & Cloro, diafragma & 2408.15 & $72,94 \%$ \\
\hline 17 & Cerâmicas vermelha* & 2369.78 & $74,79 \%$ \\
\hline 18 & Prep. mat-primas (moagem cru) & 2264.46 & $76,55 \%$ \\
\hline 19 & Café, chá, cereais * & 2220.69 & $78,29 \%$ \\
\hline 20 & Clinquerização do cimento* & 2209.07 & $80,01 \%$ \\
\hline 21 & Níquel & 2127.53 & $81,67 \%$ \\
\hline 22 & Leite e derivados & 2039.80 & $83,26 \%$ \\
\hline 23 & Oxigênio & 1981.36 & $84,81 \%$ \\
\hline 24 & Polietileno & 1521.57 & $85,99 \%$ \\
\hline 25 & Óleos e gorduras * & 1301.07 & $87,01 \%$ \\
\hline 26 & Celulose mecânica & 1243.56 & $87,98 \%$ \\
\hline 27 & Papel recuperado & 1231.27 & $88,94 \%$ \\
\hline 28 & Resinas termofixas & 1146.24 & $89,84 \%$ \\
\hline 29 & Zinco primário & 1138.21 & $90,72 \%$ \\
\hline 30 & Revestimentos cerâmicos* & 1103.15 & $91,58 \%$ \\
\hline 31 & Outros (química) & 1039.83 & $92,40 \%$ \\
\hline 32 & Gusa coke & 940.33 & $93,13 \%$ \\
\hline 33 & Panificação & 847.18 & $93,79 \%$ \\
\hline 34 & cloro, membrana & 806.93 & $94,42 \%$ \\
\hline 35 & Eteno (etileno) & 753.73 & $95,01 \%$ \\
\hline 36 & Preparação de matéria prima & 732.90 & $95,58 \%$ \\
\hline 37 & Preparação do produto final & 732.90 & $96,15 \%$ \\
\hline 38 & Amônia & 633.71 & $96,65 \%$ \\
\hline 39 & Cloro, mercúrio & 627.56 & $97,14 \%$ \\
\hline 40 & Outros (alimentos e bebidas) & 572.84 & $97,58 \%$ \\
\hline 41 & Fiação & 510.97 & $97,98 \%$ \\
\hline 42 & Carboneto calcio (acetileno) & 479.21 & $98,36 \%$ \\
\hline 43 & Cobre refinado & 390.77 & $98,66 \%$ \\
\hline 44 & Alumínio secundário (sucata) & 355.68 & $98,94 \%$ \\
\hline 45 & Cobre primário & 325.79 & $99,19 \%$ \\
\hline 46 & Cobre secundário & 293.39 & $99,42 \%$ \\
\hline 47 & Plásticos & 234.06 & $99,61 \%$ \\
\hline 48 & Outros (têxtil) & 233.78 & $99,79 \%$ \\
\hline 49 & Polipropileno & 219.81 & $99,96 \%$ \\
\hline 50 & Estanho & 52.24 & $100,00 \%$ \\
\hline 51 & Sinterização & 0.32 & $100,00 \%$ \\
\hline 52 & Redução direta & 0.00 & $100,00 \%$ \\
\hline
\end{tabular}




\section{C}

\section{Conceitos sobre as MEEs}

Segundo Worrell et al. (2003) e Abdelaziz et al. (2011), pode-se assumir que o tempo de retorno (PBT) de uma MEE so no tempo $t$ pode ser definido por

$$
P B T_{s o, t}=\frac{C_{s o, t}^{I}}{C_{s o, t}^{*}},
$$

onde $C_{s o, t}^{I}$ é o custo de investimento anual (R\$) com a MEE so no tempo $t$, e $C_{s o, t}^{*}$ é a economia de custo total $(\mathrm{R} \$)$ gerado pela MEE so no tempo $t$.

Com base em Hart e Liu (HART; LIU, 2015) , a economia de custo gerada pela MEE so no tempo $t$ pode ser definida por

$$
C_{s o, t}^{*}=C_{s o, t}^{E}-C_{s o, t}^{M},
$$

onde $C_{s o, t}^{E}$ é a economia de custo ( $\mathrm{R} \$$ ) gerado pela MEE so no tempo $t$, e $C_{s o, t}^{M}$ é o custo pela manutenção (R\$) da MEE so no tempo $t$.

Segundo Fleiter et al. (2012) e Huang et al. (2016), tem-se que o custo de investimento anual $\left(C_{s o, t}^{I}\right)$ da MEE so no tempo $t$ pode ser escrito por

$$
C_{s o, t}^{I}=C \frac{1}{(1+r)^{t}}
$$

onde $C$ é o custo de investimento anualizado, e $r$ é a taxa de desconto.

O custo de manutenção $C_{s o, t}^{M}$ da MEE so no tempo t pode ser calculado por

$$
C_{s o, t}^{M}=C^{m} \frac{1}{(1+r)^{L t-t+1}},
$$

onde $C^{m}$ é custo de manutenção anualizado, $L t$ é o tempo de vida da MEE so, e $r$ é a taxa de desconto.

O modelo de crescimento logístico foi reescrito por McKendrick e Pai (1912) pela equação diferencial dada por

$$
\frac{d N}{d t}=r N\left(1-\frac{N}{K}\right)
$$

onde $r$ é a taxa de crescimento e $K$ é o valor máximo atingido por $N$. A solução da equação diferencial (C-5) é dada por

$$
N(t)=\frac{K}{1+\left(\frac{k-N_{0}}{N_{0}}\right) e^{-r t}} .
$$


Assumindo que o valor máximo de $K=N=1$, tem-se que

$$
N(t)=\frac{1}{1+\left(\frac{1-N_{0}}{N_{0}}\right) e^{-r t}},
$$

onde $N(t)$ descreve o crescimento entre 0 e 1 .

Com base no modelo de crescimento logístico (C-5, C-6, C-7), a distribuição da expectativa do tempo de retorno pode ser escrito por

$$
f\left(P B T_{s o, t}\right)=1-\frac{N}{1+\left(\frac{N-f(0)}{f(0)}\right) e^{-\beta * P B T_{s o, t}}},
$$

onde $f(0)$ é o valor inicial de percentual da difusão $\left(P B T_{s o, t}=0\right), N$ é o valor máximo de percentual da difusão $(N=1), \beta$ é o coeficiente de declividade da função logística. 
D

\section{Percentual de consumo de eletricidade para as tecnologias transversais}

Tabela D.1: Percentual de consumo de eletricidade por tecnologia transversal do subsetor de papel e celulose.

\begin{tabular}{l|c}
\hline Tecnologia transversal & Percentual \\
\hline Bombas & 54,16 \\
Ventilação & 20,66 \\
Ar comprimido & 12,56 \\
Outros motores & 7,43 \\
Iluminação & 1,6 \\
Refrigeração & 0,30 \\
\hline
\end{tabular}

Tabela D.2: Percentual de consumo de eletricidade por tecnologia transversal do subsetor de metais não-ferrosos e outros de metalurgia.

\begin{tabular}{l|c}
\hline Tecnologia transversal & Percentual \\
\hline Bombas & 2,06 \\
Ventilação & 6,49 \\
Ar comprimido & 1,60 \\
Outros motores & 20,16 \\
Iluminação & 0,20 \\
Refrigeração & 0 \\
\hline
\end{tabular}


E

\section{Resumo dos valores calculados de difusão tecnológica}

Tabela E.1: Resumo dos valores calculados de difusão aplicados nos processos do subsetor de papel e celulose: taxa de difusão por medida de eficiência energética para diferentes cenários.

\begin{tabular}{|c|c|c|c|c|c|c|c|c|c|c|}
\hline \multirow[t]{3}{*}{ Processos } & \multirow{3}{*}{$\begin{array}{l}\text { Medidas de eficiência } \\
\text { energética }\end{array}$} & \multicolumn{9}{|c|}{ Taxa de difusão (\%) } \\
\hline & & \multirow{2}{*}{$\begin{array}{l}\text { Ano inicial } \\
2010\end{array}$} & \multicolumn{4}{|c|}{$\begin{array}{l}\text { Cenário de difusão } \\
\text { autônoma }\end{array}$} & \multicolumn{4}{|c|}{$\begin{array}{l}\text { Cenário de difusão } \\
\text { máxima }\end{array}$} \\
\hline & & & 2020 & 2030 & 2040 & 2050 & 2020 & 2030 & 2040 & 2050 \\
\hline \multirow[t]{3}{*}{ Papel } & Refinadores eficientes & 1,91 & 4.17 & 6.71 & 8.39 & 9.13 & 4.64 & 12.62 & 26.54 & 35.80 \\
\hline & Otimização dos refinadores & 13,14 & 19.03 & 23.58 & 26.34 & 27.78 & 20.91 & 38.92 & 47.34 & 49.48 \\
\hline & $\begin{array}{l}\text { Melhoramento na química de } \\
\text { fibras }\end{array}$ & 0,35 & 1.07 & 2.48 & 3.92 & 4.69 & 1.23 & 5.76 & 20.40 & 31.86 \\
\hline $\begin{array}{l}\text { Química de } \\
\text { celulose }\end{array}$ & Gaseificação de licor negro & 0.31 & 6.56 & 7.27 & 7.27 & 7.27 & 9.56 & 22.49 & 22.50 & 22.50 \\
\hline \multirow{3}{*}{$\begin{array}{l}\text { Mecânica de } \\
\text { celulose }\end{array}$} & Eficiência elevada (GW) & 0,07 & 3.57 & 3.57 & 3.57 & 3.58 & 14.22 & 33.50 & 33.50 & 33.50 \\
\hline & Pré-tratamento enzimático & 0,09 & 2.13 & 2.20 & 2.20 & 2.20 & 6.30 & 8.50 & 8.50 & 8.50 \\
\hline & Refinadores eficientes (TMP) & 2,75 & 4.66 & 6.43 & 7.59 & 8.18 & 5.12 & 10.35 & 14.47 & 15.98 \\
\hline \multirow{4}{*}{$\begin{array}{l}\text { Papel } \\
\text { reciclado }\end{array}$} & Polpação de alta consistência & 13,34 & 18.55 & 22.60 & 25.16 & 26.57 & 19.96 & 34.13 & 43.98 & 48.08 \\
\hline & Rastreamento eficiente & 8,80 & 12.59 & 15.60 & 17.51 & 18.56 & 18.56 & 27.53 & 40.17 & 46.61 \\
\hline & Otimização De-Inking & 0,31 & 1.48 & 5.00 & 8.81 & 10.24 & 1.72 & 11.32 & 39.31 & 48.99 \\
\hline & Dispersor eficiente & 13,38 & 18.54 & 22.75 & 25.58 & 27.22 & 20.97 & 39.16 & 47.48 & 49.43 \\
\hline
\end{tabular}

Tabela E.2: Resumo dos valores calculados de difusão para cada MEE aplicado as tecnologias transversais: taxa de difusão por medida de eficiência energética em diferentes cenários.

\begin{tabular}{|c|c|c|c|c|c|c|c|c|c|}
\hline \multirow{3}{*}{$\begin{array}{l}\text { Medidas de eficiência } \\
\text { energética }\end{array}$} & \multicolumn{9}{|c|}{ Taxa de difusão (\%) } \\
\hline & \multirow{2}{*}{$\begin{array}{l}\text { Ano inicial } \\
2010\end{array}$} & \multicolumn{4}{|c|}{$\begin{array}{l}\text { Cenário de difusão } \\
\text { autônoma }\end{array}$} & \multicolumn{4}{|c|}{$\begin{array}{l}\text { Cenário de difusão } \\
\text { máxima }\end{array}$} \\
\hline & & 2020 & 2030 & 2040 & 2050 & 2020 & 2030 & 2040 & 2050 \\
\hline Ventiladores de alta eficiência & 1,24 & 5.67 & 17.05 & 27.12 & 30.44 & 6.48 & 24.92 & 44.66 & 48.42 \\
\hline Manutenção regular de ventiladores & 37,59 & 45.78 & 49.26 & 50.51 & 50.92 & 54.33 & 85.53 & 96.22 & 98.57 \\
\hline Motores IE2 & 2,20 & 6.69 & 15.87 & 25.76 & 31.18 & 7.79 & 28.99 & 46.70 & 49.49 \\
\hline Controlador de velocidade & 19,84 & 25.51 & 34.75 & 38.99 & 40.49 & 27.52 & 41.60 & 47.47 & 48.64 \\
\hline Motores IE3 & 0,01 & 0.44 & 0.26 & 0.62 & 0.73 & 0.49 & 0.31 & 2.11 & 14.25 \\
\hline Movimentação direta em vez de V-Belt & 37,59 & 45.78 & 49.26 & 50.51 & 50.92 & 53.78 & 84.33 & 95.68 & 98.41 \\
\hline Bombas de alta eficiência & 1,24 & 5.67 & 17.05 & 27.12 & 30.44 & 6.48 & 24.92 & 44.66 & 48.42 \\
\hline Avoid oversizing & 23,91 & 25.04 & 34.78 & 38.68 & 39.84 & 27.44 & 43.78 & 48.83 & 49.52 \\
\hline Manutenção regular de bombas & 23,91 & 36.37 & 44.07 & 47.08 & 48.06 & 38.40 & 47.31 & 49.18 & 49.55 \\
\hline Compressores de alta eficiência & 11,78 & 22.72 & 32.30 & 37.01 & 38.70 & 24.77 & 40.72 & 47.40 & 48.65 \\
\hline Manutenção regular de ar comprimido & 17.50 & 28.80 & 37.91 & 40.35 & 40.86 & 32.09 & 48.04 & 49.76 & 49.92 \\
\hline Compressores eficientes & 11,78 & 25.29 & 35.08 & 38.83 & 39.89 & 27.85 & 44.67 & 48.88 & 49.57 \\
\hline Manutenção regular de refrigeração & 11,78 & 28.80 & 37.91 & 49.74 & 40.86 & 32.05 & 47.93 & 40.36 & 49.92 \\
\hline Manutenção regular de iluminação & 64,34 & 69.14 & 70.73 & 71.22 & 71.37 & 76.99 & 94.28 & 98.53 & 99.39 \\
\hline LEDs & 54,40 & 59.86 & 62.21 & 63.15 & 63.51 & 67.82 & 89.81 & 96.82 & 98.53 \\
\hline Luminárias eficientes & 0,20 & 0.75 & 2.56 & 6.80 & 11.95 & 0.88 & 5.90 & 26.42 & 42.19 \\
\hline
\end{tabular}


Tabela E.3: Resumo dos valores calculados de difusão aplicados aos processos do subsetor de metais não-ferrosos: taxa de difusão por medida de eficiência energética para diferentes cenários.

\begin{tabular}{|c|c|c|c|c|c|c|c|c|c|c|}
\hline \multirow[t]{3}{*}{ Processos } & \multirow{3}{*}{$\begin{array}{l}\text { Medidas de eficiência } \\
\text { energética }\end{array}$} & \multicolumn{9}{|c|}{ Taxa de difusão (\%) } \\
\hline & & \multirow{2}{*}{$\begin{array}{l}\text { Ano inicial } \\
2010\end{array}$} & \multicolumn{4}{|c|}{$\begin{array}{l}\text { Cenário de difusão } \\
\text { autônoma }\end{array}$} & \multicolumn{4}{|c|}{$\begin{array}{l}\text { Cenário de difusão } \\
\text { máxima }\end{array}$} \\
\hline & & & 2020 & 2030 & 2040 & 2050 & 2020 & 2030 & 2040 & 2050 \\
\hline \multirow{5}{*}{$\begin{array}{l}\text { Alumínio } \\
\text { primário }\end{array}$} & Anodos inertes & 0,37 & 0,97 & 2,72 & 4,42 & 6,71 & 1,91 & 8,27 & 16,04 & 31,26 \\
\hline & Cátodo húmido & 0,02 & 0,29 & 2,98 & 10,61 & 13,26 & 0,35 & 3,67 & 18,72 & 27,53 \\
\hline & PFPB & 43,18 & 46,74 & 48,51 & 49,33 & 49,70 & 48,26 & 49,57 & 49,91 & 49,98 \\
\hline & $\begin{array}{l}\text { Otimização do controle } \\
\text { de eletrólise }\end{array}$ & 9,98 & 19,79 & 22,71 & 23,16 & 23,22 & 24,74 & 38,94 & 46,44 & 48,99 \\
\hline & $\begin{array}{l}\text { Design de células } \\
\text { de otimização }\end{array}$ & 0,01 & 16,40 & 16,40 & 16,40 & 16,40 & 49,71 & 49,99 & 49,99 & 50,00 \\
\hline \multirow{7}{*}{$\begin{array}{l}\text { Cobre } \\
\text { primário } \\
\text { Cobre } \\
\text { secundário }\end{array}$} & Gerenciamento de otimização & 0,41 & 46,07 & 47,37 & 47,37 & 47,37 & 48,87 & 49,99 & 49,99 & 49,99 \\
\hline & Recuperação de calor residual & 3,37 & 7,96 & 13,25 & 16,44 & 17,68 & 44,24 & 44,49 & 44,49 & 44,50 \\
\hline & Melhoria da combustão & 11,82 & 13,71 & 14,71 & 15,18 & 15,39 & 16,28 & 20,34 & 22,77 & 24,00 \\
\hline & Controle melhorado do processo & 11,90 & 13,60 & 14,57 & 15,07 & 15,32 & 16,27 & 20,34 & 22,78 & 24,01 \\
\hline & Refinaria melhorada & 11,90 & 13,60 & 14,57 & 15,07 & 15,32 & 16,27 & 20,34 & 22,78 & 24,01 \\
\hline & Queimadores recuperados & 11,90 & 13,60 & 14,57 & 15,07 & 15,32 & 16,27 & 20,34 & 22,78 & 24,01 \\
\hline & Pré-aquecimento da sucata & 11,90 & 13,60 & 14,57 & 15,07 & 15,32 & 16,27 & 20,34 & 22,78 & 24,01 \\
\hline \multirow{3}{*}{$\begin{array}{l}\text { Cobre } \\
\text { refinado }\end{array}$} & Pacote de eficiência & 0,41 & 46,07 & 47,37 & 47,37 & 47,37 & 48,87 & 49,99 & 49,99 & 49,99 \\
\hline & Novos queimadores & 4,20 & 9,33 & 15,02 & 18,55 & 20,01 & 31,76 & 46,49 & 46,99 & 46,99 \\
\hline & Aquecimento rápido & 3,37 & 7,96 & 13,25 & 16,44 & 17,68 & 44,24 & 44,49 & 44,49 & 44,50 \\
\hline $\begin{array}{l}\text { Zinco } \\
\text { primário }\end{array}$ & Recuperação de calor residual & 3,38 & 7,96 & 13,25 & 16,44 & 17,68 & 44,24 & 44,49 & 44,49 & 44,50 \\
\hline
\end{tabular}

Tabela E.4: Evolução do consumo médio de eletricidade e o percentual de redução do consumo, quando comparado ao cenário frozen, por processo definido no subsetor de papel e celulose.

\begin{tabular}{|c|c|c|c|c|}
\hline \multirow{3}{*}{ Processo } & \multirow{3}{*}{ Ano } & \multicolumn{3}{|c|}{ Cenários } \\
\hline & & Frozen & & \\
\hline & & Consumo (PJ) & Consumo (PJ) & Redução (\%) \\
\hline \multirow{4}{*}{ Papel } & 2020 & 14,69 & 14,62 & 0,46 \\
\hline & 2030 & 18,51 & 18,35 & 0,85 \\
\hline & 2040 & 23,30 & 23,04 & 1,12 \\
\hline & 2050 & 29,09 & 28,72 & 1,29 \\
\hline \multirow{4}{*}{ Química de celulose } & 2020 & 51,29 & 48,72 & 5,00 \\
\hline & 2030 & 64,63 & 61,02 & 5,59 \\
\hline & 2040 & 81,34 & 76,79 & 5,59 \\
\hline & 2050 & 101,58 & 95,90 & 5,59 \\
\hline \multirow{4}{*}{ Mecânica de celulose } & 2020 & 5,06 & 4,96 & 2,00 \\
\hline & 2030 & 6,37 & 6,22 & 2,34 \\
\hline & 2040 & 8,02 & 7,82 & 2,53 \\
\hline & 2050 & 10,02 & 9,75 & 2,62 \\
\hline \multirow{4}{*}{ Papel reciclado } & 2020 & 5,78 & 5,74 & 0,58 \\
\hline & 2030 & 7,28 & 7,18 & 1,35 \\
\hline & 2040 & 9,16 & 8,99 & 1,88 \\
\hline & 2050 & 11,44 & 11,21 & 2,06 \\
\hline
\end{tabular}


Tabela E.5: Evolução do consumo médio de eletricidade e o percentual de redução do consumo, quando comparado ao cenário frozen, por processo definido no subsetor de metais não-ferrosos e outros de metalurgia.

\begin{tabular}{|c|c|c|c|c|}
\hline \multirow{3}{*}{ Processo } & \multirow{3}{*}{ Ano } & \multicolumn{3}{|c|}{ Cenários } \\
\hline & & \multirow{2}{*}{$\begin{array}{c}\text { Frozen } \\
\text { Consumo (PJ) }\end{array}$} & \multicolumn{2}{|c|}{ Cost } \\
\hline & & & Consumo (PJ) & Redução (\%) \\
\hline \multirow{4}{*}{ Alumínio primário } & 2020 & 47,08 & 46,23 & 1,79 \\
\hline & 2030 & 59,53 & 57,65 & 3,16 \\
\hline & 2040 & 74,97 & 71,99 & 3,98 \\
\hline & 2050 & 92,22 & 87,75 & 4,85 \\
\hline \multirow{4}{*}{ Alumínio secundário* } & 2020 & 1,62 & & - \\
\hline & 2030 & 2,05 & & - \\
\hline & 2040 & 2,59 & & - \\
\hline & 2050 & 3,18 & & 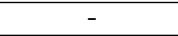 \\
\hline \multirow{4}{*}{ Cobre primário } & 2020 & 1,30 & 1,27 & 2,05 \\
\hline & 2030 & 1,64 & 1,60 & 2,18 \\
\hline & 2040 & 2,06 & 2,02 & 2,19 \\
\hline & 2050 & 2,54 & 2,48 & 2,19 \\
\hline \multirow{4}{*}{ Cobre secundário } & 2020 & 0,87 & 0,86 & 0,43 \\
\hline & 2030 & 1,16 & 1,15 & 0,76 \\
\hline & 2040 & 1,53 & 1,52 & 0,94 \\
\hline & 2050 & 1,98 & 1,96 & 1,05 \\
\hline \multirow{4}{*}{ Cobre refinado } & 2020 & 1,59 & 1,57 & 1,15 \\
\hline & 2030 & 2,01 & 1,96 & 2,47 \\
\hline & 2040 & 2,53 & 2,46 & 3,08 \\
\hline & 2050 & 3,12 & 3,01 & 3,40 \\
\hline \multirow{4}{*}{ Zinco primário } & 2020 & 4,15 & 4,13 & 0,50 \\
\hline & 2030 & 5,51 & 5,46 & 1,00 \\
\hline & 2040 & 7,29 & 7,19 & 1,30 \\
\hline & 2050 & 9,41 & 9,28 & 1,42 \\
\hline \multirow{4}{*}{ Estanho* } & 2020 & 0,37 & & - \\
\hline & 2030 & 0,47 & & - \\
\hline & 2040 & 0,59 & & - \\
\hline & 2050 & 0,73 & & - \\
\hline \multirow{4}{*}{ Níquel* } & 2020 & 5,34 & & - \\
\hline & 2030 & 6,75 & & - \\
\hline & 2040 & 8,51 & & - \\
\hline & 2050 & 10,46 & & - \\
\hline \multirow{4}{*}{ Silício metálico* } & 2020 & 6,81 & & - \\
\hline & 2030 & 8,62 & & - \\
\hline & 2040 & 10,85 & & - \\
\hline & 2050 & 13,35 & & - \\
\hline
\end{tabular}

* Não foi considerada nenhuma medida de eficiência. 


\section{Estudo simulado}

A fim de avaliar o desempenho do modelo proposto (modelo 4-3), foi realizado um estudo de simulação. Para a geração dos dados artificiais foram fixados arbitrariamente os seguintes valores dos parâmetros de variância $\sigma_{s}^{2}=$ 25 e $\sigma_{p}^{2}=10^{-12}$. Os valores dos consumos dos diferentes processos ao longo do tempo foram sorteados das suas respectivas distribuições a priori, em que cada processo $i$, para $i=1,2,3,4$, no tempo $t$, para $t=1, \cdots, T$, é normalmente distribuído com média $S E C_{i, t} \times \operatorname{Prod}_{i, t}$, cujos valores são conhecidos e foram utilizados, e variância $\sigma_{p}^{2}$.

A Figura F.1 apresenta os dados artificiais simulados.

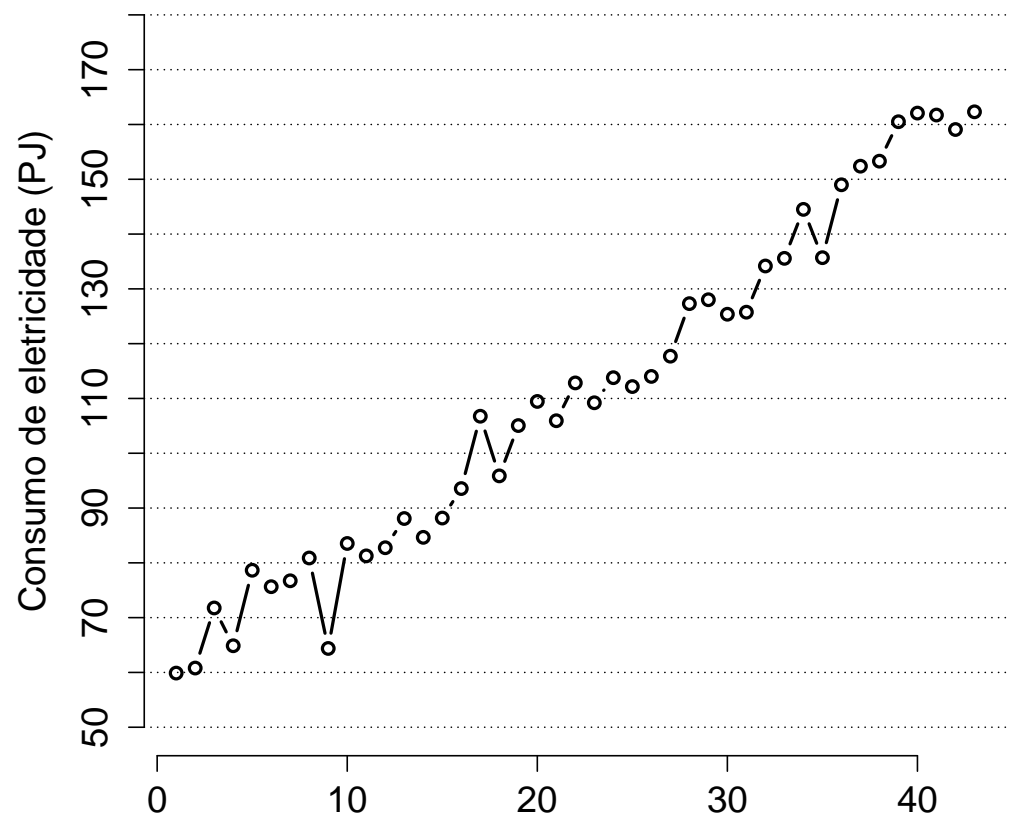

Figura F.1: Dados artificiais gerado pelo modelo proposto.

Foram simuladas 30000 iterações do algoritmo de MCMC, com aquecimento de 10000 e espaçamento de 40 iterações. As Figuras F.2 e F.3 apresentam os histogramas das distribuições a posteriori obtidas de cada um dos parâmetros do modelo. 

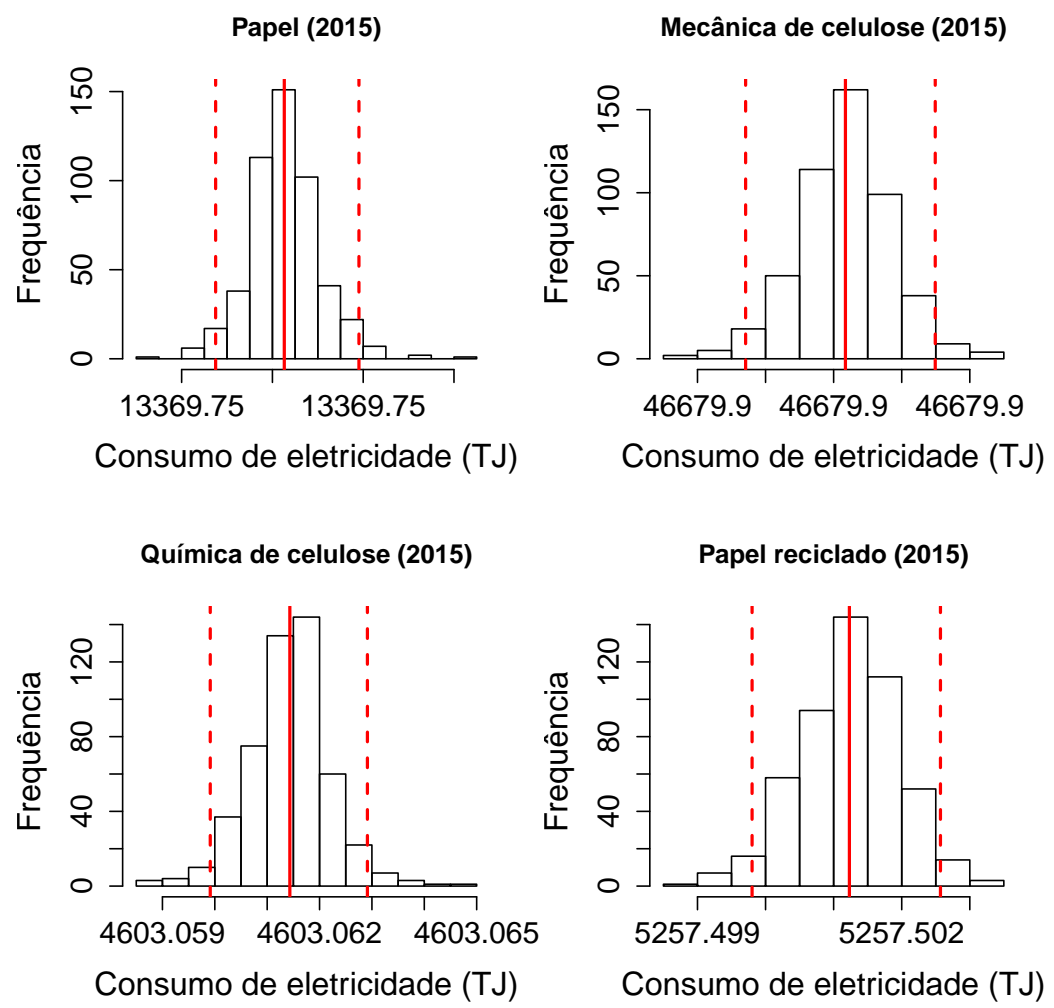

Figura F.2: Estudo simulado: Histogramas das distribuições a posteriori dos parâmetros do modelo para o processo simulado com os valores verdadeiros dos parâmetros (linha vertical vermelha) e o intervalo de credibilidade de $95 \%$ (linha tracejada vermelha).
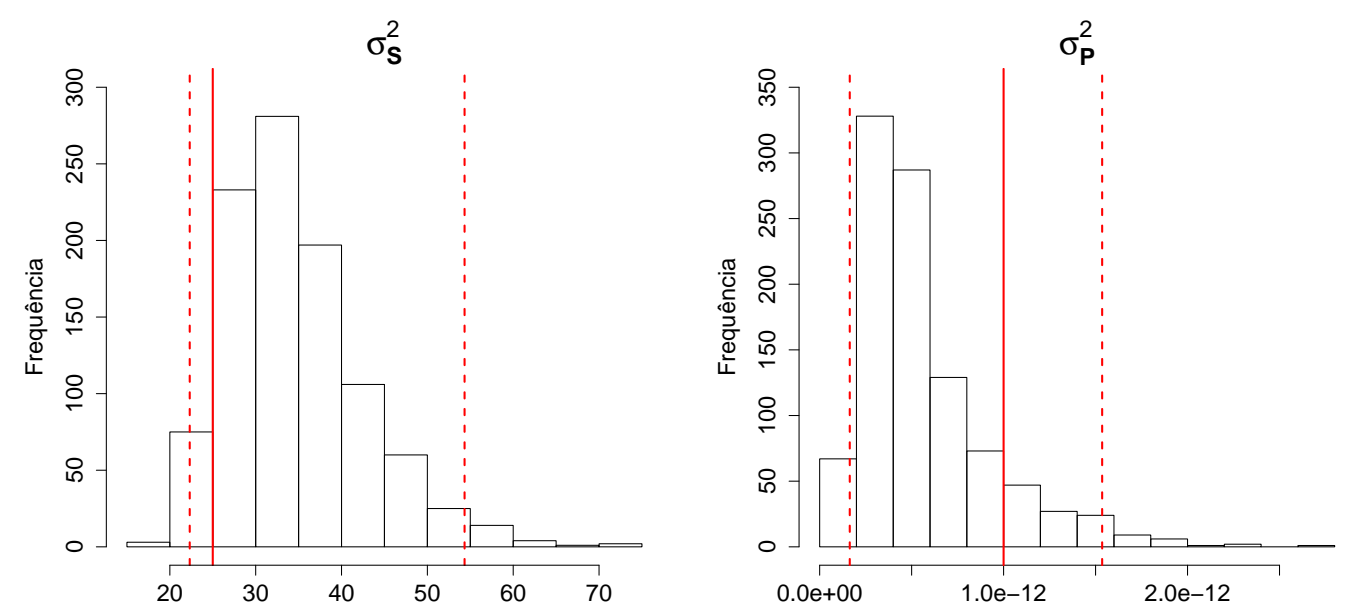

Figura F.3: Estudo simulado: Histogramas das distribuições a posteriori das variâncias do modelo com os valores verdadeiros dos parâmetros (linha vertical vermelha) e o intervalo de credibilidade de $95 \%$ (linha tracejada vermelha).

Analisando os resultados (Figuras F.2 e F.3) pode-se observar que as distribuições a posteriori encontram-se concentradas em torno dos valores verdadeiros dos parâmetros do modelo. 


\section{Referências bibliográficas}

ABDELAZIZ, E. A.; SAIDUR, R.; MEKHILEF, S. A review on energy saving strategies in industrial sector. Renewable and Sustainable Energy Reviews, v. 15, p. 150-168, 2011.

ANG, B. W.; LIU, F. L.; CHEW, E. P. Perfect decomposition techniques in energy and environmental analysis. Energy Policy, v. 31, p. 1561-1566, 2003.

ARDAKANI, F.; ARDEHALI, M. Long-term electrical energy consumption forecasting for developing and developed economies based on different optimized models and historical data types. Energy, v. 65, n. Supplement C, p. $452-461$, 2014. ISSN 0360-5442.

ATHANASOPOULOS, G.; AHMED, R. A.; HYNDMAN, R. J. Hierarchical forecasts for australian domestic tourism. International Journal of Forecasting, v. 25, p. $146-166,2009$.

BACEN. Banco Central do Brasil (BACEN): Sistemas de Expectativas de Mercado. Available https://www3.bcb.gov.br/expectativas/publico/consulta/serieestatisticas, 2015.

BEER, J.; WORRELL, E.; BLOKT, K. Long-term energy-efficiency improvements in the paper and board industry. Energy, v. 23, p. 21-42, 1997.

BERGER, J. O. Statistical Decision Theory and Bayesian Analysis. Second edition. New York: Springer-Verlag, 1985.

BERNARDO, J.; SMITH, A. Bayesian Inference in Statistical Analysis. Second edition. New York: Wiley, 1994.

BERNTSEN, P. B.; TRUTNEVYTE, E. Ensuring diversity of national energy scenarios: Bottom-up energy system model with modeling to generate alternatives. Energy, v. 126, p. 886-898, 2017. ISSN 0360-5442.

BOBMANN, T.; STAFFELL, I. The shape of future electricity demand: Exploring load curves in 2050 germany and britain. Energy, v. 90, p. 1317-1333, 2015.

BOX, G. E. P.; TIAO, G. C. Bayesian Inference in Statistical Analysis. Second edition. New York: John Wiley \& Sons, 1973.

BRILL, J. E. D.; CHANG, S.-Y.; HOPKINS, L. Modeling to generate alternatives: The hsj approach and an illustration using a problem in land use planning. Management Science, v. 28, p. 221-235, 1982. 
BRUNKE, J.-C.; BLESL, M. Energy conservation measures for the german cement industry and their ability to compensate for rising energy-related production costs. Journal of Cleaner Production, v. 82, p. 94-111, 2014.

BRYK, A. S.; RAUDENBUSH, S. W. Hierarchical Linear Models for Social and Behavioral Research: Applications and Data Analysis Methods. First edition. Newbury Park, California: Sage Publications, 1992.

BRYK, A. S.; RAUDENBUSH, S. W. Hierarchical Linear Models for Social and Behavioral Research: Applications and Data Analysis Methods. Second edition. [S.I.]: Sage Publications, 2002.

CABRAL, J. de A.; LEGEY, L. F. L.; CABRAL, M. V. de F. Electricity consumption forecasting in Brazil: A spatial econometrics approach. Energy, v. 126 , p. $124-131,2017$. ISSN 0360-5442.

CAGNO, E. et al. A novel approach for barriers to industrial energy efficiency. Renewable and Sustainable Energy Reviews, v. 19, p. 290-308, 2013.

CALILI, R. F. et al. Estimating the cost savings and avoided $\mathrm{CO}_{2}$ emissions in Brazil by implementing energy efficient policies. Energy Policy, v. 67, p. 4-15, 2014.

CHATEAU, B.; LAPILLONNE, B. Long-term energy demand forecasting a new approach. Energy Policy, v. 6, p. 140-157, 1978.

CHATEAU, B.; LAPILLONNE, B. The medee models for long term energy demand forecasting. Socio-Economic Planning Sciences, v. 15, p. 53-58, 1981.

COCHRANE, D.; ORCUTT, G. H. Application of least squares regression to relationships containing auto-correlated error terms. Journal of the American Statistical Association, v. 44, p. 32-61, 1949.

COLLINS, D. W. Predicting earnings with sub-entity data: some further evidence. Journal of Accounting Research, v. 14, p. 163-177, 1976.

DAI, H. et al. Closing the gap? top-down versus bottom-up projections of china's regional energy use and $\mathrm{CO}_{2}$ emissions. Applied Energy, v. 162, p. 1355-1373, 2016.

DANGERFIELD, B. J.; MORRIS, J. S. Top-down or bottom-up: aggregate versus disaggregate extrapolations. International Journal of Forecasting, v. 8, p. 233-241, 1992.

DECAROLIS, J. et al. Modelling to generate alternatives with an energy system optimization model. Environmental Modelling \& Software, v. 79, p. $300-310$, 2016. ISSN 1364-8152.

DECAROLIS, J. F. Using modeling to generate alternatives (mga) to expand our thinking on energy futures. Energy Economics, v. 33, n. 2, p. $145-152,2011$. ISSN 0140-9883. 
DUNN, D. M.; WILLIAMS, W. H.; DECHAINE, T. L. Aggregate versus sub aggregate models in local area forecasting. Journal of the American Statistical Association, v. 71, p. 68-71, 1976.

EEP. 7 Energy-Efficiency Improvement Opportunities In Lighting System. Available:

http://electrical-engineering-portal.com/7-energy-efficiency-improvement -opportunities-in-lighting-system, 2015.

EEP. Six energy efficiency improvement opportunities in fan systems. Available: http://electrical-engineering-portal.com/6-energy-efficiency-improvement -opportunities-in-fan-systems, 2015.

EPE. Aspectos Fundamentais de Planejamento Energético. Disponível: http://siteantigo.sudene.gov.br/conteudo/download, 2005.

EPE. Avaliação da Eficiência Energética e Geração

Distribuída para os próximos 10 anos (2014-2023). Available:

http://www.epe.gov.br/mercado/Documents/S2014.

EPE. Balanço Energético Nacional. Available: https://ben.epe.gov.br., 2015.

EPE. Balanço Energético Nacional. Available: https://ben.epe.gov.br, 2016.

EPE. Estudo da Demanda de Energia, Nota Técnica DEA 13/15, Demanda de energia 2050. Available: https://ben.epe.gov.br., 2016.

EPE. Matriz Energética Nacional 2017 - Ano Base 2016. Available:

https: / / ben.epe.gov.br/BENRelatoriolnicial.aspx?anoColeta $=2017 \&$ anoFim Coleta $=2016,2017$.

FARLA, J.; BLOK, K.; SCHIPPER, L. Energy efficiency developments in the pulp and paper industry: A cross-country comparison using physical production data. Energy Policy, v. 97, p. 745-758, 1997.

FLEITER, T. et al. Energy efficiency in the german pulp and paper industry - a model-based assessment of saving potentials. Energy, v. 40, p. 84-99, 2012.

FLEITER, T. et al. Where are the promising energy-efficient technologies? a comprehensive analysis of the german energy-intensive industries. In: ECEEE SUMMER STUDY, ENERGY EFFICIENCY FIRST: THE FOUNDATION OF A LOW-CARBON SOCIETY. •. [S.I.], 2011.

FLIEDNER, G. Hierarchical forecasting: issues and use guidelines. Industrial Management \& Data Systems, v. 101, p. 5-12, 2001.

FLUES, F.; RüBBELKEB, D.; VöGELE, S. An analysis of the economic determinants of energy efficiency in the european iron and steel industry. Journal of Cleaner Production, v. 104, p. 250-263, 2015.

GAMERMAN, D.; LOPES, H. Markov Chain Monte Carlo - Stochastic Simulation for Bayesian Inference. Second edition. [S.I.]: Chapman and Hall, 2006. 
GELFAND, A.; SMITH, A. F. M. Sampling-based approaches to calculating marginal densities. Journal of the American Statistical Association, v. 85, p. 398-409, 1990.

GELMAN, A.; RUBIN, D. Intervention analysis with applications to economic and environmental problems. Journal of the American Statistical Association, v. 7, p. 457-472, 1992.

GEMAN, S.; GEMAN, D. Stochastic relaxation, gibbs distributions and the bayesian restoration of images. IEEE Transactions on Pattern Analysis and Machine Intelligence, v. 6, p. 721-741, 1984.

GEORGIOU, P. N. A bottom-up optimization model for the long-term energy planning of the greek power supply sector integrating mainland and insular electric systems. Computers \& Operations Research, v. 66, n. Supplement C, p. $292-$ 312, 2016. ISSN 0305-0548.

GEROSKI, P. A. Models of technology diffusion. Research Policy, v. 29, p. 603-625, 2000.

GEWEKE, J. Evaluating the accuracy of sampling-based approaches to the calculation of posterior moments. In: IN BAYESIAN STATISTICS. [S.I.]: University Press, 1992. p. 169-193.

GHEDAMSIA, R. et al. Modeling and forecasting energy consumption for residential buildings in algeria using bottom-up. Energy and Buildings, v. 121, p. 309-317, 2016.

GIRALDO, L.; HYMAN, B. Energy end-use models for pulp, paper, and paperboard mills. Energy, v. 20, p. 1005-1019, 1995.

GIRALDO, L.; HYMAN, B. An energy process-step model for manufacturing paper and paperboard. Energy, v. 21, p. 667-681, 1996.

GOLDSTEIN, H. Multilevel Statistical Models. Second edition. London: Edward Arnold, 1995.

HAHN, H.; MEYER-NIEBERG, S.; PICKL, S. Electric load forecasting methods: Tools for decision making. European Journal of Operational Research, v. 199, n. 3, p. $902-907,2009$. ISSN 0377-2217.

HART, R.; LIU, B. Methodology for Evaluating Cost-effectiveness of Commercial Energy Code Changes. Washington 99352, 2015.

HASTINGS, W. Monte carlo sampling methods using markov chains and their applications. Biometrika, v. 57, p. 97-109, 1970.

$H E$, $Y$. et al. Urban long term electricity demand forecast method based on system dynamics of the new economic normal: The case of tianjin. Energy, v. 133, n. Supplement C, p. $9-22,2017$. ISSN 0360-5442.

HERBST, A. et al. Introduction to energy systems modelling. Swiss Journal of Economics and statistic, v. 148, p. 111-135, 2012. 
HIRST, E.; BROWN, M. Closing the efficiency gap: barriers to the efficient use of energy. Resources, Conservation and Recycling, v. 3, p. 267-281, 1990.

HONG, T.; FAN, S. Probabilistic electric load forecasting: A tutorial review. International Journal of Forecasting, v. 32, n. 3, p. $914-938,2016$. ISSN 0169-2070.

HOURCADE, J. C. et al. Hybrid modeling: New answers to old challenges. The Energy Journal, Special issue, v. 27, p. 1-12, 2006.

HUANG, Y. H.; CHANG, Y. L.; FLEITER, T. A critical analysis of energy efficiency improvement potentials in taiwan's cement industry. Energy Policy, v. 96, p. 14-26, 2016.

HUSSAIN, A.; RAHMAN, M.; MEMON, J. A. Forecasting electricity consumption in pakistan: the way forward. Energy Policy, v. 90, n. Supplement C, p. $73-80$, 2016. ISSN 0301-4215.

HYNDMAN, R. J. et al. Optimal combination forecasts for hierarchical time series. Computational Statistics \& Data Analysis, v. 55, p. 2579-2589, 2011.

HYNDMAN, R. J.; ATHANASOPOULOS, G. Forecasting: principles and practice. http://otexts.org/fpp/, 2013. Accessed on 23/04/2017.

HYNDMAN, R. J.; LEE, A. J.; WANG, E. Fast computation of reconciled forecasts in hierarchical and grouped time series. v. 55, 2014.

HYNDMAN, R. J.; LEE, A. J.; WANG, E. Fast computation of reconciled forecasts for hierarchical and grouped time series. Computational Statistics \& Data Analysis, v. 97, p. 16-32, 2016.

IBGE. Pesquisa Industrial Anual. Available:

http://www.sidra.ibge.gov.br/bda/pesquisas/pia/, 2015.

IETD. Pulp and Paper. http://ietd.iipnetwork.org/content/pulp-and-paper, 2006.

JACOBSEN, H. K. Integrating the bottom-up and top-down approach to energy-economy modelling: the case of denmark. Energy Economics, v. 20, p. 443-461, 1998.

JAFFE, A. B.; STAVINS, R. N. The energy paradox and the diffusion of conservation technology. Resource and Energy Economics, v. 16, p. 91-122, 1994.

JAKOB, M.; CATENAZZI, G.; FLEITER, T. Ex-ante estimation of the eu ecodesign directive's impact on the long-term electricity demand of the tertiary sector. In: ECEEE SUMMER STUDY PROCEEDINGS. •. [S.I.], 2013.

JOCHEM, E. et al. EU-Project ADAM: Adaption and Mitigation Strategies: Supporting European Climate Policy? Deliverable M1.1: Report of the Base Case Scenario for Europe and Full Description of the Model System. [S.I.], 2007.

KABOLI, S. H. A. et al. Long-term electrical energy consumption formulating and forecasting via optimized gene expression programming. Energy, v. 126, n. Supplement C, p. 144 - 164, 2017. ISSN 0360-5442. 
KABOLI, S. H. A.; SELVARAJ, J.; RAHIM, N. Long-term electric energy consumption forecasting via artificial cooperative search algorithm. Energy, v. 115 , n. Part 1 , p. $857-871,2016$. ISSN 0360-5442.

KARALI, N.; XU, T.; SATHAYE, J. Reducing energy consumption and $\mathrm{CO}_{2}$ emissions by energy efficiency measures and international trading: A bottom-up modeling for the u.s. iron and steel sector. Applied Energy, v. 120, p. $133-146$, 2014.

KINNEY, W. R. Predicting earnings: entity versus sub-entity data. Journal of Accounting Research, v. 9, p. 127-136, 1971.

KOLTSAKLIS, N. E.; LIU, P.; GEORGIADIS, M. C. An integrated stochastic multi-regional long-term energy planning model incorporating autonomous power systems and demand response. Energy, v. 82, n. Supplement C, p. $865-888$, 2015. ISSN 0360-5442.

KOOPMANS, C. C.; VELD, D. W. Bridging the energy efficiency gap: using bottom-up information in a top-down energy demand model. Energy Economics, v. 23, p. 57-75, 2001.

KRAMER, K. J. et al. Energy efficiency improvement and cost saving opportunities for the pulp and paper industry. https://www.energystar.gov/ia/business/industry/downloads/Pulpand-Paper -Energy-Guide.pdf, 2009.

KRAMER, K. J. et al. Energy Efficiency Improvement and Cost Saving Opportunities for the Pulp and Paper Industry. https://www.energystar.gov/ia/business/industry/downloads/Pulp-and-Paper -Energy-Guide.pdf, 2009.

KURAMOCHI, T.; WAKIYAMA, T.; KURIYAMA, A. Assessment of national greenhouse gas mitigation targets for 2030 through meta-analysis of bottom-up energy and emission scenarios: A case of japan. Renewable and Sustainable Energy Reviews, v. 77, n. Supplement C, p. 924 - 944, 2017. ISSN 1364-0321.

LEE, C.-Y.; HUH, S.-Y. Forecasting new and renewable energy supply through a bottom-up approach: The case of south korea. Renewable and Sustainable Energy Reviews, v. 69, n. Supplement C, p. 207 - 217, 2017. ISSN 1364-0321.

LEON, N.; PESSANHA, J. F. M. DinÂmica da evoluÇÃo do consumo de energia no setor residencial. In: SEMINÁRIO NACIONAL DE PRODUÇÃO E TRANSMISSÃO DE ENERGIA ELÉTRICA (SNPTEE). • . [S.I.], 2005.

LIMANOND, T.; SAJJAKAJJOMNONKWAO; ARTITSRIKAEW. Projection of future transport energy demand of thailand. Energy Policy, v. 39, p. 2754-2763, 2011.

LINDLEY, D. V.; SMITH, A. F. M. Bayes estimates for the linear model. Journal of the Royal Statistical Society, Series B, v. 34, p. 1-41, 1972. 
MATHEWS, J. A.; BARONI, P. The industrial logistic surface: Displaying the impact of energy policy on uptake of new technologies. Energy, v. 57, p. 733-740, 2013.

MCKENDRICK, A. G.; PAI, M. K. The rate of multiplication of micro-organisms: A mathematical study. Proceedings of the Royal Society of Edinburgh, v. 31, p. 649-653, 1912.

METROPOLIS, N. et al. Equation of state calculations by fast computing machine. Journal of Chemical Physics, v. 21, p. 1089-1091, 1953.

MIGON, H. S.; GAMERMAN, D.; LOUZADA, F. Statistical Inference: an Integrated Approach. Second edition. [S.I.]: London, 2015.

MME. Balanço de Energia Útil (BEU). Available:

http://www.feng.pucrs.br/ eberson/Balan2005.

NEELIS, M. et al. Approximation of theoretical energy-saving potentials for the petrochemical industry using energy balances for 68 key processes. Energy, v. 32, p. 1103-1123, 2007.

ODA, J. et al. Diffusion of energy efficient technologies and $\mathrm{CO}_{2}$ emission reductions in iron and steel sector. Energy Economics, v. 29, p. 868-888, 2007.

O'HAGAN, A. Probabilistic uncertainty specification: Overview, elaboration techniques and their application to a mechanistic model of carbon flux. Environmental Modelling \& Software, v. 36, p. 35-48, 2012.

PANKRATZ, A. Forecasting with dynamic regression models. New York: John Wiley \& Sons, 1991.

PAO, H. T.; TSAI, C. M. Modeling and forecasting the $\mathrm{CO}_{2}$ emissions, energy consumption, and economic growth in brazil. Energy, v. 36, p. 2450-2458, 2011.

PERWEZ, U. et al. The long-term forecast of pakistan's electricity supply and demand: An application of long range energy alternatives planning. Energy, v. 93, n. Part 2, p. 2423 - 2435, 2015. ISSN 0360-5442.

PéREZ-GARCíA, J.; MORAL-CARCEDO, J. Analysis and long term forecasting of electricity demand trough a decomposition model: A case study for spain. Applied Energy, v. 97, p. 127-143, 2016.

PROCEL/INFO. Oportunidades de eficiência energética para a Indústria, Relatório Setorial, Setor de Papel e celulose. Available: http://www.procelinfo.com.br, 2010.

PUKSEC, $T$. et al. Forecasting long-term energy demand of croatian transport sector. Energy, v. 57, p. 169-176, 2013.

RAO, K. U.; KISHORE, V. V. N. A review of technology diffusion models with special reference to renewable energy technologies. Renewable and Sustainable Energy Reviews, v. 14, p. 1070-1078, 2010. 
ROBERT, C. P.; CASELLA, G. Monte Carlo Statistical Methods. Second edition. New York: Springer - Verlag, 2004.

SAIDUR, R. A review on electrical motors energy use and energy savings. renewable and sustainable. Renewable and Sustainable Energy Reviews, v. 14, p. 877-898, 2010.

SAYGIN, D. et al. Potential of best practice technology to improve energy efficiency in the global chemical and petrochemical sector. Energy, v. 36, p. 5779-5790, 2011.

SAYGIN, D. et al. Benchmarking the energ yuse of energy-intensive industries in industrialized and in developing countries. Energy, v. 36, p. 6661-6673, 2011.

SCHWARZ, H.-G. Technology diffusion in metal industries: driving forces and barries in the german aluminium smelting sector. Cleaner Production, v. 16S1, p. S37-S49, 2008.

SILVA, F. L. C. et al. Forecast of long-term electricity consumption of the industrial sub-sector of pulp and paper in brazil using a bottom-up approach. Procedia Computer Science, v. 55, p. 514-522, 2015.

SMITH, A. F. M. A general bayesian linear model. Journal of the Royal Statistical Society, Series B, v. 35, p. 61-75, 1973.

SWAN, L. G.; UGURSAL, V. I. Modeling of end-use energy consumption in the residential sector: A review of modeling techniques. Renewable and Sustainable Energy Reviews, v. 13, p. 1819-1835, 2009.

SZABó, L. et al. A world model of the pulp and paper industry: Demand, energy consumption and emission scenarios to 2030. Environmental Science \& Policy, v. 12, p. 257-269, 2009.

TANAKA, K. Review of policies and measures for energy efficiency in industry sector. Energy Policy, v. 39, p. 6532-6550, 2011.

THANGAVELU, S. R.; KHAMBADKONE, A. M.; KARIMI, I. A. Long-term optimal energy mix planning towards high energy security and low ghg emission. Applied Energy, v. 154, n. Supplement C, p. 959 - 969, 2015. ISSN 0306-2619.

TIERNEY, L. Markov chains for exploring posterior distribuitions. annals of statistics. Annals of Statistics, v. 22, p. 1701-1728, 1994.

TOLMASQUIM, M. T. GERAÇÃO DE ENERGIA ELÉTRICA NO BRASIL. Primeira edição. Rio de Janeiro: Interciência, 2005.

TRUTNEVYTE, E. Expanse methodology for evaluating the economic potential of renewable energy from an energy mix perspective. Applied Energy, v. 111, n. Supplement C, p. 593 - 601, 2013. ISSN 0306-2619.

TRUTNEVYTE, E. Does cost optimization approximate the real-world energy transition? Energy, v. 106, n. Supplement C, p. 182 - 193, 2016. ISSN 0360-5442. 
UUSITALO, L. et al. An overview of methods to evaluate uncertainty of deterministic models in decision support. Environmental Modelling \& Software, v. 63, p. 24-31, 2015.

WIERZBOWSKI, M.; LYZWA, W.; MUSIAL, I. Milp model for long-term energy mix planning with consideration of power system reserves. Applied Energy, v. 169, p. 93 - 111, 2016. ISSN 0306-2619.

WORRELL, E. et al. Productivity benefits of industrial energy efficiency measures. Energy, v. 28, p. 1081-1098, 2003.

WORRELL, E.; PRICE, L. Policy scenarios for energy efficiency improvement in industry. Energy Policy, v. 29, p. 1223-1241, 2001.

$\mathrm{XU}, \mathrm{J} . \mathrm{H}$. et al. Energy consumptionandco2 emissions in china's cement industry: A perspective from Imdi decomposition analysis. Energy Policy, v. 50, p. 821-832, 2012.

$\mathrm{XU}, \mathrm{J} . \mathrm{H}$. et al. $\mathrm{CO}_{2}$ emissions reduction potential in china's cement industry compared to iea's cement technology roadmap up to 2050. Applied Energy, v. 130, p. 592-602, 2014.

YI, B.-W.; XU, J.-H.; FAN, Y. Inter-regional power grid planning up to 2030 in china considering renewable energy development and regional pollutant control: A multi-region bottom-up optimization model. Applied Energy, v. 184, n. Supplement C, p. 641-658, 2016. ISSN 0306-2619.

ZELLNER, A.; TOBIAS, J. A note on aggregation, disaggregation and forecasting performance. Journal of Forecasting, v. 19, p. 457-469, 2000. 